This document was prepared in conjunction with work accomplished under Contract No. DE-AC09-96SR18500 with the U. S. Department of Energy.

\title{
DISCLAIMER
}

This report was prepared as an account of work sponsored by an agency of the United States Government. Neither the United States Government nor any agency thereof, nor any of their employees, makes any warranty, express or implied, or assumes any legal liability or responsibility for the accuracy, completeness, or usefulness of any information, apparatus, product or process disclosed, or represents that its use would not infringe privately owned rights. Reference herein to any specific commercial product, process or service by trade name, trademark, manufacturer, or otherwise does not necessarily constitute or imply its endorsement, recommendation, or favoring by the United States Government or any agency thereof. The views and opinions of authors expressed herein do not necessarily state or reflect those of the United States Government or any agency thereof.

This report has been reproduced directly from the best available copy.

Available for sale to the public, in paper, from: U.S. Department of Commerce, National Technical Information Service, 5285 Port Royal Road, Springfield, VA 22161, phone: (800) 553-6847, fax: (703) 605-6900

email: orders@ntis.fedworld.gov

online ordering: http://www.ntis.gov/help/index.asp

Available electronically at http://www.osti.gov/bridge

Available for a processing fee to U.S. Department of Energy and its contractors, in paper, from: U.S. Department of Energy, Office of Scientific and Technical Information, P.O. Box 62, Oak Ridge, TN 37831-0062,

phone: (865)576-8401,

fax: (865)576-5728

email: $\underline{\text { reports@ adonis.osti.gov }}$ 
WSRC-TR-2002-00159

Page 2 of 78

Revision 0

(Left intentionally blank.) 


\section{Steady and transient thermal analysis of the DWPF Melter operation}

Hector N. Guerrero

Dennis F. Bickford

Publication Date: January, 2003

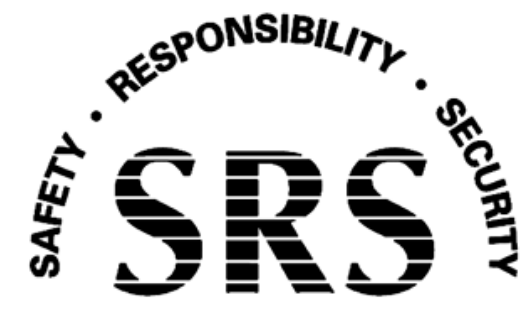


DOCUMENT:

TITLE:
WSRC-TR-2002-00159 Rev. 0

Steady and transient thermal analysis of the DWPF Melter operation

\section{APPROVALS}

Date:

Hector N. Guerrero, Author (EES/EDS/SRTC)

Date:

D. F. Bickford, Immobilization Technology Section

Date:

D. Burns, ETF/EDS/EES Manager

Date:

M. R. Duignan, Technical Reviewer, ETF/EDS/EES

Date:

B. L. Lewis, PCE/WDED/HLWCE Manager

Date:

E. W. Holtzscheiter, ITS/WTT Manager 
1. Executive Summary 8

2. Introduction 12

3. Purpose of Analysis 13

4. Analysis Summaries 13

4.1 Comparison with Yosioka's Model 13

4.2 Averaged Power Data for Three Macrobatch Feeds 14

4.3 Detailed Power Inputs and Heat Loss Distributions 17

4.4 Historical Power Trends 21

4.5 Transient Analysis 25

5. Method of Analysis 27

6. Calculation Results 30

6.1 Benchmarking with Power Data 30

6.2 Distribution of Power Losses - Macrobatch 1

6.3 Summary of Power Distribution for Various Cases 33

6.3.1 Design Case - Melt Rate of 224 Lbs/hr 36

6.3.2 Power Distribution for the Reduced Foam Case 37

6.4 Transient Analysis Results 38

6.4.1 Comparison with DWPF Melter Production Runs 38

6.4.2 Separate Effects 49

7. Conclusions and Recommendations 58

8. Nomenclature 60

9. References 62

Appendix A Detailed Calculation Method for Steady State and Transient 63 Thermal Response of DWPF Melter

\section{$\underline{\text { List of Tables }}$}

1. Distribution of Power Losses at Various Feed Rates and Glass Melting Parameters 35

A-1 Radiation View Factors vs. Cold Cap Area Fraction 72

A-2 List of Transmission Factors at 0.3 atm Steam 75 
1. Averaged DWPF Power Inputs Under 0.45-0.6 gpm Feed- Macrobatches 1, 2, 38

2. Averaged DWPF Power Inputs Under Idling Conditions - Macrobatches 1, 2, 39

3. Vapor Space Temperatures During Period, 3/2000-4/2000 10

4. DWPF Melter Daily Averaged Power Data from 11/1/97 to 2/18/98-Macrobatch 114

5. DWPF Melter Monthly Averaged Power Data from 1/99 to 8/99- Macrobatch 2

6. Variation of Vapor Space Temperatures for Macrobatches 1 and $2 \quad 16$

7. DWPF Melter Daily Averaged Power Data from 2/1/02 to 6/23/02- Macrobatch 316

8. Power Loss Distribution for Macrobatch 1 Idling Conditions 18

9. Power Loss Distribution for Macrobatch 1 Full Feed Conditions 18

10. Power Loss Distribution for Macrobatch 2 Idling Conditions 19

11. Power Loss Distribution for Macrobatch 2 Full Feed Conditions 19

12. Power Loss Distribution for Macrobatch 3 Idling Conditions 20

13. Power Loss Distribution for Macrobatch 3 Full Feed Conditions 20

14. Average Power Inputs for Period 5/1/97-4/30/02 Under 0.45-0.6 gpm Feed 22

15. Average Power Inputs for Period 5/1/97-4/30/02 Under Idling Conditions 23

16. Thermal History in the DWPF Upper Plenum Under Idling Conditions 24

17. Distribution of Melter Power Losses as a Function of Feed Rate -Macrobatch 1

18. Distribution of Heat Sources and Heat Consumption in the Cold Cap- Macrobatch 134

19. Theoretical Power Distribution for Nominal Feed Rate of $0.939 \mathrm{gpm} 36$

20. Predicted Power Distribution for a Melt Rate of $224 \mathrm{lbs} / \mathrm{hr}$ Based 37 on a 50\% Increase in Effective Convective Coefficient

21. DWPF Melter Macrobatch 1 Feed Rate, Electrode Power, and Dome Heater 40 Power for the Period, 12/01-23/97

22. Average Power Conditions for DWPF Melter Run 12/01-23/97 41

23. Measured and Calculated Glass Temperatures for DWPF Run 12/01-23/97 41

24. Measured and Calculated Vapor Space Temperatures for DWPF Run 12/01-23/97 42

25. Measured and Calculated Dome Heater Temperatures for DWPF Run 12/01-23/97 42

26. DWPF Melter Macrobatch 2 Feed Rate, Electrode Power, and Dome Heater 43 Power for the Period, 2/09-19/01

27. Average Power Conditions for Flow Transient of Run 2/09-19/01 
28. Measured and Calculated Glass Melt Temperatures for DWPF Run 2/09-19/01 44

29. Measured and Calculated Vapor Space Temperatures for DWPF Run 2/09-19/01 45

30. Measured and Calculated Dome Heater Temperatures for DWPF Run 2/09-19/01 45

31. DWPF Melter Macrobatch 2 Feed Rate, Electrode Power, and Dome Heater Power for the Period, 7/02-04/99 46

32. Average Power Conditions for DWPF Melter Run 7/02-04/99 47

33. Measured and Calculated Glass Melt Temperatures for DWPF Run 7/02-04/99 47

34. Measured and Calculated Vapor Space Temperatures for DWPF Run 7/02-04/99 48

35. Measured and Calculated Dome Heater Temperatures for DWPF Run 7/02-04/99 48

36. Electrode Power Increase Transient - Case 1

37. Glass, Vapor Space and Dome Heater Temperature Increases Due to Electrode Power Increase - Case 1 50

38. Increase in Glass Surface Area due to Electrode Power Increase - Case 1

39. Radiant and Convective Heat Transfer during Electrode Power Increase - Case 151

40. Change in Melt Rate Due to Electrode Power Increase - Case 1

41. Step Increase in Feed Rate to 90 lbs./hr from Zero Feed and Corresponding Melt Rate - Case 2

42. Glass, Vapor Space and Dome Heater Temperature Increases Due to Electrode Power Increase - Case 2

43. Decrease in Glass Surface Area Due to Step Increase in Feed Rate - Case 3

44. Changes in Radiant Heat to Upper Plenum and Cold Cap, Convective Heat To Cold Cap due to a Step Change in Feed Rate - Case 2 54

45. Dome Heater Power Increase Transient - Case 3

46. Glass, Vapor Space and Dome Heater Temperature Changes Due to Electrode Power Increase - Case $3 \quad 56$

47. Glass Surface Area Increase Due to a Dome Heater Power Increase - Case $3 \quad 56$

48. Radiant Heats to Upper Plenum and Cold Cap Due to a Dome Heater Power Increase - Case $3 \quad 57$

49. Increase in Melt Rate Due to a Dome Heater Power Increase - Case 3 


\section{Executive Summary}

At HLW (High Level Waste) Division's request, an analysis has been performed of power usage at characteristic times in the Defense Waste Processing Facility (DWPF) production. For the first time in the Department of Energy (DOE) complex, a program has been developed permitting the monitoring or systematic categorizing of power and heat distribution in an operating waste glass production melter. To date, the Defense Waste Processing Facility (DWPF) Melter power and heat trends have been analyzed in terms of individual or total power sources. The method applied here provides a steady state balance between melter power inputs and various heat losses under continuous feeding/pouring or idling conditions. Power comes from two electrode circuits and separately controlled dome heaters. Heat energy is lost through the melter shell, as well as evaporation of water, heating of steam and in-leakage air, chemical reactions, and heating of glass. These various power consumption pathways are not constant and depend on melter operation, such as feed rate, solids ratio, feed batch and net melt pool circulation. The analysis uses the lumped parameter approach to sum the power inputs and proportion them to the various power uses, providing an overall perspective of the power distribution. Through the analysis of a practical melt rate model (personal computer based), the separate effects of engineering and physico-chemical batch effects can be obtained for quick evaluation of their effects on melt rate. The thermal model provides the framework where laboratory determination of batch effects, e.g., specific heat, viscosity, thermal conductivity, etc., can be fed in and the melt rate predicted.

- Average power inputs for the three macrobatch ${ }^{1}$ feeds, since the beginning of radioactive operatio, are summarized in the bar chart of Figure 1 for the case of nominally similar feed conditions of $0.45-0.6 \mathrm{gpm}$. A decrease in electrode power is noticeable from Macrobatch 1

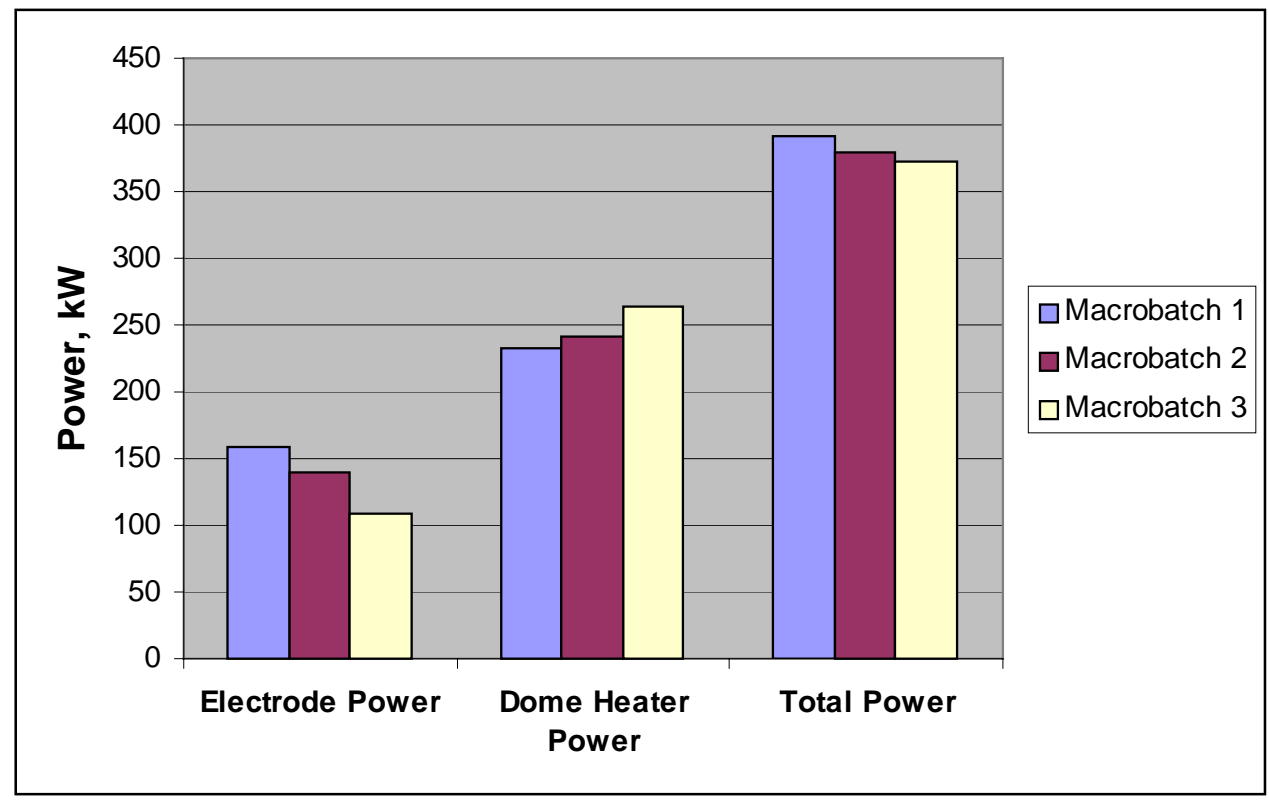

Figure 1 Averaged DWPF Power Inputs Under 0.45-0.6 gpm Feed for Macrobatches 1, 2, 3

\footnotetext{
${ }^{1}$ Macrobatch 1=Sludge Batch 1A, Macrobatch 2=Sludge Batch 1B, Macrobatch 3=Sludge Batch 2. Macrobatch feeds involve different waste compositions, chemistry or glass frit. The time periods when Macrobatches 1,2, and 3 were introduced are given in Sec. 4.4.
} 
to Macrobatch 2 and then to Macrobatch 3. This behavior is consistent with an interface layer buildup on top of the glass, or material deposits, which would reduce glass circulation.

Average melter power inputs under idling conditions for the three macrobatches are represented in Figure 2. Electrode and dome heater powers for Macrobatch 3 deviated significantly from those of Macrobatch 1 and Macrobatch 2, which were similar. However, the total power was fairly constant for all three batches. This too is consistent with a change that would reduce the power transfer to the plenum, such as an interface layer buildup, or material deposits in the melter which would reduce glass circulation.

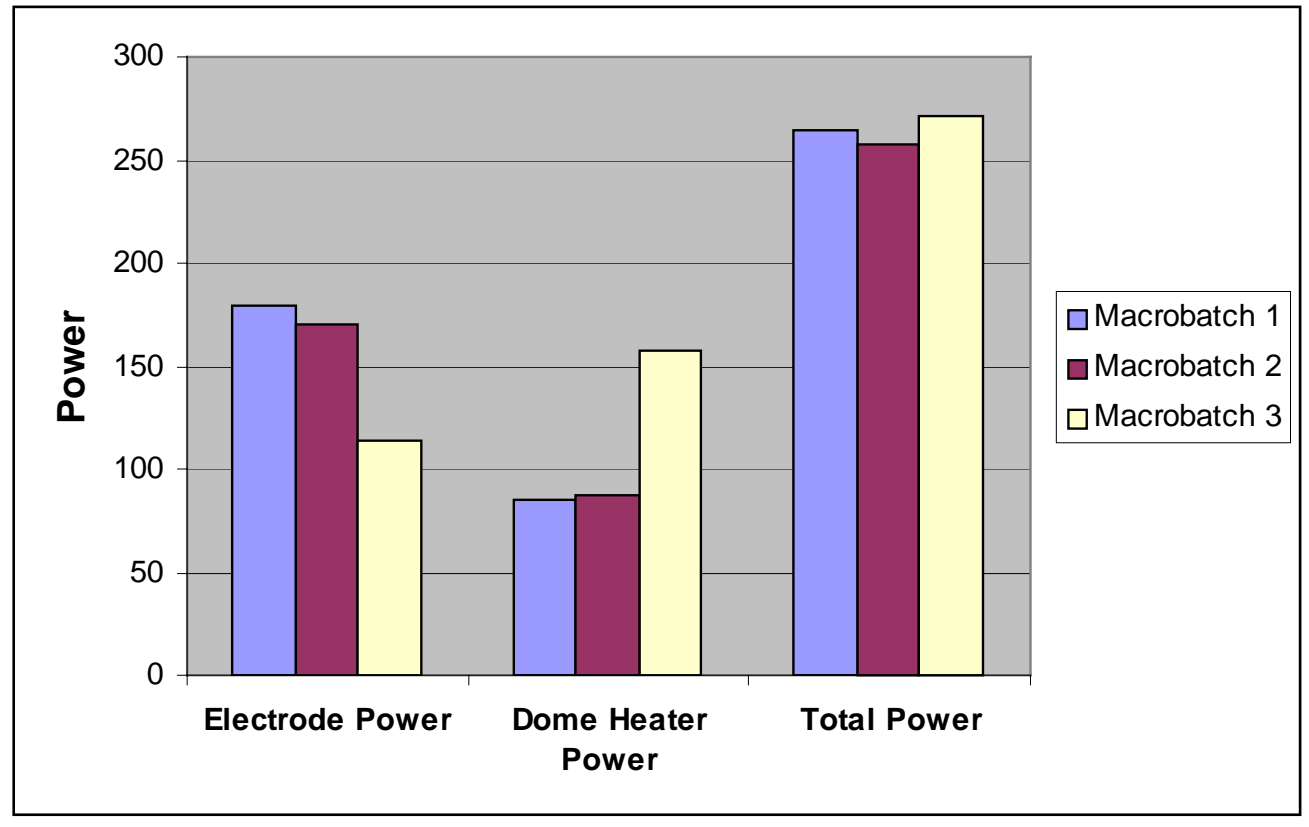

Figure 2 Averaged DWPF Power Inputs under Idling Conditions for Macrobatches 1, 2, and 3

The above trends indicate a thermal property change that may be due to a physical change in the interface layer between the cold cap and the melt pool, or a change that reduced glass circulation, such as thick deposits on the melter bottom. In Macrobatch 2, the melt rate decreased approximately $20 \%$ from that of Macrobatch 1 due to the cold cap blanketing the glass surface at a lower feed rate $(0.55 \mathrm{gpm}$ vs. $0.7 \mathrm{gpm})$ than before. There is some experimental evidence (but not conclusive) of a significantly increased foam or crystalline layer between the cold cap and the melt pool, which can reduce heat transfer. The lumped parameter model confirms that a thermally resistant interface layer reduced the convection heat transfer from melt pool to cold cap, which decreased the electrode power requirement for the same melt pool temperature.

- A somewhat different problem was encountered in Macrobatch 3 where the electrode power decreased under both feeding and idling conditions and the idling vapor space temperature also decreased. The lumped model indicated that a thermally resistant layer was present under feeding conditions, where the reduced convection heat from the melt pool was 
compensated by increased radiant heat to the cold cap (increased dome heater power) to maintain the same melt rate. At idling conditions, calculations show that the radiant heat from the glass surface decreased, as well as the effective glass surface temperature, implying a resistant layer which may be due to a persistent foam layer or melt resistant material

- During the period, $3 / 2000-4 / 2000$, increased air in-leakage through feed tubes seals caused long pouring times. Figure 3 shows the indicated (or measured) vapor space temperatures during this period, showing that the upper plenum temperature decreased significantly compared to previous normal temperatures (see Figure 6). Feed rates as low as $0.4 \mathrm{gpm}$ could only be achieved before exceeding the safety basis value for the indicated vapor space temperature. The heat balance in the column labeled "Air leak" of Table 1, provides a possible explanation. If an additional air leak of $225 \mathrm{lbs} / \mathrm{hr}$ were added to the normal (designed) leakage of $560 \mathrm{lbs} / \mathrm{hr}$ and a cold cap coverage of 0.8 were assumed, a heat balance would be attained for a vapor temperature of $500^{\circ} \mathrm{C}$. (This value has been corrected for radiant heat effect on the indicated or measured temperature of $600^{\circ} \mathrm{C}$ ). Thus, the assumption of an air leak reducing melt rate is supported by this model.

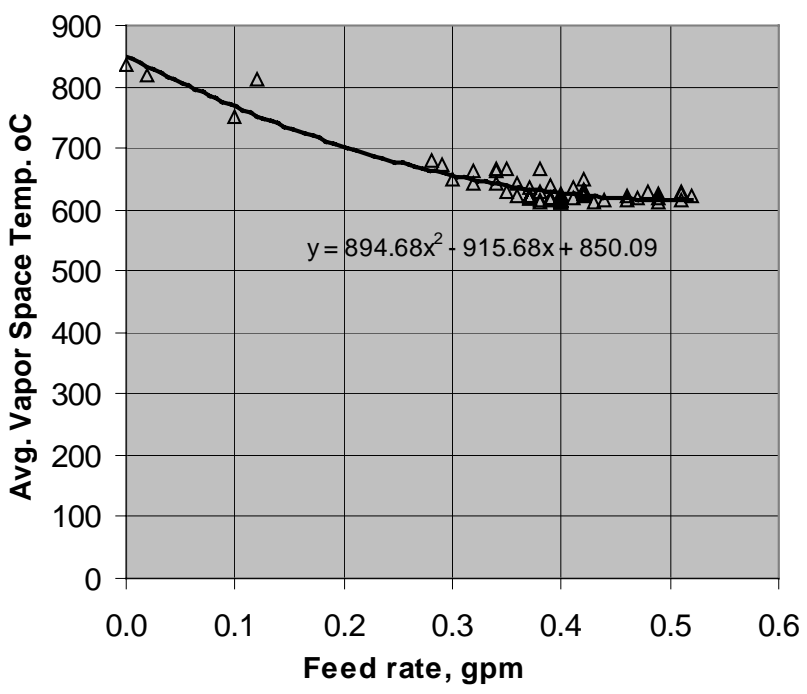

Figure 3 Indicated Vapor Space Temperatures During Period, 3/2000-4/2000

- Under Macrobatch 1 and 2 conditions, the available power from the electrodes to add to the cold cap from the melt pool or transferred to the top of the cold cap via the upper plenum is $90 \mathrm{~kW}$ and $68.5 \mathrm{~kW}$, respectively, based on the lower shell heat loss. It is much less for Macrobatch 3, at $25.7 \mathrm{~kW}$. Adding more than this value through the electrodes is not feasible due to the glass pool temperature limitation. The actual glass slurry batch is known to have foaming characteristics. If the effective thermal conductivity of the melting glass including foam is increased, then electrode power may be increased without exceeding the glass temperature limit.

The decrease in convective heat transfer from the glass to the cold cap in Macrobatch 2 (relative to Macrobatch 1) is believed to be due to increased foaming, while the decrease in 
Macrobatch 3 may be due to both foaming and the presence of a crystalline layer in Macrobatch 3. Considering only the foaming effect, we assume that the foam could be broken up by dilutants, or a different frit is used so that the effective heat transfer coefficient (including foam and convective film) is increased by 50\%, then higher electrode power (208 $\mathrm{kW}$ ) can be introduced without exceeding the glass temperature of $1150^{\circ} \mathrm{C}$, as shown in Table 1. The design mass melt flux of $9 \mathrm{lbm} / \mathrm{hr}^{-\mathrm{ft}^{2}}$ (based on a melt rate of $224 \mathrm{lbs} / \mathrm{hr}$ and available glass surface area of $24.7 \mathrm{ft}^{2}$ ) can therefore be achieved. This might be accomplished by changes in the melter feed composition, or increased convection of the glass in the melter pool.

- One conclusion from this analysis is that the radiant heat from the uncovered glass surface is quite low due to a low glass surface temperature of around $850^{\circ} \mathrm{C}$, necessary to achieve heat balance. This is probably true because the glass at the cold cap/glass pool interface is significantly colder than the average glass temperature and convective currents are insufficient to maintain good mixing with glass from deeper layers. Thus, the current batch melt rate may be improved by increasing the glass surface temperature through increased convection. That is, the glass surface temperature is maintained high by continually bringing heat from lower glass regions. This would increase the heat radiated from the glass surface, Q3, to add to the radiant heat to the cold cap. Thus, the electrode power could be increased by increasing the convective heat transfer to the cold cap and radiant heat transfer from the glass surface, without increasing the bulk glass temperature. Such an outcome may be achieved by an airlift type of bubbler.

- Results of the transient thermal analysis results are summarized in Sec. 4.5 and discussed in more detail in Sec. 6.4. It simulates three representative DWPF Melter runs, where step changes in feed rate, and electrode and dome heater powers were made to new steady values. Comparison between the data and the predictions serves to evaluate the method and suggest areas for additional analysis. Then the analysis is repeated for the separate effects of the control parameters while the others are held constant. Thus the results give an understanding of the physical processes going on and of the rates at which changes occur. The study can provide guidance to operators as to expected changes in melter parameters when certain control inputs are performed. 


\section{Introduction}

The DWPF Melter is basically a furnace in the shape of a cylinder, approximately $6 \mathrm{ft}$. inside diameter and $7 \mathrm{ft}$. internal height dimension. It has an external steel shell and is lined inside with refractory insulation. Glass frit and radioactive material in the form of a water slurry is fed through two feed tubes that penetrate the shell top lid. The solids ratio (mass ratio of glass frit plus radioactive material to total slurry) is typically 0.49 . A molten glass pool about $3 \mathrm{ft}$. deep forms at the bottom of the melter and is heated by direct passage of direct current from two pairs of electrodes built into the side wall of the melter. In normal operation, the slurry water evaporates by radiation heating from eight dome heaters and heating by the melt pool and a crust forms on top of the molten glass surface. This is called the cold cap. Thus, at steady state, there is continuous formation of cold cap material and melting of this material and a throughput flow is maintained during pouring from a riser connected to the bottom of the melter and to a vertical pour spout. The optimum condition has been found where $10 \%$ of the glass surface is uncovered to transfer heat to the upper plenum and then reflected to the top of the cold cap. This aids in evaporating the slurry water. The objective of this study is to develop the computational techniques that will help maximize the melt rate.

The DWPF Melter steady state thermal response has previously been estimated based on smaller scale melter operations with a different melter feed composition (Ref. 9.1). This provided estimates of the optimum conditions for melter operation. Since 1995, the melter has accumulated a large database of melter operating conditions, which can be used to validate the present analytical model. The model is useful as a means of comparing the thermal performance of the melter with different feeds and can provide possible causes of changes in melter operational conditions and melt rate. Also, this model allows sensitivity analysis to be conducted to determine what operational changes will have beneficial effects on the melt rate. Specifically, such analysis may be useful in examining both melter feed batch and melter operation changes in heat of melting and specific heat required with varying amounts of reductants. Another approach is to increase the effective glass/cold cap film coefficient to the required value estimated by the model by air sparging or power skewing. These methods can be evaluated by physical modeling or computational modeling.

Further, a transient thermal analysis was performed, which is needed to acquaint operators on what physical processes are occurring after an operator action. This also provides operators with what potential final melter parameters are reached following the action and the rates at which these parameters change. 


\section{Purpose of Analysis}

An engineering study of the steady and transient thermal response of the DWPF Melter based on a lumped parameter approach is performed to determine the glass-melting rate, glass, vapor space, and dome heater temperatures under various modes of operation. To close the circle on the 1988 steady state analysis of Yoshioka (Ref. 9.1), we compare his analysis with actual DWPF power data. (Ref. 9.1 will be called the design basis calculation.). After making the necessary modifications to obtain close approximation of actual melter data, the lumped model can be used to:

- facilitate the analyses of existing melter problems from a thermal perspective to determine possible causes.

- provide a quick way of evaluating proposed methods of increasing melt rate and other changes to melter operation.

- $\quad$ provide the boundary conditions such as shell heat losses, radiant heat fluxes to the cold cap and upper plenum for more detailed Computational Fluid Dynamics (CFD) analyses of the glass melt and cold cap.

- obtain a transient analysis of melter operation and to acquire an insight into the physical mechanisms occurring during transients.

The lumped parameter model is inherently limited in that space variations in glass and cold cap temperatures and heat transfer coefficients for glass to cold cap convection are not accounted; and data for benchmarking are also limited. However, the work described here provides a framework, which can be improved as more data is obtained. A 3-dimensional model using computational fluid dynamics is currently being developed which may in the future provide more accurate averaged parameters for this lumped parameter model.

\section{Analysis Summaries}

\subsection{Comparison with Yosioka's model}

A comparison between Yosioka's predictions and actual DWPF data shows that the actual total shell heat losses (inferred from melter power data) are 91\% higher than the design basis. Also, the actual effective heat transfer coefficient from the glass pool to the cold cap is $11 \%$ (Macrobatch 1) and 32\% (Macrobatch 2) lower, respectively, than the design basis. Yoshioka's model was then modified by estimating shell heat losses from the DWPF data. The heat of melting is estimated, as in Ref. 9.1, by using the specific heat of the glass over the entire heated temperature range plus an averaged heat of reaction, i.e.,

$$
\text { Hbatch }=\int_{20^{\circ} \mathrm{C}}^{1150^{\circ} \mathrm{C}} c_{p g}(T) d T+\int_{20^{\circ} \mathrm{C}}^{1150^{\circ} \mathrm{C}} \Delta H_{r}(T) d T .
$$

The nomenclature and model used are given in Sec. 8.0 and Appendix A, respectively. A radiant heat exchange model that includes the upper plenum vapor ${ }^{2}$ is incorporated to obtain a good

\footnotetext{
${ }^{2}$ Ref. 9.1 did not include steam as a participating medium and all surfaces did not fully participate in the radiation exchange
} 
estimate of the upper plenum and the cold cap temperature. This modified model is used to calculate the components of the power consumed at various steady feed rates. The calculation may suggest approaches to improving the melt rate.

The steady state analysis of the design case for a melt rate of $224 \mathrm{lbs} / \mathrm{hr}$ (based on a feed rate of $0.939 \mathrm{gpm}, 46 \%$ solids content, and $80 \%$ calcination ratio) and a cold cap coverage of $89 \%$ basically agrees with the power loss distribution results of Yosioka (Ref. 9.1). That analysis assumed the same melt rate flux of $9 \mathrm{lbs} / \mathrm{hr}^{-\mathrm{ft}^{2}}$ as that obtained during the Scaled Glass Melter (SGM) and Integrated DWPF Melter System (IDMS) runs to predict the required electrode and dome heater powers. However, these conditions are not representative of the nitric acid flow sheet operations in the larger DWPF melter with actual waste.

\subsection{Averaged Power Data for Three Macrobatch Feeds}

- Daily DWPF Melter power data (Ref. 9.3) as a function of feed rate for the period, 11/97 to 2/98, representative of Macrobatch 1 feed, are summarized in Figure 4. The scatter of the total power data points around the linear trend-line is much tighter than for the corresponding data points for the electrode and dome heater powers. This suggests that it is the total power that is important and the trend-lines for the electrode power and dome heater power should also be linear. Using the equations for the trend-lines, it is apparent that the electrode power was initially high $(173 \mathrm{~kW})$ at zero feed and decreased slightly to $163 \mathrm{~kW}$ at $0.75 \mathrm{gpm}$. The dome heater power increased linearly from $103 \mathrm{~kW}$ at $0 \mathrm{gpm}$ feed rate to $278 \mathrm{~kW}$ at 0.75 gpm. In DWPF operation, glass melt pool and dome heater temperature limits dictate the above power settings. These conditions resulted in a melt mass flux of $8 \mathrm{lbs} / \mathrm{hr}^{-\mathrm{ft}^{2}}$ at the maximum feed of $0.75 \mathrm{gpm}$ and $49 \%$ solids ratio. This was only $87 \%$ of the

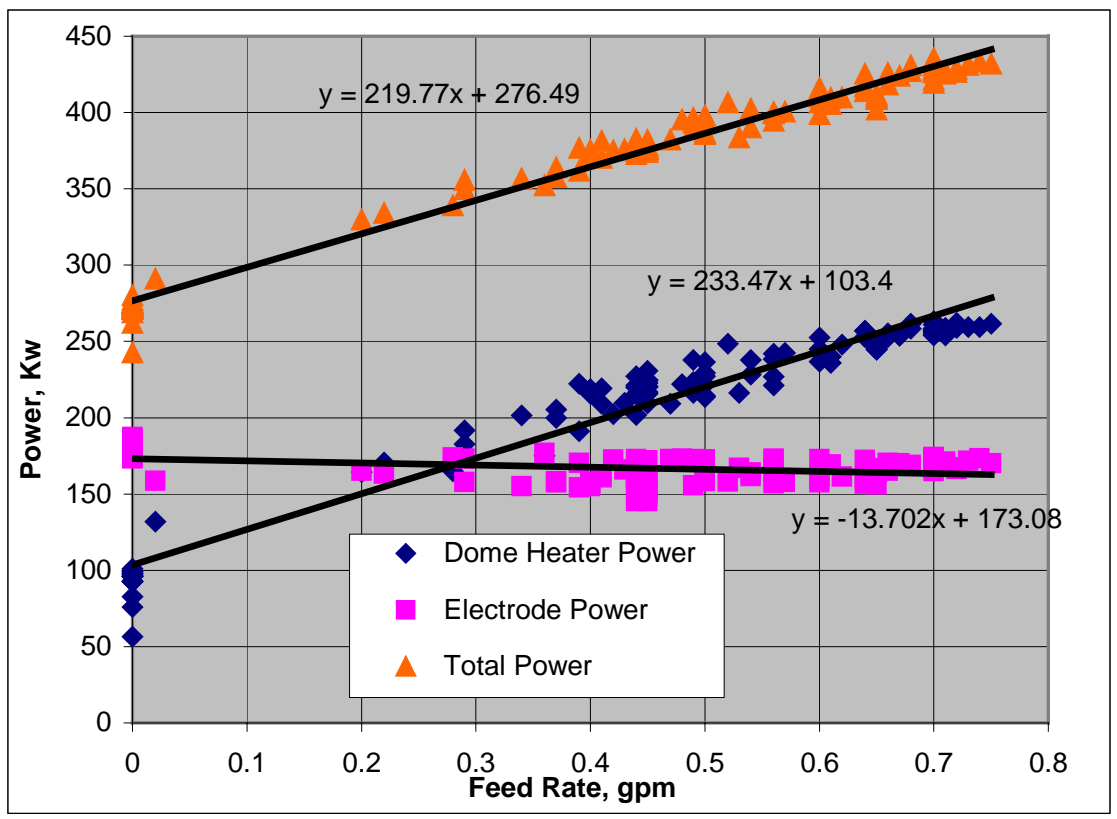

Figure 4 DWPF Melter Daily Averaged Power Data from 11/1/97 to 2/18/98 - Macrobatch 1 
value achieved in the SGM and IDMS runs. This may be attributable to scale-up effects; or, the current nitric acid flow sheet feed is slower melting than the formic acid flow sheet used for most of the pilot scale studies.

- A similar set of daily power data for the period, 1/99 to 8/99, representing Macrobatch 2 runs are plotted in Figure 5. More recent data extending to 12/31/02 suggest small changes in the data fit not incorporated in Figure 5. There are some differences from the Macrobatch 1 data in the electrode and dome heater data, but the total power data as a function of feed rate are closely similar to those of Macrobatch 1 . The major difference between the two is that the feed for Macrobatch 2 went only as high as $0.6 \mathrm{gpm}$, while for Macrobatch 1, a $0.75 \mathrm{gpm}$ feed was achieved. Therefore since the maximum feed is dictated by the cold cap reaching about $90 \%$ of the melter surface area before control problems become significant, we can surmise that foaming was more extensive for Macrobatch 2. The scatter in the data is significantly higher than for Macrobatch 1. Possibly, Macrobatch 2 may have been less homogeneous than Macrobatch 1. There was also another difference in the two series, as given by Figure 6 . Here the indicated vapor space temperatures are plotted for both series in Figure 6. This shows that the vapor space temperature for Macrobatch 2 was lower than Macrobatch 1 by as much as $27^{\circ} \mathrm{C}$. This temperature difference has a strong effect on heat loss due to steam and air mass loss and upper shell heat loss. More importantly, a decrease in vapor space temperature towards the limiting safety basis value reduces the allowable feed rate.

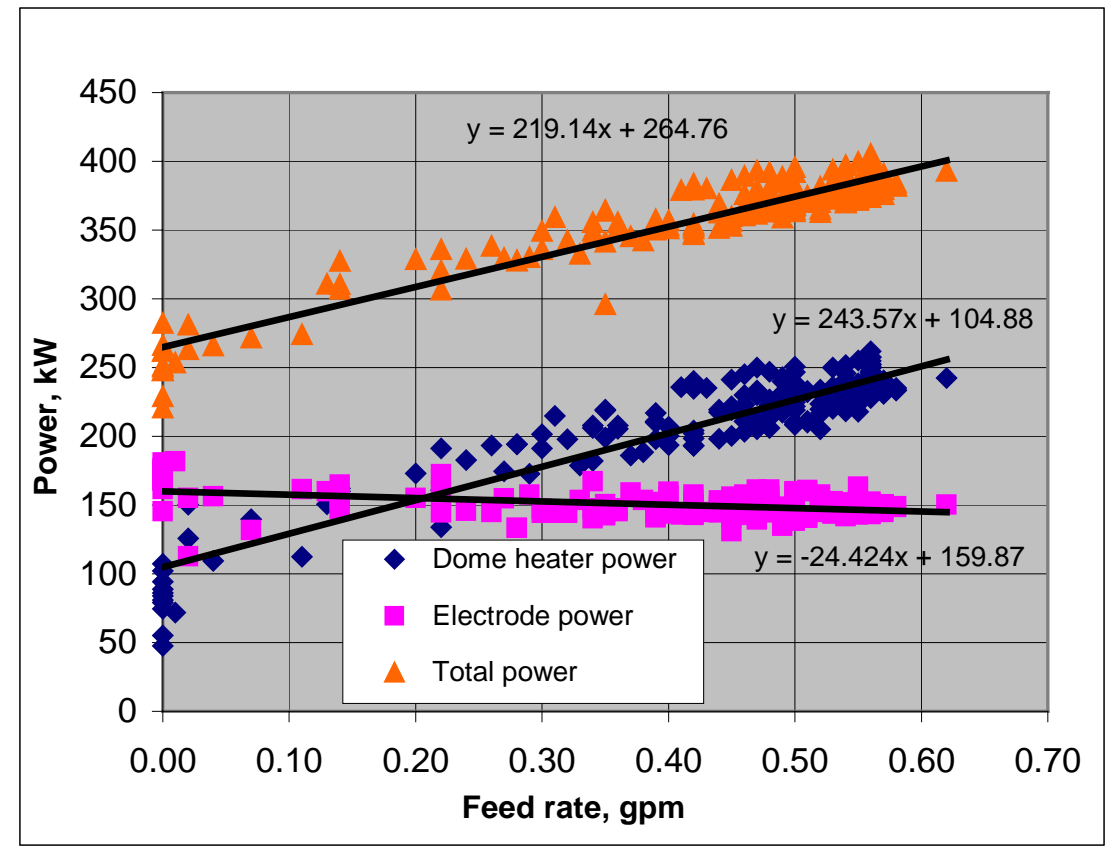

Figure 5 DWPF Melter Averaged Power Data from 1/99 to 8/99 - Macrobatch 2 


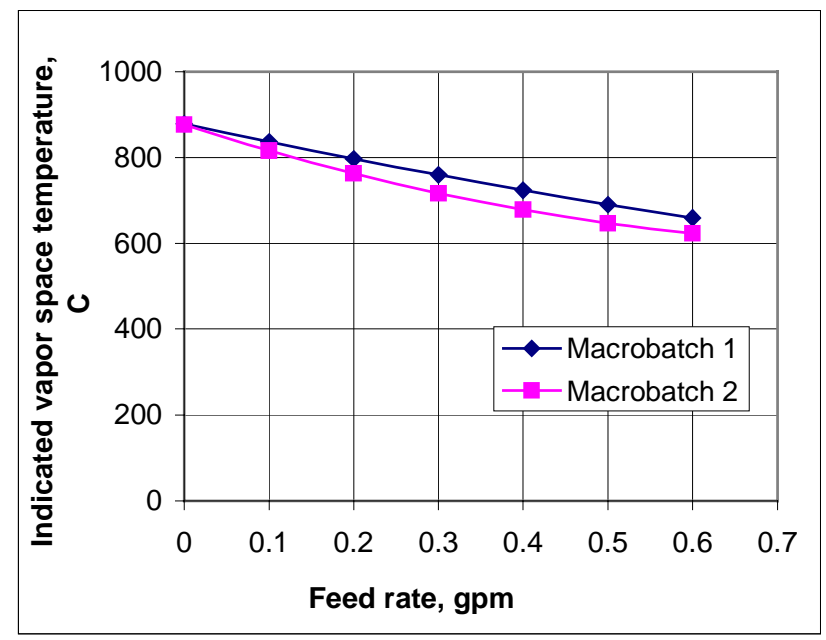

Figure 6 Variation of IndicatedVapor Space Temperatures forMacrobatches 1 and 2

- A third set of power data is given in Figure 7 for the period 2/1/02 to 6/23/02, representing Macrobatch 3 feed conditions. A significant change occurred in comparison with Macrobatches 1 and 2. The electrode power decreased to an average value of $101 \mathrm{~kW}$ (down from $173 \mathrm{~kW}$ for Macrobatch 1 and $160 \mathrm{~kW}$ for Macrobatch 2) for idling conditions. At maximum feeding conditions, the electrode power decreased to $110 \mathrm{~kW}$ (down from 163 $\mathrm{kW}$ for Macrobatch 1 and $144 \mathrm{~kW}$ for Macrobatch 2).

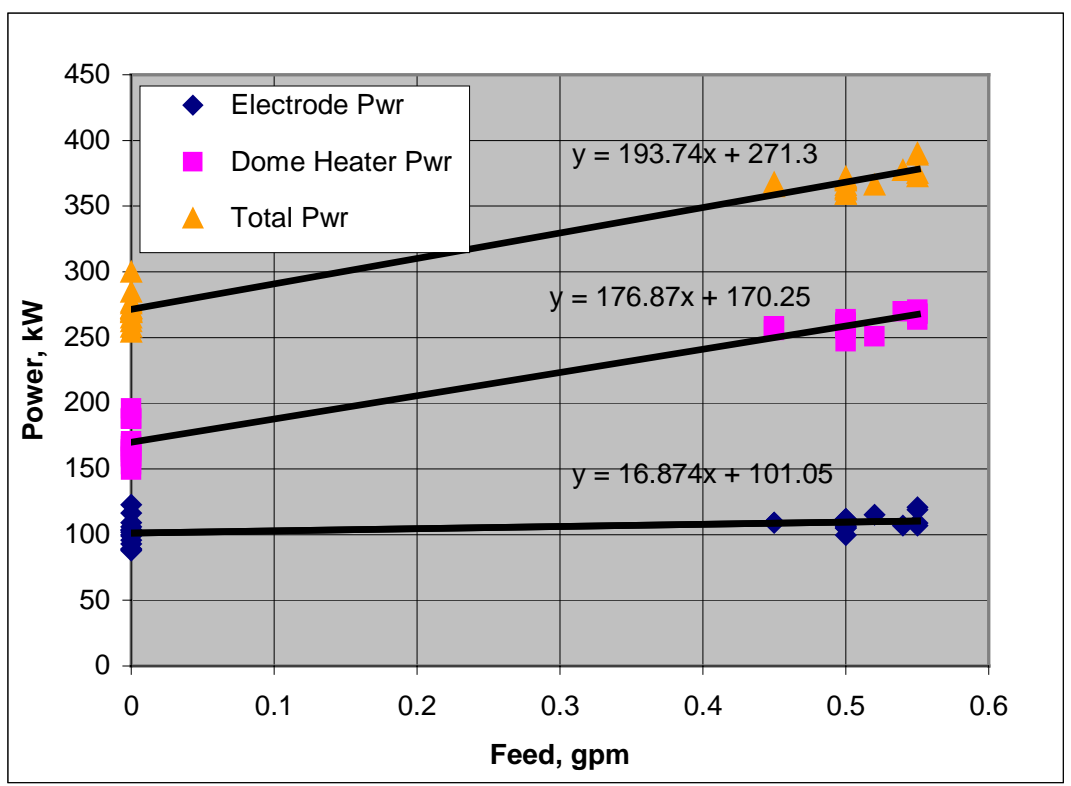

Figure 7 DWPF Melter Averaged Power from 2/1/02-6/23/02 - Macrobatch 3 
- The steady state analysis was benchmarked against Macrobatch 1 data, at zero feed rate where there was no cold cap and at $0.7 \mathrm{gpm}$ feed rate where the cold cap essentially covered all but $10 \%$ of the glass top surface. At zero feed, all of the total power went to the shell heat losses and heating of in-leakage air; while at maximum feed, all of the electrode power went to the lower shell heat loss, convective heat absorbed by the cold cap, and radiation loss to the plenum. The results indicate twice as large heat losses through the melter shell than predicted earlier. Conduction and radiation heat losses from shell penetrations were not analyzed in detail in the earlier assessment (Ref. 9.1).

\subsection{Detailed Power Inputs and Heat Loss Distributions}

- A typical detailed distribution of power consumption for Macrobatch 1 idling conditions is given in Figure 8, and for Macrobatch 1 full feed conditions in Figure 9. The electrode power under idling conditions is $173 \mathrm{~kW}$ and the dome heater power is $103.4 \mathrm{~kW}$, as shown in Figure 4. The total energy input is partitioned into shell heat losses ( $79 \mathrm{~kW}$ and $106.4 \mathrm{~kW})$, heat lost with in-leakage air $(47.5 \mathrm{kw})$ and minor heat losses.

Under feeding conditions of $0.7 \mathrm{gpm}$, we assume the same electrode power. The dome heater power is $266.8 \mathrm{~kW}$. The energy required to eliminate subcooling and evaporate the water is $19.7 \%(87 \mathrm{~kW})$ of the total energy input and the actual amount of energy required to melt the glass is only $10.7 \%(47 \mathrm{~kW})$. The shell heat losses amount to about $41 \%$ of the total energy input and the energy lost by gas mass flux due to air in-leakage, steam and calcined gas is about $14.6 \%$. The remainder are miscellaneous losses. Based on the linearity assumption and a full coverage at $0.75 \mathrm{gpm}$, the cold cap coverage is $91 \%$ (ratio of feed rates, 0.7 $\mathrm{gpm} / 0.75 \mathrm{gpm}=0.91$ ). The resulting melt mass flux is $8 \mathrm{lbs} / \mathrm{hr}-\mathrm{ft}^{2}$ (melt rate of $200 \mathrm{lbs} / \mathrm{hr}$ and glass surface area of $24.7 \mathrm{ft}^{2}$ ), which is $11 \%$ less than assumed for the design conditions (Ref. 9.1).

- Similar distributions of power inputs and losses for Macrobatch 2 idling and full feed conditions of $0.55 \mathrm{gpm}$ are given in Figures 10 and 11, respectively. These refer to runs in 11/01 and 12/01 near the end of Macrobatch 2 in order to determine any significant changes experienced with Macrobatch 3. The melt rate was $155 \mathrm{lbs} / \mathrm{hr}$ for a solids ratio of 49\%, which is $20 \%$ less than the design value. The electrode power had dropped down to 138.4 $\mathrm{kW}$ (from $173 \mathrm{~kW}$ for Macrobatch 1) under full feed conditions. This suggests that something happened with the cold cap, perhaps significantly more foaming in Macrobatch 2, as compared to Macrobatch 1 . The electrode power under idling conditions remained similar to that in Macrobatch 1 and the dome heater power was slightly less. This suggests that under similar temperature distributions, the thermal behavior of the melter under idling conditions did not change from Macrobatch 1 to Macrobatch 2.

- Corresponding power input/loss distributions for Macrobatch 3 are given in Figures 12 and 13 for idling and full feed of $0.5 \mathrm{gpm}$, respectively. We may compare the electrode power for feeding conditions for the three macrobatches, even as the feed rates are different, since electrode power varied only $5-8 \%$ with feed rate. The electrode power for feeding conditions 
WSRC-TR-2002-00159

Revision

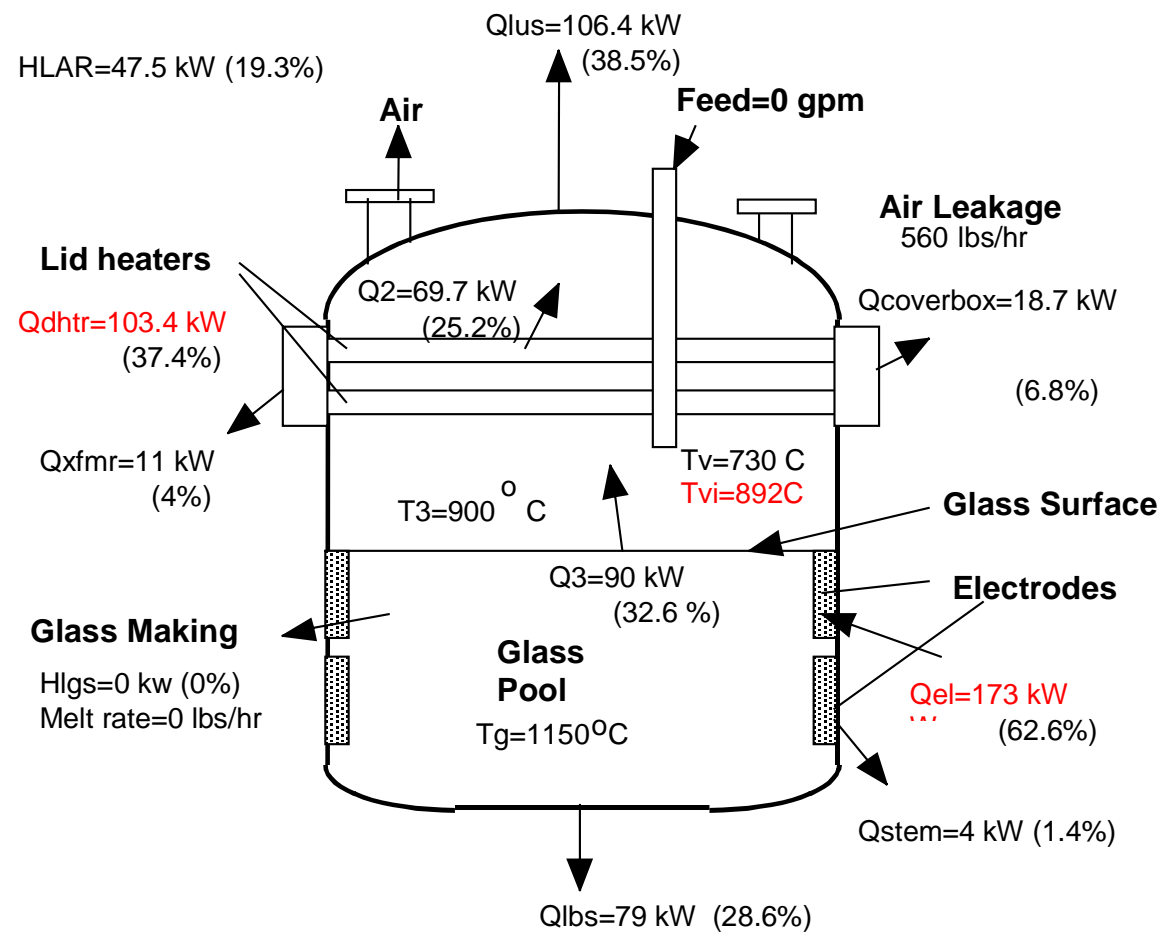

Figure 8 Power Loss Distribution for Macrobatch 1 Idling Conditions

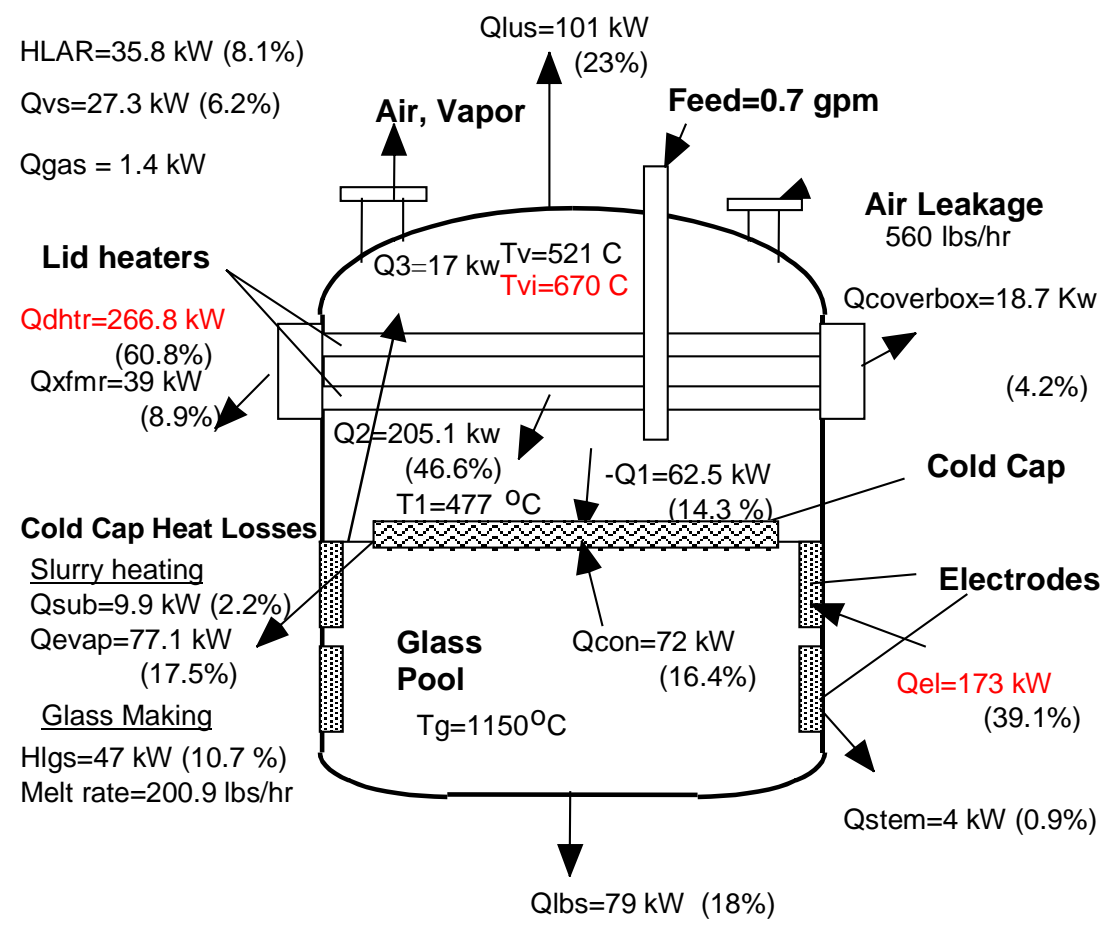

Figure 9 Power Loss Distribution for Macrobatch 1 Full Feed Conditions 
WSRC-TR-2002-00159

Revision

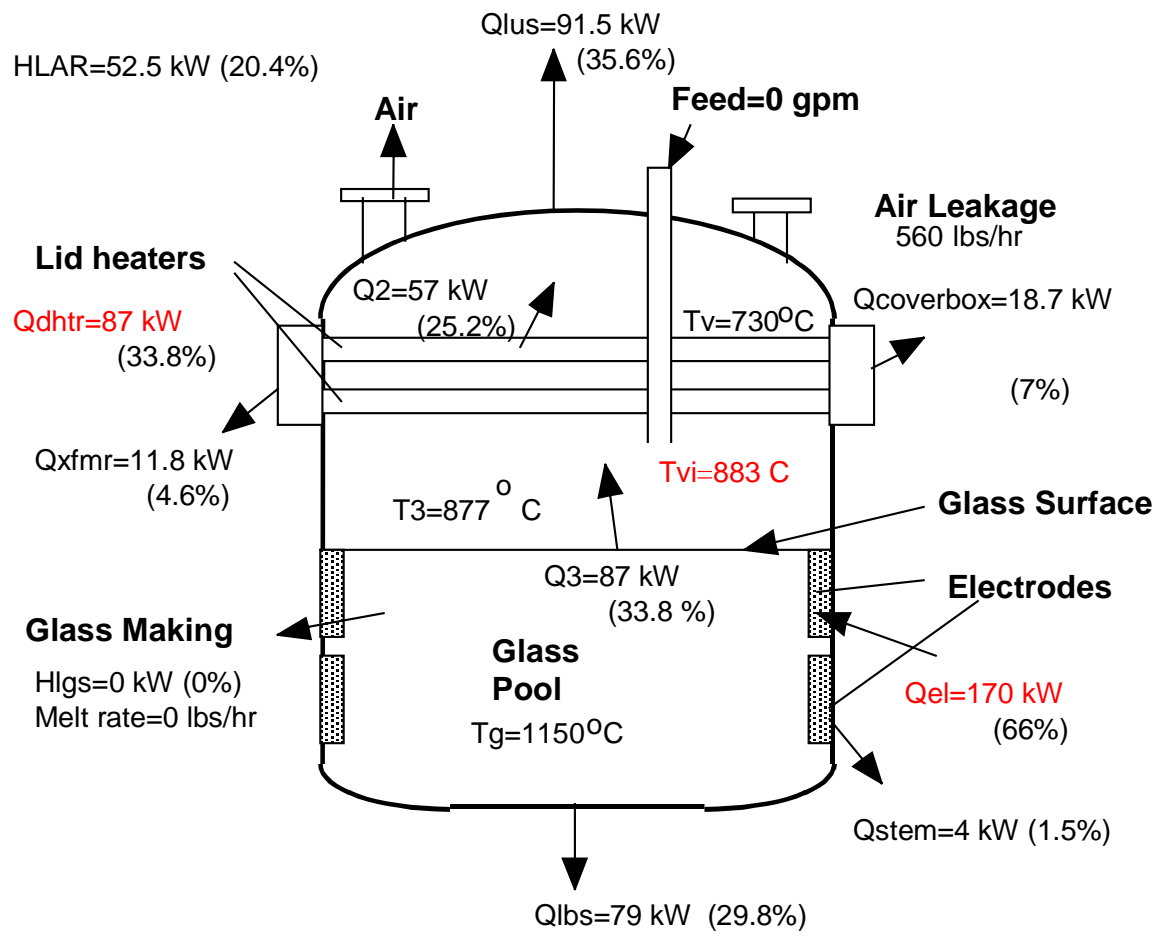

Figure 10 Power Loss Distribution for Macrobatch 2 Idling Conditions

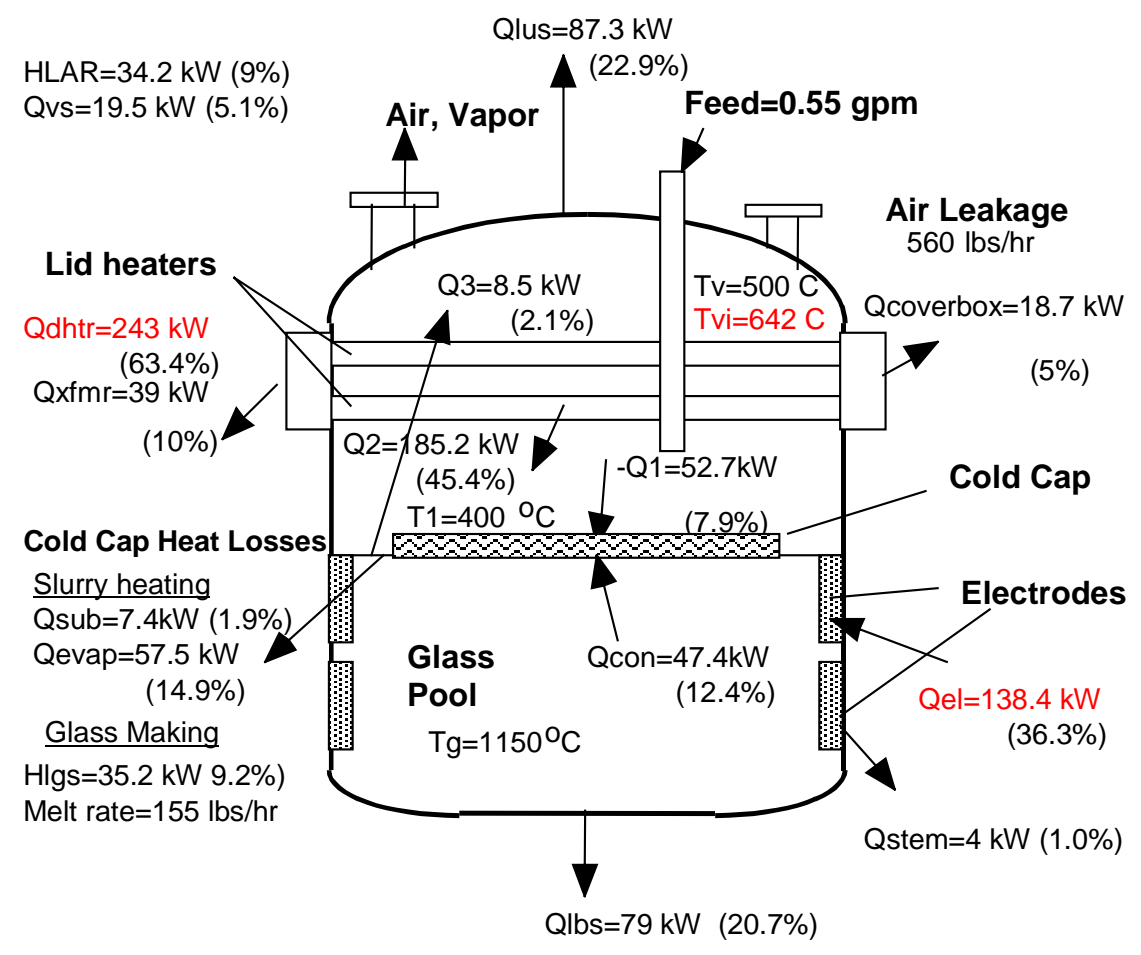

Figure 11 Power Loss Distribution for Macrobatch 2 Full Feed 
WSRC-TR-2002-00159

Revision

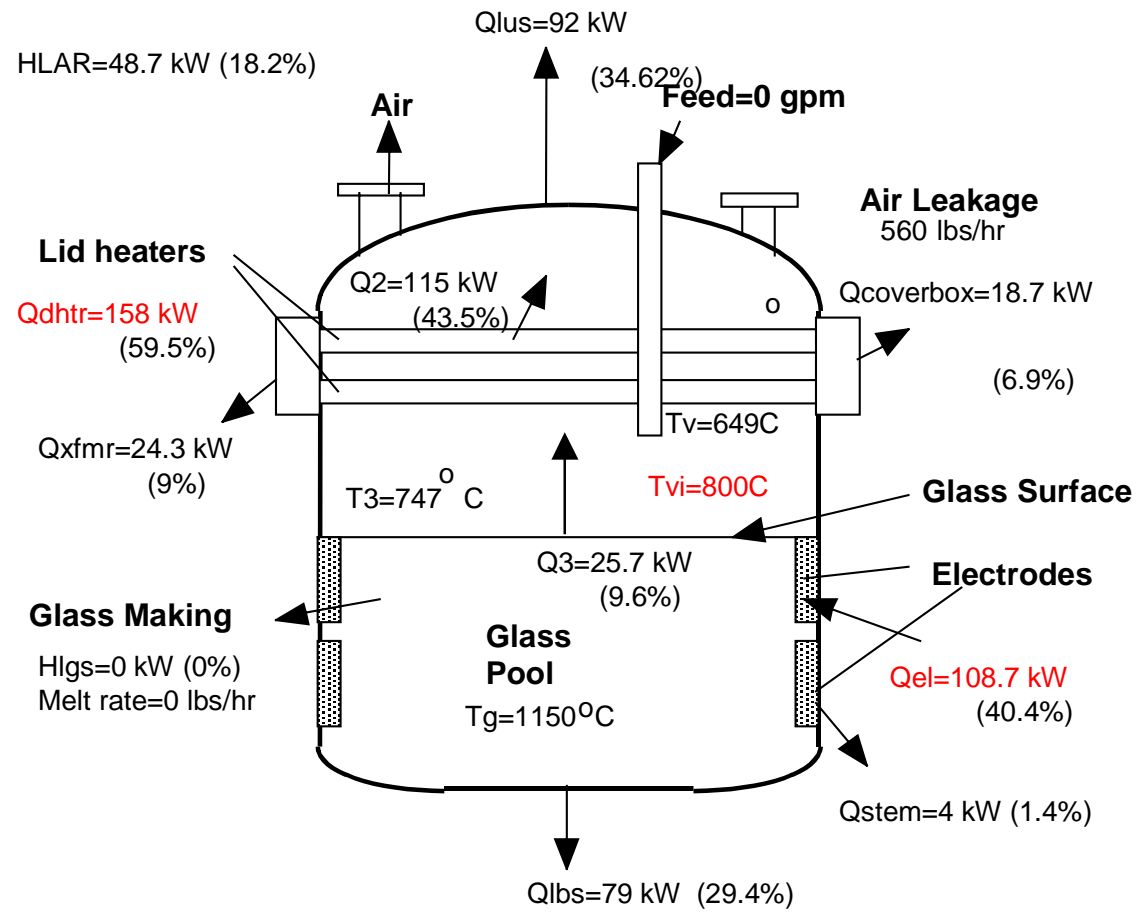

Figure 12 Power Loss Distribution for Macrobatch 3 Idling Conditions

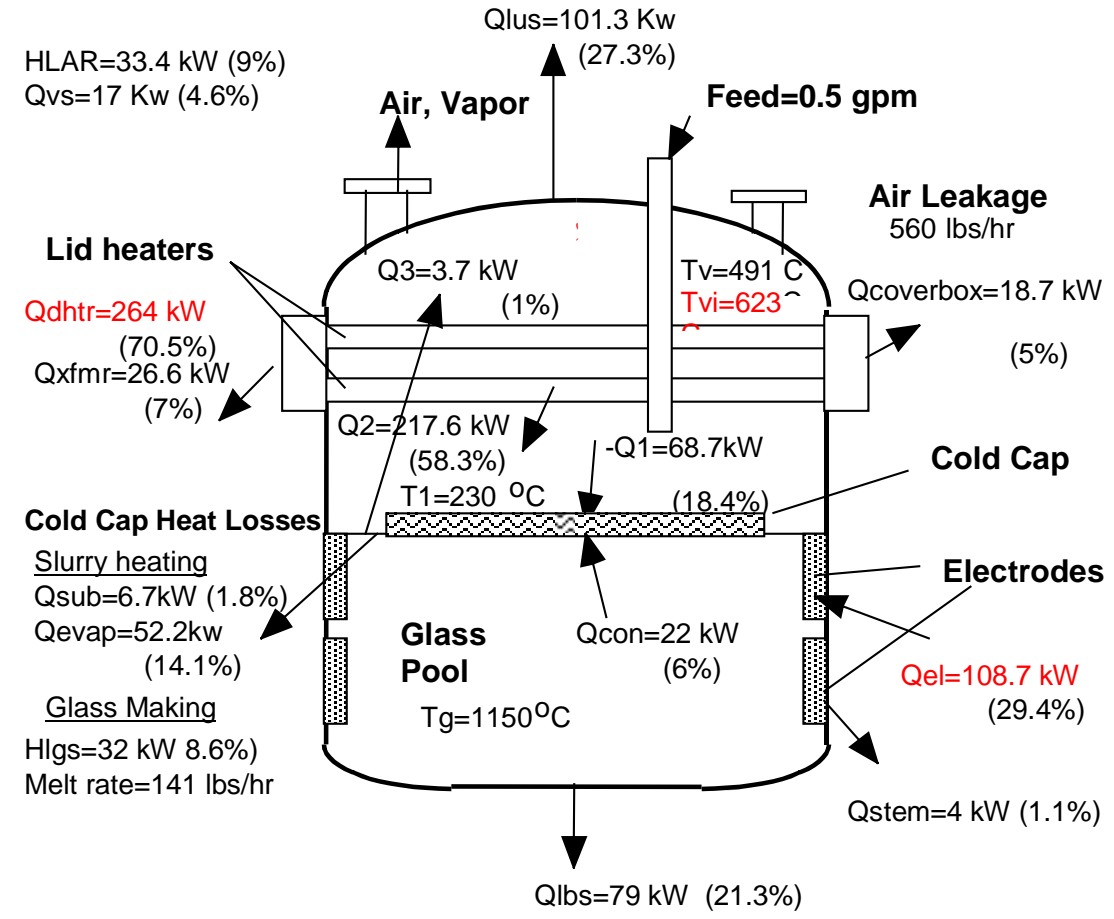

Figure 13 Power Loss Distribution for Macrobatch 3 Full Feed Conditions 
dropped to $108.7 \mathrm{~kW}^{3}$ (from $173 \mathrm{~kW}$ for Macrobatch 1 and $138.4 \mathrm{~kW}$ for Macrobatch 2). This suggests that significantly more foaming is occurring or a thermally resistant layer in the cold cap or glass top surface layer has formed.

This decrease in electrode power is made up by increasing the dome heater power, $264 \mathrm{~kW}$ (up from $243 \mathrm{~kW}$ for Macrobatch 2 for close to the same feed rate). Under idling conditions, the indicated vapor space temperature (Tvi) decreased to $800^{\circ} \mathrm{C}$ (from $892^{\circ} \mathrm{C}$ in Macrobatch 1 and $883^{\circ} \mathrm{C}$ in Macrobatch 2). The corrected vapor temperatures are given by the label Tv. The electrode power dropped to $108.7 \mathrm{~kW}$ (from $173 \mathrm{~kW}$ and $170 \mathrm{~kW}$ for Macrobatches 1 and 2 , respectively).

Using the lumped model for idling conditions, the glass surface temperature, T3, and the radiant flux from the glass surface, Q3, can be predicted, as shown in Figure 12 to be $747^{\circ} \mathrm{C}$ and $25.7 \mathrm{~kW}$, respectively. The corresponding values for Macrobatches 1 and 2 are $900^{\circ} \mathrm{C}$, $877^{\circ} \mathrm{C}$ and $90 \mathrm{~kW}, 87 \mathrm{~kW}$, respectively. This appears to confirm the premise that a thermally resistant upper glass layer has formed, e.g., spinels.

Also, using the lumped model for feeding conditions, the cold cap surface temperature, T1, and radiant heat, Q1, absorbed by the cold cap from the dome heaters and plenum surfaces can be predicted. These are shown in Figure 13 to be $230^{\circ} \mathrm{C}$ and $68.7 \mathrm{~kW}$, respectively. The corresponding values for Macrobatch 2, which has close to the same feed rate are: $400^{\circ} \mathrm{C}$ and $52.7 \mathrm{~kW}$. The cold cap temperature is an effective temperature which implies that a large proportion of the cold cap is covered with wet slurry. The decreased convective heat, Qcon, from the melt pool of $22 \mathrm{~kW}$ (down from $47.4 \mathrm{~kW}$ from Macrobatch 2) does not provide sufficient heat to evaporate the slurry and therefore, more radiant heat, Q1, is required. This further supports the premise of a thermally insulating layer at the glass/cold cap interface.

\subsection{Historical Power Trends}

As a result of the changes observed with Macrobatch 3, more extensive historical data trending was performed to determine if changes were gradual or abrupt. This includes data starting in 5/97, when stable pouring conditions were first established using pour spout inserts, to 4/02. Power history data at quarterly intervals are plotted in Figure 14 for feeding conditions of and Figure15 for idling conditions.

\footnotetext{
${ }^{3}$ Averaged over data runs for full feed conditions, not from curve fit of Fig. 7 which includes idling conditions.
} 


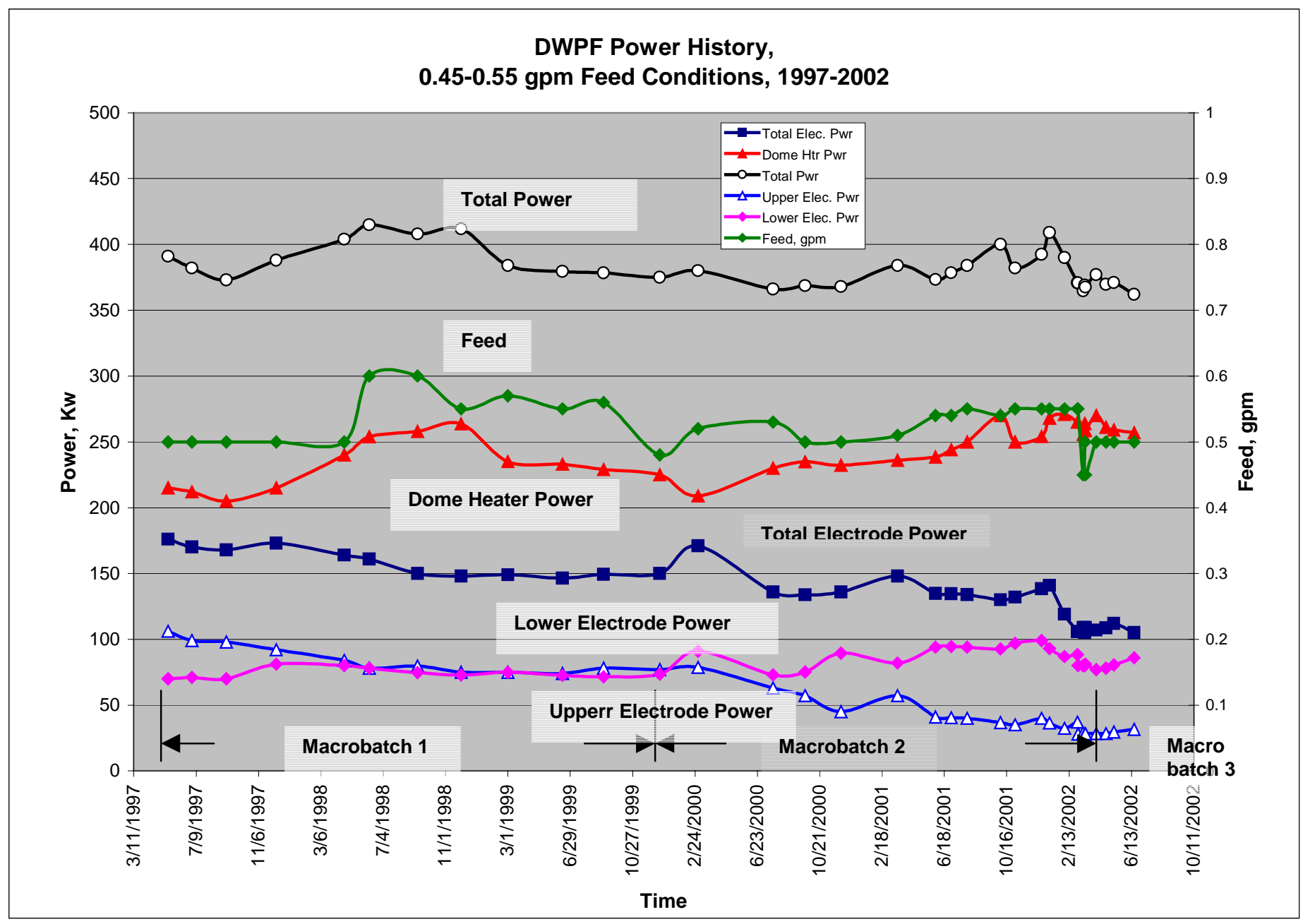

Figure 14 Averaged Power Inputs for Period 5/1/97-4/30/02 Under 0.45-0.6 gpm Feed

Figure 14 shows the electrode power decreasing from Macrobatch 1 to Macrobatch 2, and even a more dramatic decrease at the tail end of Macrobatch 2 to Macrobatch 3 for nominally similar feed rates of $0.45-0.6 \mathrm{gpm}$. The dome heater power, by contrast, increased to maintain the total power. The figure also shows the increasing trend in the upper electrode power and the opposite trend for the lower electrode power. 


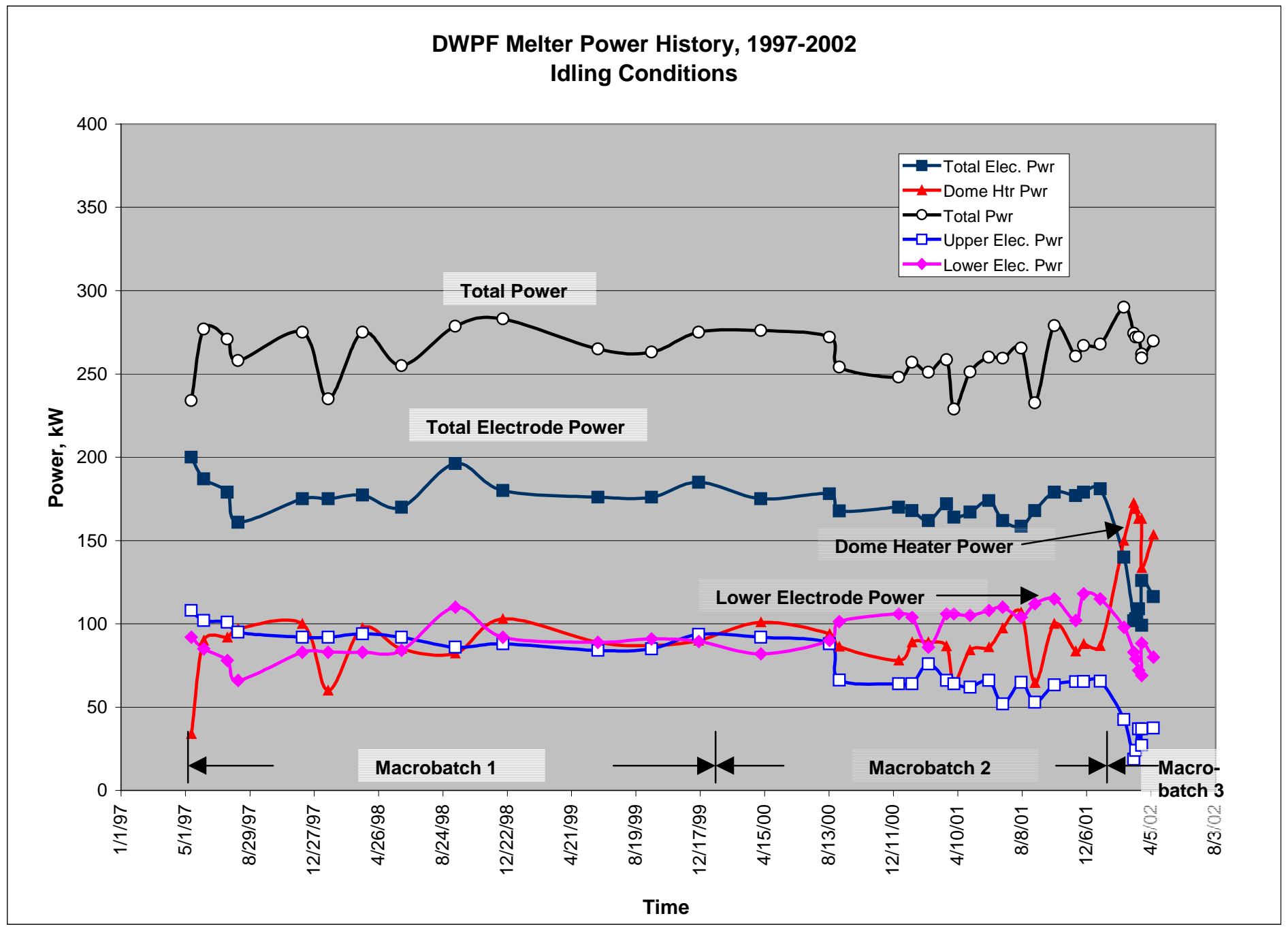

Figure 15 Averaged Power Inputs for Period 5/1/97-4/30/02 Under Idling Conditions

Historical idling power data, shown in Figure 15, indicate that the total electrode power and dome heater power remained fairly constant for Macrobatches 1 and 2, but that there was a significant drop in the electrode power and increase in dome heater power in Macrobatch 3 relative to Macrobatch 2. The total power remained fairly constant even with Macrobatch 3, where the electrode power drop was compensated by the increase in dome heater power. 


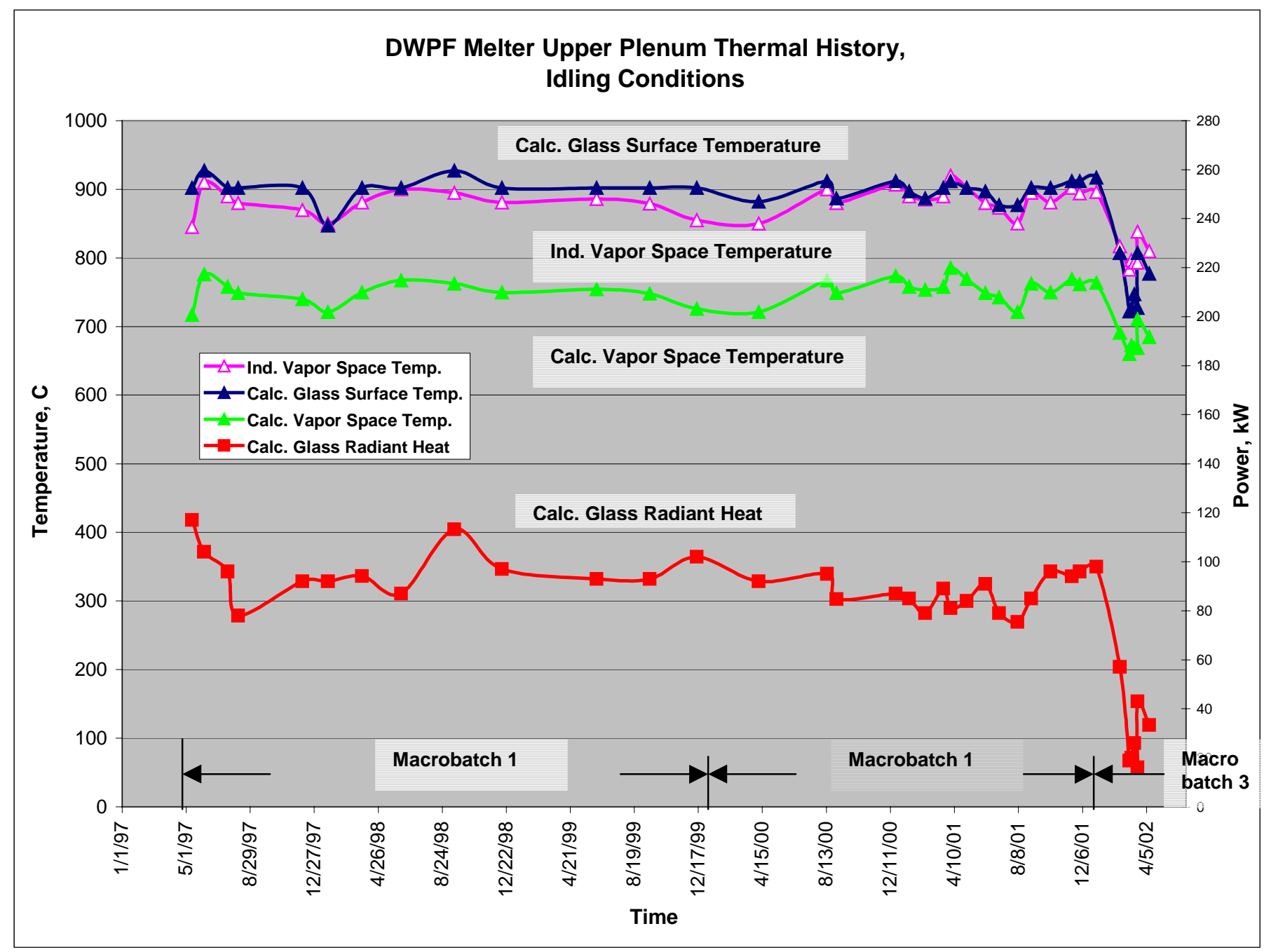

Figure 16 Thermal History in the DWPF Upper Plenum Under Idling Conditions

The trend of the vapor space temperature for Macrobatches 1-3 is shown in Figure 16, where an abrupt drop in this temperature occurred in the transition from Macrobatch 2 to Macrobatch 3. The corrected vapor space temperature, which accounts for radiation effects, is also shown. The calculated vapor space temperature is the theoretical true vapor temperature. The lumped parameter model with its radiation heat exchange model, shows that the calculated glass surface temperature and radiant heat from the glass surface to the upper plenum decreased from Macrobatch 2 to 3. This is consistent with a thermally resistant upper glass surface layer. 


\subsection{Transient Analysis}

Detailed transient thermal analysis results are found in Sec. 6.4. Three representative DWPF Melter runs ${ }^{4}$ are simulated, where step changes in feed rate, and electrode and dome heater powers were made to new steady values. Comparison between the data and the predictions serves to evaluate the model and suggest areas for additional analysis. Then the analysis is repeated for the separate effects of the control parameters while the others are held constant. Thus the results give an understanding of the physical processes going on and of the rates at which changes occur. The study is not intended to be part of an Authorization document or technical baseline. However, the results can provide guidance to operators as to expected changes in melter parameters when certain control inputs are performed.

The transient analysis consists of simultaneous first order differential equations for the rates of change of the glass pool temperature, the upper plenum vapor temperature, and the glass surface area, and other heat balance relations. In the transient model, a film heat transfer coefficient derived from the steady state heat balance of the actual batch is used. This set of equations involves strong couplings between the glass temperature, the vapor temperature, and glass surface area. These are highly nonlinear equations due to the $4^{\text {th }}$ power exponent of the temperature in the radiation terms. Consequently, the equations are solved numerically using PDEASE, a 2-dimensional partial differential equation solver by Macsyma, Inc. (Ref. 7.2).

- The transient analysis model is benchmarked against DWPF Melter data that are representative of typical feed rate increase and decrease transients. These transients include the effect of the type of feed (Macrobatch 1 or Macrobatch 2) and various feed rates. Reasonable agreement is achieved between the analysis and the data for 3 melter runs during the periods, 12/01-23/97, 7/2-4/99, and 2/09-19/01. These periods were chosen because they included melter operations at steady feeding, idling, and then back to steady feeding for at least 24 hours at each stage so that thermal inertia effects have stabilized. Reasonably close agreement between prediction and data is achieved when the actual run has the same electrode and dome heater powers as the average value over several runs because the analysis is based on correlations of electrode/dome heater powers to the feed rate. When there is a large deviation of the actual run power to the average value, better agreement can be achieved if the average values for the corresponding feed rates were used. This is due to possible inaccurate prediction of the glass surface temperature (as affected by the glass bulk temperature and flow circulation) which controls radiant heat to the plenum. Further, the difference between Macrobatch 1 and Macrobatch 2 runs is the use of heat transfer coefficient values of $0.0648 \mathrm{~kW} / \mathrm{m}^{2}-{ }^{\circ} \mathrm{K}$ and $0.052 \mathrm{~kW} / \mathrm{m}^{2}-{ }^{\circ} \mathrm{K}$ for convection between the cold cap and the glass melt.

- The transient model is also used to investigate the separate effects of varying one parameter (feed rate, electrode power or dome heater power) while holding the others constant as an aid in operations. The objective is to understand the interplay of the various heat transfer mechanisms in the melter, as these affect the controlled temperatures and melt rates. Three separate effect cases are investigated based on a Macrobatch 2 run (2/09-19/01). In the first

\footnotetext{
${ }^{4} \mathrm{~A}$ run is an arbitrary time period, since the melter is running continuously hot.
} 
case, the electrode and dome heater powers are held constant corresponding to an initial flow of $0.5 \mathrm{gpm}$ and then the electrode power is increased an amount equal to what would be added if the feed rate were reduced to zero. The result is to increase the glass temperature, the exposed glass surface area and the radiant heat to the upper plenum. What is not known is a potential increase in glass surface temperature with a reduced cold area, increasing the radiant heat to the upper plenum further and decreasing the bulk glass temperature.

- In the second case, conditions for zero feed rate are initially held constant. Then a step increase in feed rate is initiated while maintaining electrode and dome heater powers. The result is that the glass, vapor space, and dome heater temperatures all decrease as the cold cap area increases. The convective and radiant heats to the cold cap increase with the growth in cold cap area, with a corresponding decrease in radiant heat to the upper plenum.

- In the third case, conditions for full feed of $0.50 \mathrm{gpm}$ is maintained and then a step increase in dome heater power is initiated. The dome heater and vapor space temperatures then increase while the glass temperature decreases as the cold cap area decrease. The radiant heat to the upper plenum and cold cap also increase, resulting in a momentary increase in melt rate. This scenario brings some light to the case of supplying an additional source of radiant heat to the upper plenum through the use of bubblers bringing heat from deeper layers to the surface of the glass. Here, a higher melt rate may be expected. 


\section{Method of Analysis}

This analysis uses a lumped parameter approach for simplicity and to provide an overall perspective of a very complex process. The averaged or lumped parameters of the model can come from more detailed 3-dimensional computational fluid dynamics models currently in progress, from experiments, or from DWPF data. First a steady state heat balance of the melter is calculated. This calculation borrows heavily from the 1988 analysis of Yoshioka, (Ref. 9.1) including property parameter relations. The BASIC program archived for this work did not seem to correspond to the logic presented in Reference 9.1, and running that program did not provide the same results as in the report. In that report, the vapor temperature was assumed known, $680^{\circ} \mathrm{C}$ at design conditions, and the demanded (required) electrode power and dome heater powers were calculated. Due to high actual upper shell heat losses in the melter, the measured vapor temperatures are much lower, typically $493^{\circ} \mathrm{C}$ (with radiation correction) at $0.7 \mathrm{gpm}$ (Macrobatch 1). Consequently, the heat balance calculation was redone, using most of the same equations in the Basic program. The present calculation however differs from Ref. 9.1 in that the radiation heat transfer in the melter upper plenum accounts for radiation exchange among all the surfaces in the upper plenum and includes the steam as participating media (Ref. 9.4). The results of the steady state heat balance closely resemble the results of Ref. 9.1 if the same inputs are used. The present analysis however assumes the electrode power, dome heater power, and feed rate are known functions of time. Further, estimates of the shell heat losses based on actual DWPF Melter power data, which are almost twice as much as those in Ref. 9.1, are used. Then the glass, vapor space, and dome heater temperatures, and internal heat distributions are then calculated.

The detailed equations solved for the steady state heat balance are given in Appendix A. These can also be obtained from the transient equations (Appendix A, Equations A-38 to A-44) by equating the time variable terms to zero. The steady state equations were programmed in an Excel spreadsheet. While the number of equations equals the number of variables, direct solution of the equations is very difficult because of the nonlinear nature of the equations, where the radiation terms involve temperatures to the $4^{\text {th }}$ power. Yoshioka used an iterative method to obtain convergence on the cold cap coverage and glass surface temperature. He also assumed a cold cap surface temperature of $100^{\circ} \mathrm{C}$. For this work, the transient equations were used with trial values for the cold cap temperature and glass surface temperature, input values of electrode and dome heater powers and total feed rate. The initial value of the cold cap coverage is based on a linear relation with feed rate. If the trial solutions are correct, the variable values of the vapor temperature, glass surface area, glass pool temperature, lid heater temperature, and heat losses reach a steady state value after a sufficiently long time. These values are then checked with the Excel program. By comparison, the calculated cold cap upper surface temperature ranges from $450^{\circ}-477^{\circ} \mathrm{C}$, which is in the film boiling regime for water.

The transient analysis focuses on the melter glass pool, the cold cap, and the steam/air temperature responses. Transient heat balance equations are written for the rate of increase in temperature of the glass pool and the air/vapor mass in the plenum. The cold cap coverage is variable and highly dependent on the difference between the total feed rate and the actual melt rate. Here, a constant cold cap height and porosity is assumed (if changes are slow enough) so that the cold cap expands if the feed rate exceeds the melt rate, and vice-versa. The radiation 
view factors are functions of the cold cap area and thus vary with time. These result in three simultaneous first order differential equations for the melter glass temperature, the vapor temperature, and the uncovered glass surface area. No time lags are assumed due to radiant heat transfer, boiling, and melting. Additional relations are included for the convective heat flux from the glass pool to the cold cap, the radiant heat flux from the glass surface, the heat flux from the lid heaters, the heat absorbed by the cold cap from the upper plenum. The steam is fully participating in the radiant heat exchange. (In Yosioka's analysis, steam was not included in the radiation exchange.) The terms in the following equations are referred to the Nomenclature section (Sec. 8.0) and also to the melter schematic in Figure 8 and other figures.

Rate of increase of glass pool temperature

The rate of increase in the glass pool temperature is due to the heat capacity of the glass and the difference in the electrode power and energy transferred to the cold cap, the upper plenum and heat losses.

$$
\begin{aligned}
& \text { Mp* } \mathrm{dTg} / \mathrm{dt}=(\text { Qel - Q3- Qcon - Qlus - Qlbs - Qstem }) / \text { Hbatch } \\
& \text { Where Hbatch }=\left(\int_{20^{\circ} \mathrm{C}}^{1150^{\circ} \mathrm{C}} c_{p g} d T+\int_{20^{\circ} \mathrm{C}}^{1150^{\circ} \mathrm{C}} \Delta H_{r} d T\right)
\end{aligned}
$$

\section{Rate of increase of upper plenum vapor temperature}

The rate of increase in the upper plenum vapor/air temperature is due to:

- the heat capacity of the air/vapor, and

- the difference in the total heat radiated to the interior of the plenum from all surfaces,

- and the heat losses from the upper shell and superheating of the air and vapor.

Here, Q1 through Q5 are the net radiant heats from the cold cap (Q1), dome heaters (Q2), glass area $(\mathrm{Q} 3)$, plenum side walls $(\mathrm{Q} 4)$ and upper lid (Q5). The sign convention is positive for heat towards the interior. Thus the sum of heat losses through the side wall and upper lid (Qlus) is equal to the sum of the negative values of Q4 and Q5. Q1 is the negative value of the net radiant heat absorbed by the cold cap. Q2 is the net heat radiated from the dome heaters, which is the dome heater total power less heat lost from the cover box (Qcoverbox) and dome heater end losses due to connectors and transformer bus bars (Qhtrloss).

$$
\begin{aligned}
& \text { Ms*cps*dTv/dt }+\mathrm{Ma}^{*}{ }^{*} \mathrm{pa}^{*} \mathrm{dTv} / \mathrm{dt}=\mathrm{Q} 1+\mathrm{Q} 2+\mathrm{Q} 3-\mathrm{Qlus}-(\mathrm{Qcoverbox}+\text { Qhtrloss + HLAR } \\
& + \text { Qvs+Qgas })
\end{aligned}
$$

\section{Rate of increase of uncovered glass surface area}

The rate of increase in the glass surface area (A3) is obtained through a mass balance between the total solids feed rate (TFR) and the actual melt rate (MR).

$$
\rho c{ }^{*} \text { porosity } * \mathrm{dA} 3 / \mathrm{dt} * \mathrm{hc}=\mathrm{MR}-\mathrm{TFR} * f c
$$

where porosity may be a function of feed composition, $f c$ is the calcination ratio or the fraction of solids converted to glass after evolution of gas during chemical reaction in the melting process. The calcination ratio used is 0.89 as given in Ref. 9.3. 


\section{Melt rate equation}

By performing a heat balance on the cold cap, Equation 5 below follows. Here, the sum of the convective heat from the glass pool, Qcon, and the net radiant heat absorbed by the cold cap, Q1, is used to evaporate the feed water, melt the glass, and raise its temperature to the operating temperature.

Qcon-Q1 $=$ SFR $*$ cpw $^{*}(100-25)+\mathrm{SFR} * \Delta$ Hevap + MR $*$ Hbatch

Where,

Hbatch $=\left(\int_{20^{\circ} \mathrm{C}}^{1150^{\circ} \mathrm{C}} c_{p} d T+\int_{20^{\circ} \mathrm{C}}^{1150^{\circ} \mathrm{C}} \Delta H_{r} d T\right)=\operatorname{cpg}^{*}($ Tsoft-25) $+\Delta$ Hmelting $+\operatorname{cpg} *(1150-554)$,

$\Delta$ Hmelting is estimated to be $120 \mathrm{cal} / \mathrm{gm}$ for endothermic reaction heat and $-80 \mathrm{cal} / \mathrm{gm}$ for exothermic reaction, which includes $20 \mathrm{cal} / \mathrm{gm}$ for silica melting, SFR is the water (or steam) feed rate, $\Delta$ Hevap is the heat of evaporation of water, cpw and cpg are the specific heats of water and glass, respectively. The average value of cpg over the appropriate temperature range is used in Hbatch.

Convective heat flux from glass pool

The heat convected to the cold cap by the glass, Qcon, is calculated in the transient analysis by using a film heat transfer coefficient, hcon, based on the results of the steady state heat balance where Qcon is calculated independently, and the temperature difference between the glass ( $\mathrm{Tg}$ ) and cold cap (T1) Then,

$$
\text { Qcon }=\text { hcon*Acc* }(\mathrm{Tg}-\mathrm{T} 1)
$$

Net heat radiation from cold cap

The net radiant heat from the cold cap to the interior of the upper plenum is obtained by the radiation exchange method (Ref. 3). The emissive power of the surface less the radiant heats transmitted through the vapor from other surfaces and from the vapor itself.

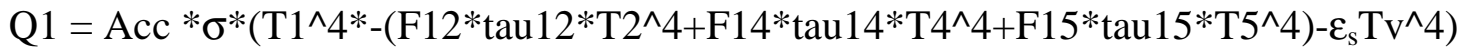

Here, Acc is the area of the cold cap, $\sigma$ is the Stefan-Boltzman constant, F12, etc. are the view factors, tau12, etc. are transmission factors through the steam medium, $\varepsilon_{\mathrm{s}}$ is emissivity of steam, $\mathrm{T} 2$ is the dome heater temperature, T4 and T5 are the upper shell side and top lid temperatures and $\mathrm{Tv}$ is the vapor temperature.

Net heat radiation from uncovered glass surface

The net radiant heat from the uncovered glass surface, Q3, is calculated in a similar manner as above.

$\mathrm{Q} 3=\mathrm{A} 3 * \sigma^{*}\left(\mathrm{Tg}^{\wedge} 4-\left(\mathrm{F} 32 * \operatorname{tau} 32 * \mathrm{~T} 2 \wedge 4+\mathrm{F} 34 * \operatorname{tau} 34 * \mathrm{~T} 4 \wedge 4+\mathrm{F} 35^{*} \operatorname{tau} 35^{*} \mathrm{~T}^{\wedge} 4\right)-\varepsilon_{\mathrm{s}} * \mathrm{Tv}^{\wedge} 4\right)$

Lid heater temperature

Knowing the lid heater power, the lid heater surface temperature, $\mathrm{T} 2$, is, 
$\mathrm{T} 2^{\wedge} 4=(1 / \sigma)^{*}\left(\mathrm{Q} 2 / \mathrm{A} 2-\sigma^{*}\left(\mathrm{~F} 21^{*} \tan 21^{*}{ }^{*} 1^{\wedge} 4+\mathrm{F} 23^{*} \tan 23^{*} 3^{\wedge} 4+\mathrm{F} 24 * \operatorname{tau} 24^{*} \mathrm{~T}^{\wedge} 4+\right.\right.$ $\left.\mathrm{F} 25^{*} \operatorname{tau} 25^{*} \mathrm{~T} 5^{\wedge} 4+\varepsilon_{\mathrm{s}} * \mathrm{Tv}^{\wedge} 4\right)$

Here, Q2 is the net dome heater power, A2 is the area of the dome heaters, and T3 is the temperature of the glass surface.

\section{Heat losses from upper plenum surfaces}

The transient heat loss from the upper plenum, Qlus, is obtained by first calculating a heat transfer coefficient based on the steady state heat balance calculations, hus, and then using Equation 10,

$$
\text { Qlus=hus*Aus*(Tv-313). }
$$

The same procedure was used to obtain the transient heat loss from the lower plenum, Qlbs, to obtain Equation 11,

$$
\text { Qlbs=hbs*Abs*(Tg-313). }
$$

These estimates can be improved in the future if radiation and conduction heat losses through shell penetrations can be determined more accurately.

\section{Calculation Results}

\subsection{Benchmarking with Power Data}

To benchmark the lumped parameter model, a calculation was done for two specific Macrobatch 1 conditions provided by the correlations of dome and electrode powers, one at zero feed and the other at $0.7 \mathrm{gpm}$. The run at zero feed represents a case of the glass surface completely uncovered. The run at $0.7 \mathrm{gpm}$ represents a case of a cold cap area covering $88.8 \%$ of the available glass surface area. The calculations use the measured dome heater temperature $\left(950^{\circ} \mathrm{C}\right)$ and the measured vapor temperature $\left(892^{\circ} \mathrm{C}\right)$ corrected for radiant heating by using the correlation given by Choi in Ref. 7.5. By doing a heat balance on the off-gas flow in the SGM melter, he obtained a correlation for corrected vapor temperature versus indicated temperature, as provided by Equation 12 .

$$
\text { Tv }=0.9168 * \text { Tind } .-128
$$

However, in his comparison with DWPF data, the above correlation under-predicted the DWPF data by as much as $50^{\circ} \mathrm{C}$. This correlation was used in the calculations but was adjusted upwards by $30^{\circ}-50^{\circ} \mathrm{C}$, which resulted in better heat balance.

An uncontrolled air in-leakage rate of $100 \mathrm{lbs} / \mathrm{hr}$ (estimated by DWPF) is also used in addition to the known controlled air in-leakage of $460 \mathrm{lbs} / \mathrm{hr}$. Also, data for dome heater transformer bus bar cooling are used, as well as natural convection cooling, to add to the heat losses to the lid heater. The predicted power distributions for 0 and $0.7 \mathrm{gpm}$ are given in Figures 8 and 9, respectively.

In the case of the zero feed run, the total power of $276.4 \mathrm{~kW}$ goes into heating the in-leakage air of $560 \mathrm{lbs} / \mathrm{hr}(47.5 \mathrm{~kW})$, heat loss through the shell of $185.4 \mathrm{~kW}$, and $33.5 \mathrm{~kW}$ for miscellaneous losses. The heat loss through the shell was calculated as the difference between the power input 


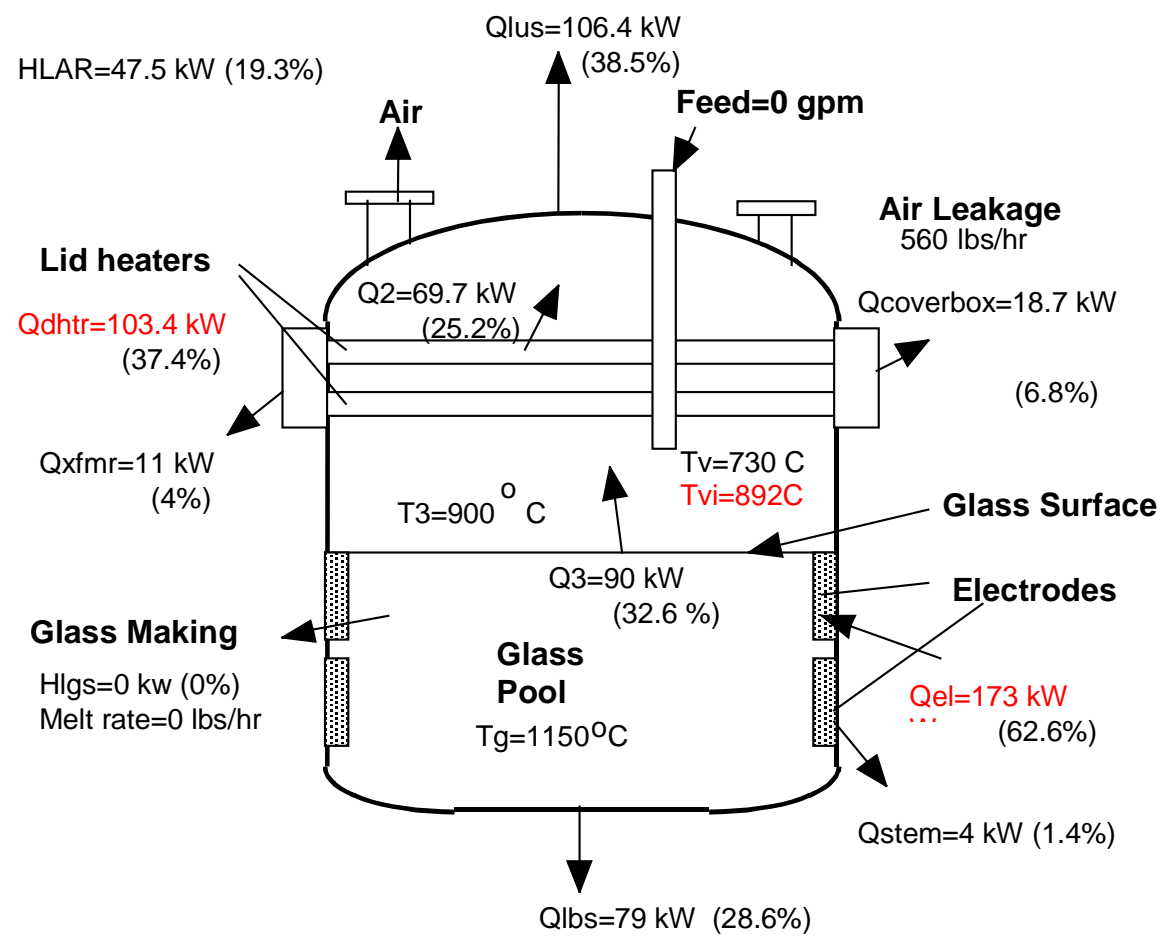

Figure 8 (repeated) Power Loss Distribution for Macrobatch 1 Idling Conditions

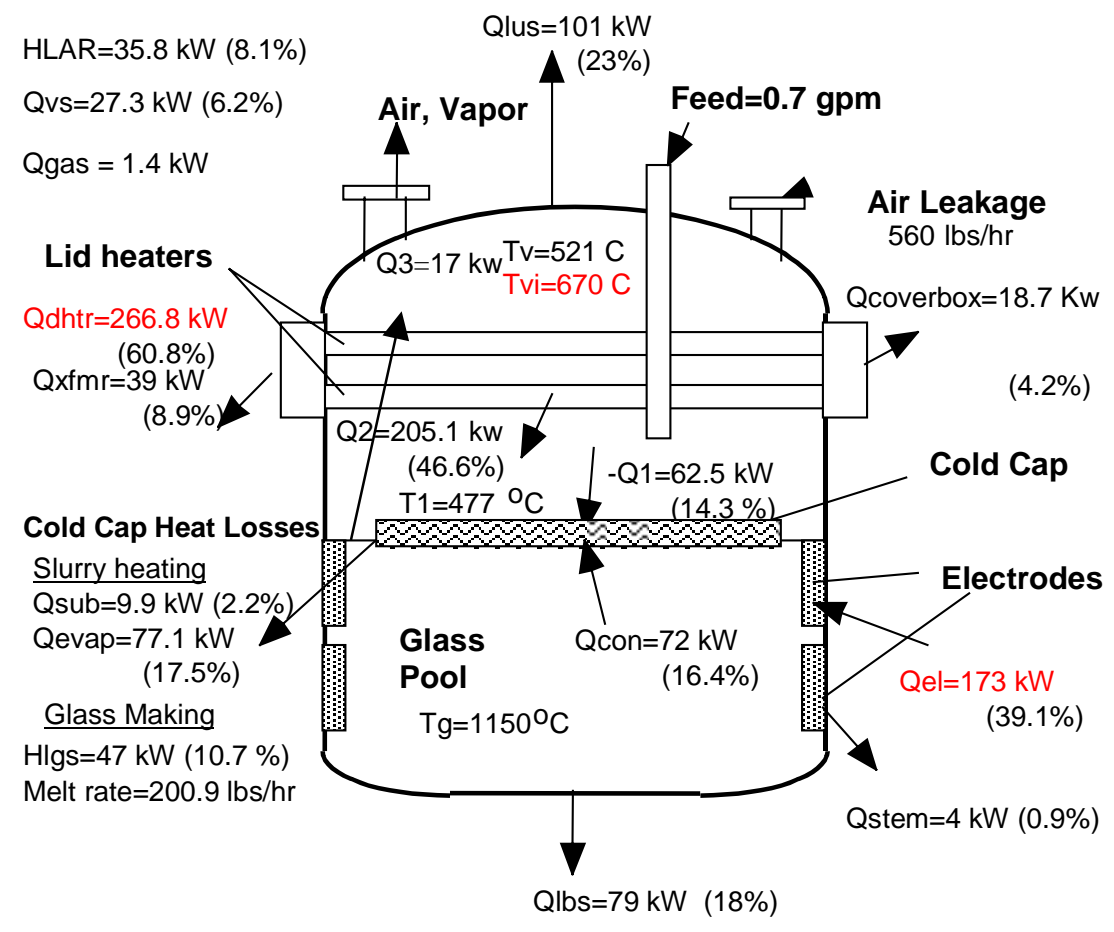

Figure 9 (repeated) Power Loss Distribution for Macrobatch 1 Full Feed Conditions 
and the leakage air loss plus miscellaneous losses. This shows that the actual shell heat loss exceeds the previous theoretical heat loss of $96 \mathrm{~kW}$ by $89 \mathrm{~kW}$. That the heat losses are high was confirmed by examining the temperature rise in the melter shell cooling water (approximately $2^{\circ} \mathrm{C}$ ) for a total flow of $365 \mathrm{gpm}$ (which suggests a heat loss of $192 \mathrm{~kW}$ !). A definitive value of the shell heat loss is not possible due to uncertainty in the temperature readings. The difference between the actual and theoretical shell heat losses can be explained by the fact that heat conduction through shell penetrations, drain valve, and radiation into the off-gas outlet flange is not considered in the theoretical calculation. The excess heat from the electrodes $(90 \mathrm{~kW})$ is radiated from the glass surface at $900^{\circ} \mathrm{C}$ to the upper plenum.

In the case of the 0.7 gpm run (Figure 9), the total power of $439.8 \mathrm{~kW}$ goes into heating the slurry $(87 \mathrm{~kW})$, making glass $(47 \mathrm{~kW})$, heating the vapor, gas, and in-leakage air $(64.5 \mathrm{~kW})$, total shell heat losses $(180 \mathrm{~kW})$ and miscellaneous losses $(65.7 \mathrm{~kW})$. From the 0 and $0.7 \mathrm{gpm}$ feed rate cases, a split of the total shell heat loss into lower and bottom shell losses can be obtained. A radiant heat loss (Q3) from the all glass surface in the zero feed case of $90 \mathrm{~kW}$, a lower shell loss (Qlbs) of $79 \mathrm{~kW}$ and upper shell heat loss (Qlus) of $106.4 \mathrm{~kW}$ is consistent with a glass temperature of $900^{\circ} \mathrm{C}$ and vapor temperature of $730^{\circ} \mathrm{C}$. Further in the $0.7 \mathrm{gpm}$ case, the cold cap is assumed to cover $90 \%$ of the glass melt surface. Of the $173 \mathrm{~kW}$ electrode power, $90 \mathrm{~kW}$ is available for natural convection to heat the cold cap from below (the same as the radiant heat to the plenum in the zero feed case). The lower shell heat loss is also assumed to be $79 \mathrm{~kW}$, as with the zero feed case, since the glass temperature is maintained constant. The remaining $4 \mathrm{~kW}$ is due to electrode stem loss. The upper plenum heat loss $(101 \mathrm{~kW})$ is obtained by subtracting the lower shell heat loss from the total shell heat. This upper shell heat loss is slightly increased over the zero feed case by $2.5 \mathrm{~kW}$ even as the upper plenum vapor temperature decreased. This heat loss increase is confirmed by an increase in shell cooling water return temperature in the data of $8 / 25 / 97$. This increase may be explained by the radiant-exchange model to be due to the steam acting as a buffer media to re-scatter radiant heat from the lid heaters. Thus, a conclusion from consideration of the two extreme cases is that a constant total value of $90 \mathrm{~kW}$ of the electrode power is available to be convected to the cold cap or radiated to the upper plenum. A portion of the radiated power to the plenum is eventually transferred to the cold cap, as the cold cap area changes in a linear proportion with feed rate.

\subsection{Distribution of Power Losses - Macrobatch 1}

The distribution of total melter power consumption for Macrobatch 1 is given in the area plot of Figure 17, where the component heat losses are stacked on top of each other. The total shell heat losses are fairly constant with feed rate, at approximately $188 \mathrm{~kW}$, from zero feed to $0.7 \mathrm{gpm}$. The heat losses for glass making and slurry water evaporation are linear with feed rate. The power loss due to leakage air decreases with feed rate due to the decrease in the vapor temperature. This is compensated by the increase in heat losses due to vapor and gas superheating. The net result is an almost linear increase of the calculated total melter power demanded with feed rate. The sum of the calculated heat loss components agrees well with the actual total melter power (diamonds).

The heat flow split surrounding the cold cap is given in Figure 18. Here, the various components: convective heat from the melt glass pool, radiant heat from the glass surface to the 
upper plenum and the incident radiant heat on the cold cap are compared to the heats to evaporate the slurry water and melt the glass and their sums.

Due to linearity of the electrode power and dome heater power to the feed rate, it is reasonable to assume that the cold cap area is linear with respect to feed rate, at least above $0.25 \mathrm{gpm}$, which is the lowest instantaneous flow rate actually applied. This linear assumption is used to generate Figure 18. Here, the convective heat Qcon increases and the radiant heat Q3 from the glass surface decreases linearly with feed rate. The convective heat, Qcon, is not based on a calculated heat transfer coefficient at the glass/cold cap interface but on subtraction of lower shell heat loss and radiant heat to the upper plenum from the electrode power. It is assumed that the heat to superheat the steam vapor, calcined gas, and leakage air comes from the dome (or lid) heaters exclusively. Then the remaining heat from the dome heaters plus the radiant heat from the glass surface and after taking upper shell heat loss into consideration, is the radiant heat incident on the top of the cold cap, -Q1.

From Figure 18 above $0.3 \mathrm{gpm}$, this remainder (-Q1)(circles) is insufficient to evaporate all the moisture in the cold cap (squares). Some portion of the convective heat from the glass pool is necessary to supplement this incident radiant heat. If a large thermal resistance due to foaming is present, then a larger cold cap area or more radiant heat from the upper plenum is necessary to generate the required glass melt rate. When the cold cap coverage reaches $100 \%$ (at a lower slurry feed rate than the design rate), additional feed and power are effectively stopped.

\subsection{Summary of Power Distribution for Various Cases}

Table 1 provides a summary of the calculated distribution of power losses at various feed rates for Macrobatch 1 and Macrobatch 2 operation. It also includes predicted power loss distributions for four other cases listed below:

(1) a case where increased air in-leakage due to feed tube seal leakage during the period, 3/2000-4/2000.

(2) the original design basis case of Ref. 7.1,

(3) a case where dilutants are added or a different frit is used that result in an increased overall convective film coefficient, by reducing the foam layer, by an assumed $50 \%$, and

(4) a case similar to Case 3 but where the heat of reaction is exothermic $(+100 \mathrm{cal} / \mathrm{gm})$. 
WSRC-TR-2002-00159

Revision

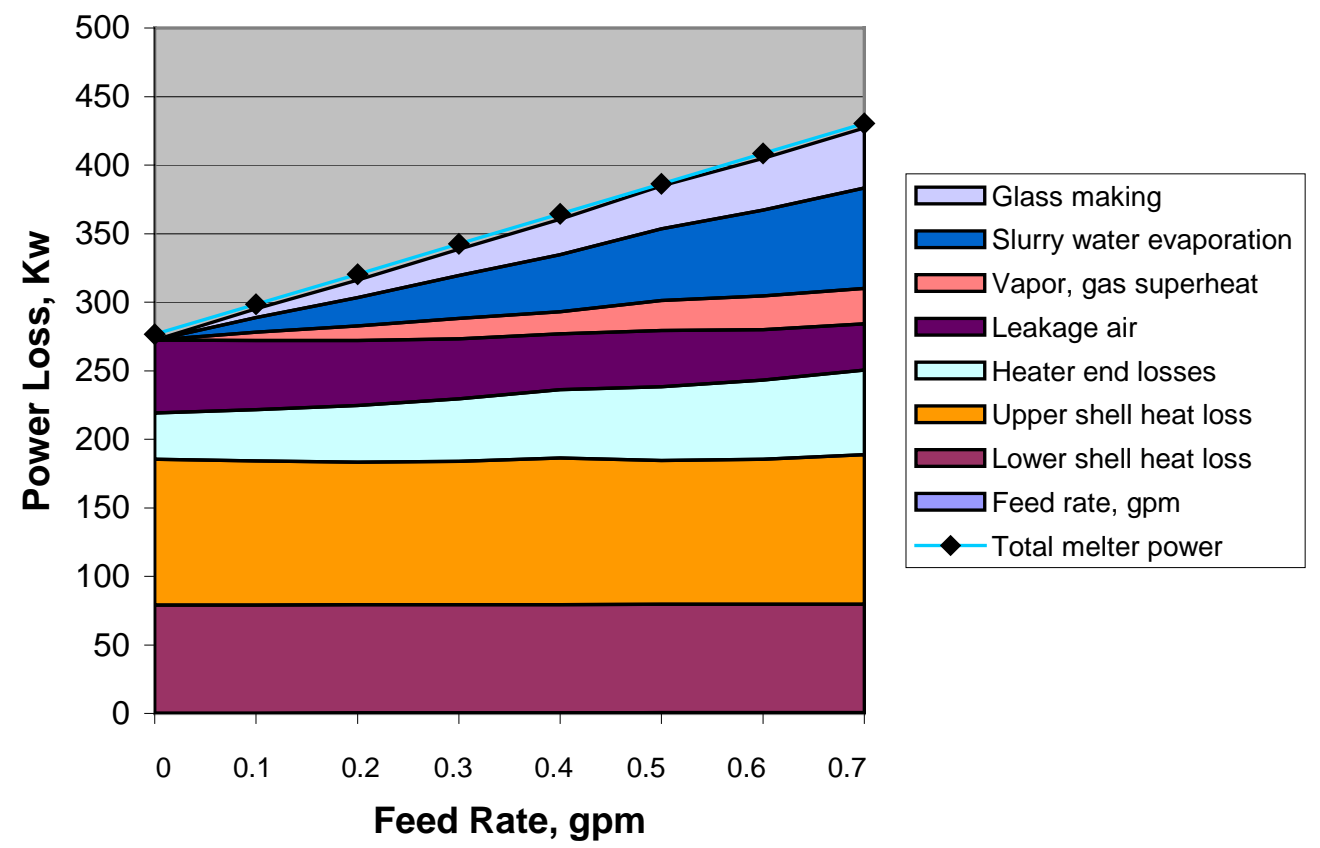

Figure 17 Distribution of Melter Power Losses as a Function of Feed Rate Macrobatch 1

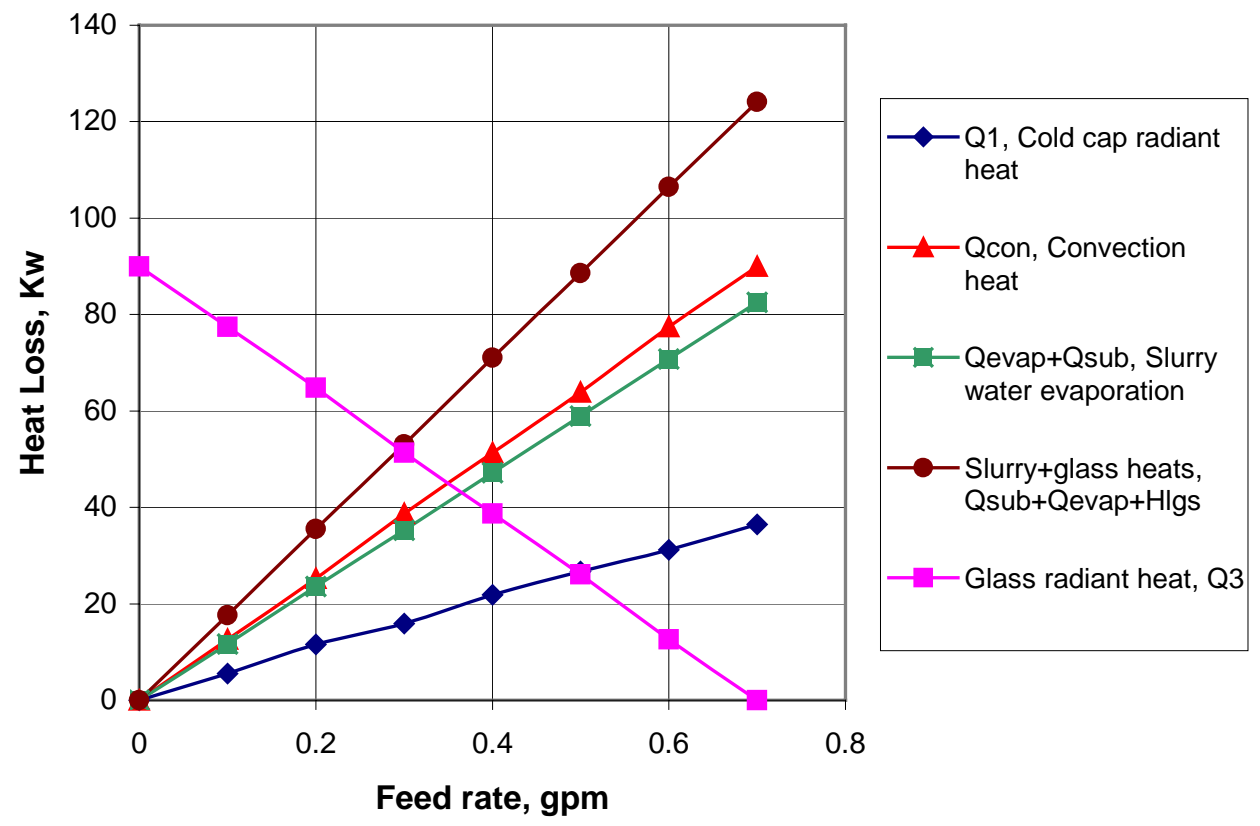

Figure 18 Distribution of Heat Sources and Heat Consumption in the Cold Cap - Macrobatch 1 
Revision

Table 1

Distribution of Power Losses at Various Feed Rates and Glass Melting Parameters

\begin{tabular}{|c|c|c|c|c|c|c|c|c|c|c|c|c|c|}
\hline Descrption & Label & Batch1 & Batch1 & Batch1 & Batch1 & Batch1 & Batch1 & Batch1 & Batch1 & Batch2 & $\begin{array}{l}\text { Batch2 } \\
\text { Air } \\
\text { Leak }\end{array}$ & $\begin{array}{l}\text { Design } \\
\text { basis }\end{array}$ & $\begin{array}{l}\text { Batch1 } \\
\text { Reduced } \\
\text { foam }\end{array}$ \\
\hline Feed & gpm & 0 & 0.1 & 0.2 & 0.3 & 0.4 & 0.5 & 0.6 & 0.7 & 0.55 & 0.4 & 0.939 & 0.78 \\
\hline Melt rate & $\mathrm{lbs} / \mathrm{hr}$ & 0 & 28.7 & 57.4 & 86.1 & 114.8 & 143.5 & 151.8 & 200.9 & 158 & 114.8 & 224 & 224 \\
\hline $\begin{array}{l}\text { Vapor } \\
\text { temp. }\end{array}$ & Tv & 730 & 697 & 659 & 618 & 579 & 560 & 533 & 493 & 520 & 500 & 680 & 493 \\
\hline $\begin{array}{l}\text { Electrode } \\
\text { power }\end{array}$ & Qel & 173 & 173 & 173 & 173 & 173 & 173 & 173 & 173 & 160 & 150 & 194.8 & 208 \\
\hline $\begin{array}{l}\text { Elec. stem } \\
\text { loss }\end{array}$ & Qstem & 4 & 4 & 4 & 4 & 4 & 4 & 4 & 4 & 4 & 4 & 4 & 4 \\
\hline $\begin{array}{l}\text { Convective } \\
\text { heat }\end{array}$ & Qcon & 0 & 12.6 & 25.2 & 38.7 & 51.3 & 63.9 & 77.4 & 90 & 68.5 & 53.2 & 100.8 & 112.5 \\
\hline $\begin{array}{l}\text { Glass surf. } \\
\text { rad. }\end{array}$ & Q3 & 90 & 77.4 & 64.8 & 51.3 & 38.7 & 26.1 & 12.6 & 0 & 8.5 & 13.8 & 38.2 & 12.5 \\
\hline $\begin{array}{l}\text { Lower } \\
\text { shell loss }\end{array}$ & Qlbs & 79 & 79 & 79 & 79 & 79 & 79 & 79 & 79 & 79 & 79 & 51.8 & 79 \\
\hline ubtotal & $\begin{array}{l}\text { QLSL(lower } \\
\text { shell) }\end{array}$ & 173 & 173 & 173 & 173 & 173 & 173 & 173 & 173 & 160 & 150 & 194.8 & 208 \\
\hline $\begin{array}{l}\text { Water } \\
\text { subcooling }\end{array}$ & Qsub & 0 & 1.3 & 2.7 & 4 & 5.4 & 6.7 & 8.1 & 9.4 & 7.4 & 5.4 & 13.4 & 10.5 \\
\hline $\begin{array}{l}\text { Water } \\
\text { evapor. }\end{array}$ & Qevap & 0 & 10.4 & 20.9 & 31.3 & 41.8 & 52.2 & 62.7 & 73.1 & 57.5 & 41.8 & 103.9 & 81.5 \\
\hline $\begin{array}{l}\text { Glass } \\
\text { melting }\end{array}$ & Hlgs & 0 & 6.4 & 12.8 & 19.2 & 25.6 & 31.4 & 37.7 & 44 & 35.2 & 25.6 & 50.7 & 50 \\
\hline Subtotal & Qcc & 0 & 18.1 & 36.4 & 54.5 & 72.8 & 90.3 & 108.5 & 126.5 & 100.1 & 72.8 & 168 & 142 \\
\hline $\begin{array}{l}\text { Cold cap } \\
\text { rad. heat }\end{array}$ & "-Q1" & 0 & 5.5 & 11.2 & 15.8 & 21.5 & 26.4 & 31.1 & 36.5 & 31.6 & 19.6 & 67.2 & 29.5 \\
\hline Slurry heat & $\begin{array}{l}\text { Qcon- } \\
\text { Q1=Qcc }\end{array}$ & 0 & 18.1 & 36.4 & 54.5 & 72.8 & 90.3 & 108.5 & 126.5 & 100.1 & 72.8 & 168 & 142 \\
\hline $\begin{array}{l}\text { Vapor } \\
\text { superheat. }\end{array}$ & Qvs & 0 & 5.3 & 9.9 & 13.8 & 15.2 & 20.4 & 23 & 24.4 & 20.5 & 14.1 & 51.1 & 27.7 \\
\hline $\begin{array}{l}\text { Calc. gas } \\
\text { superht. }\end{array}$ & Qgas & 0 & 0.35 & 0.66 & 0.92 & 1 & 1.37 & 1.54 & 1.6 & 1.4 & 1 & 1.97 & 1.85 \\
\hline $\begin{array}{l}\text { Inleak. air } \\
\text { super. }\end{array}$ & HLAR & 53.3 & 50.5 & 47.4 & 43.9 & 40.7 & 39.1 & 36.9 & 33.5 & 35.8 & 47.1 & 40.4 & 34.1 \\
\hline $\begin{array}{l}\text { Upper } \\
\text { shell loss }\end{array}$ & Qlus & 106.4 & 105 & 104.3 & 104.6 & 107.4 & 105.3 & 105.9 & 109.1 & 100.4 & 87.3 & 44.5 & 104 \\
\hline $\begin{array}{l}\text { Subtotal } \\
\text { (upp. shell) }\end{array}$ & QUSL & 159.7 & 161.15 & 162.26 & 163.22 & 164.3 & 166.17 & 167.34 & 168.6 & 158.1 & 149.5 & 137.97 & 167.65 \\
\hline $\begin{array}{l}\text { Dome htr. } \\
\text { pwr }\end{array}$ & Qdhtr & 103.4 & 126.8 & 150.1 & 173.4 & 196.8 & 220.2 & 243.5 & 266.8 & 238.9 & 205 & 186.7 & 280.6 \\
\hline $\begin{array}{l}\text { Htr. cover } \\
\text { loss }\end{array}$ & Qcoverbox & 18.7 & 18.7 & 18.7 & 18.7 & 18.7 & 18.7 & 18.7 & 18.7 & 18.7 & 18.7 & 15.7 & 18.7 \\
\hline $\begin{array}{l}\text { Dome htr. } \\
\text { End } \\
\text { losses }\end{array}$ & Qhtrloss & 11 & 14.8 & 18.7 & 23 & 27 & 31 & 35 & 39 & 35 & 27 & 0 & 43 \\
\hline $\begin{array}{l}\text { feed tube } \\
\text { loss }\end{array}$ & Qfdtubes & 4 & 4 & 4 & 4 & 4 & 4 & 4 & 4 & 4 & 4 & 4 & \\
\hline Q2= & $\begin{array}{l}\text { Qdhtr-Qcov } \\
\text { Qhtrloss- } \\
\text { Qftubes) }\end{array}$ & 69.7 & 89.3 & 108.7 & 127.7 & 147.1 & 166.5 & 185.8 & 205.1 & 181.2 & 155.3 & 167 & 214.9 \\
\hline Q2= & $\begin{array}{l}\text { QUSL-Q3- } \\
\text { Q1 }\end{array}$ & 69.7 & 89.3 & 108.7 & 127.7 & 147.1 & 166.5 & 185.8 & 205.1 & 181.2 & 155.3 & 167 & 214.9 \\
\hline Cold cap & coverage & 0 & 0.14 & 0.28 & 0.43 & 0.57 & 0.71 & 0.86 & 1 & 0.91 & 0.8 & 0.89 & 0.85 \\
\hline
\end{tabular}

All powers in $\mathrm{kW}$. Items in boldface are inputs to the calculations. 


\subsubsection{Design Case - Melt Rate of $224 \mathrm{Lbs} / \mathrm{hr}$}

The detailed calculations for the steady state heat balance and transient thermal and melt rate responses are found in Appendix A. The steady state heat balance is solved using an Excel spreadsheet. Results for the nominal case, considered by Yoshioka (feed rate $=0.939 \mathrm{gpm}$, melt rate of $224 \mathrm{lbs} / \mathrm{hr}$, vapor temperature $=680^{\circ} \mathrm{C}$, electrode power $=194.8 \mathrm{~kW}$, lid heater power $=186.7$ $\mathrm{kW}$, total air in-leakage flow $=460 \mathrm{lbs} / \mathrm{hr}$ ), are summarized in Figure 19. He assumed a cold cap area coverage of $89 \%$ and a glass surface area of $24.7 \mathrm{ft} 2$, taking into account the area taken by the electrodes. The glass melting term includes sensible heating, a silica glass heat of melting (20 cal./gm) and an endothermic reaction heat of $-100 \mathrm{cal} / \mathrm{gm}$ for the present glass formulation (no formic acid). The component heat losses responsible for slurry heating and evaporation, glass heating, and vapor superheating amount to $218.9 \mathrm{~kW}$ or $57.4 \%$ of the total power. The total heat losses through the shell $(96.3 \mathrm{~kW})$, heating of leakage air $(40.4 \mathrm{~kW})$ and miscellaneous losses $(26 \mathrm{~kW})$ make up the difference. However, this calculation did not include a number of heat loss sources such as transformer bus bar cooling, radiation into the off-gas outlet flange and other shell penetrations, which significantly increases the total heat loss as evidenced by actual power data (See Appendix A).

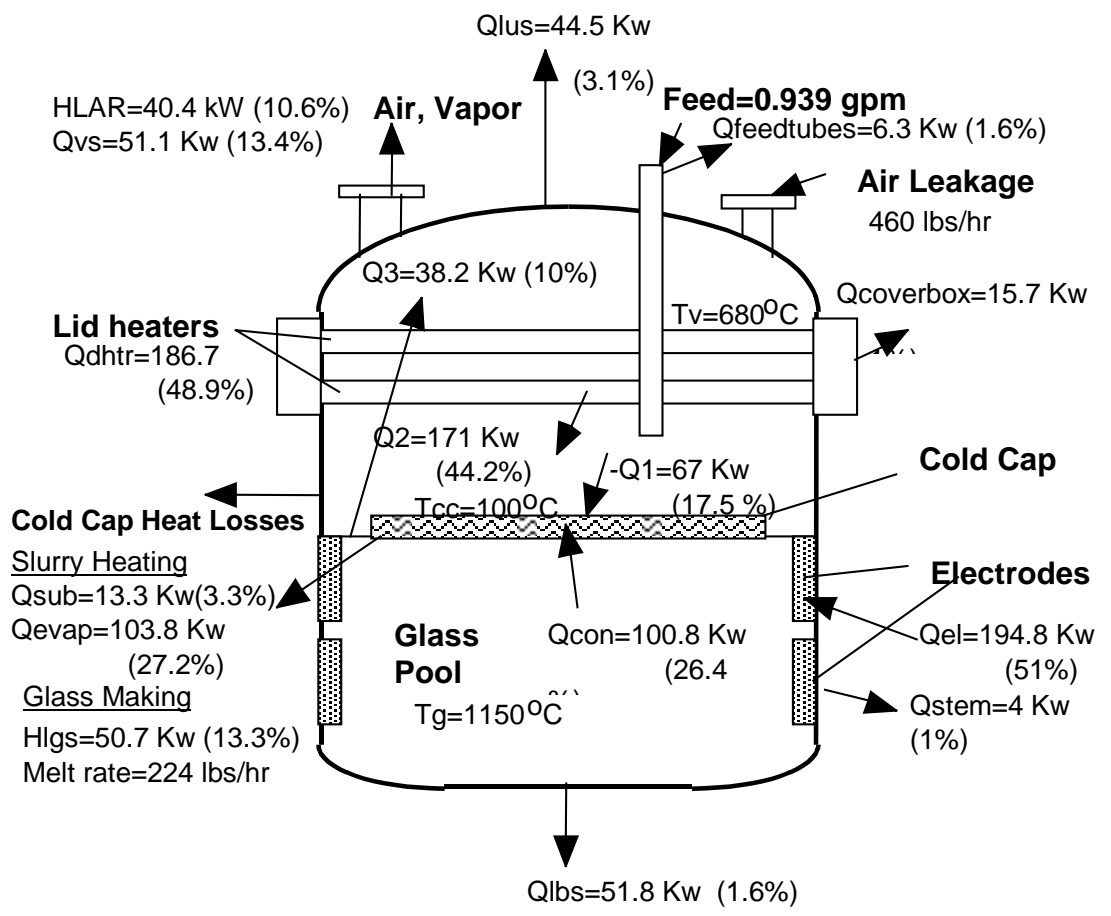

Figure 19

Theoretical Power Distribution for Nominal Feed Rate of 0.939 Gpm 


\subsubsection{Power Distribution for the Reduced Foam Case}

Current approaches being looked at to improve melt rate are: (1) to reduce foaming in the glass by adding dilutants, and (2) to increase the glass film coefficient over the natural convection value by air sparging. If these efforts are successful so that the glass to cold cap thermal resistance is reduced where the effective convective film coefficient from the glass to the cold cap is increased 50\%, the design melt rate would be achieved. The predicted power distribution is given by Figure 20. The power loss component values are taken from Table 1 (next to last column, Batch 1 "Reduced Foam"). The calculation assumes an $89 \%$ cold cap coverage achieved at this feed rate due to the decrease in thermal resistance (increased melt mass flux). The other power loss components are similar to the design basis case, except for the upper and lower shell losses and transformer bus bar losses. The assumption of 50\% increase in convective coefficient is based only in the fact that this value was achieved during the IDMS runs with formic acid flowsheet.

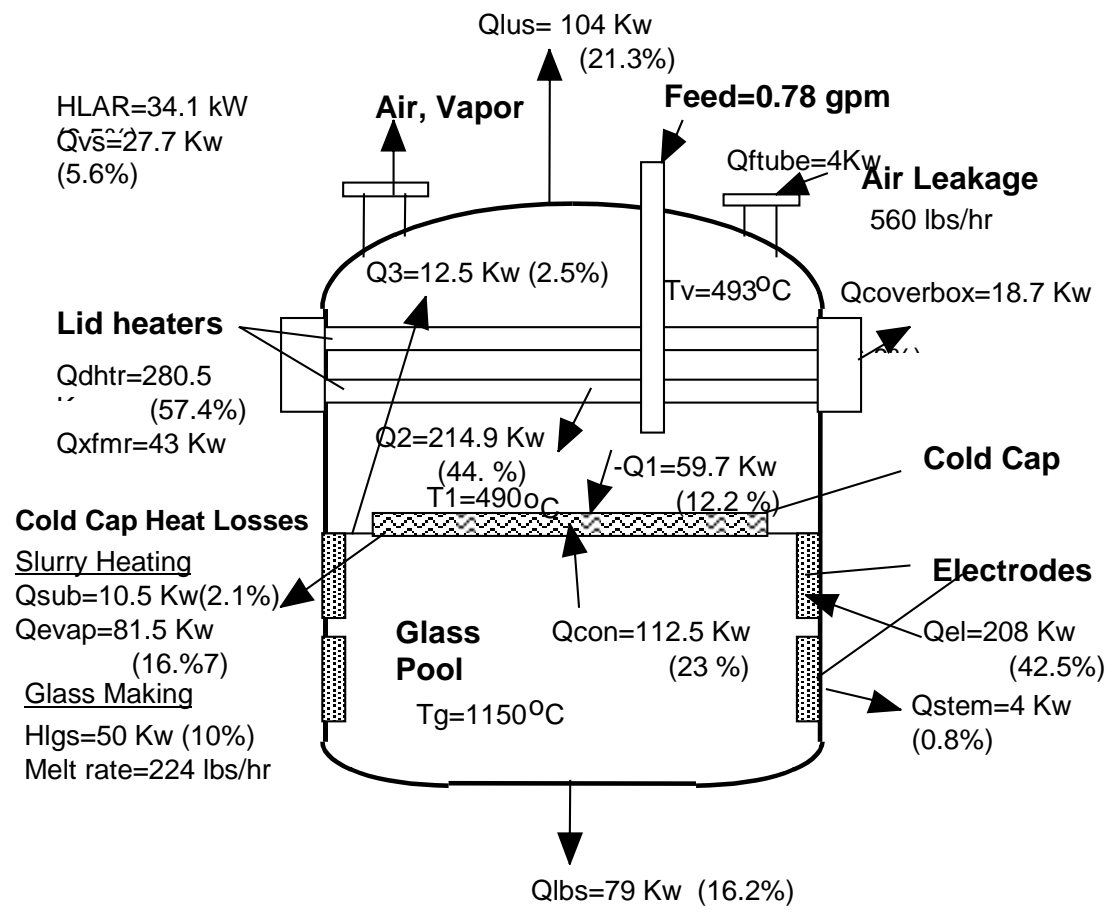

Figure 20 Predicted Power Distribution for a Melt Rate of $224 \mathrm{lbs} / \mathrm{hr}$ based on a 50\% Increase in Effective Convective Coefficient 


\subsection{Transient Analysis Results}

The transient equations, which involve 3 simultaneous first order differential equations and other relations, were solved using the mathematical software PDEase, which is a 2D partial differential equation solver (Ref. 9.2). These equations incorporate simplifications to reduce the number of variables. Consequently, the initial and equilibrium values do not exactly match the results of the steady state heat balance. In this section, representative DWPF runs for Macrobatches 1 and 2 feed which involve step changes in feed and corresponding changes in electrode and dome heater powers were simulated using the above transient analysis. Comparison of predicted vs. measured trends are qualitatively correct. A more accurate model can be developed if more accurate shell heat losses, vapor space temperature values, cold cap-toglass heat transfer coefficient and corrections for 3-dimensional effects could be determined. In a following section, the separate effects of controlling feed rate, electrode power, and dome heater power are investigated.

\subsubsection{Comparison with DWPF Melter Production Runs}

Three sets of DWPF Melter run data were obtained for the purpose of comparing specific data with computed results. The first set covers the period,12/1/97-12/23/97, when Macrobatch 1 feed rate was varied from $0.45 \mathrm{gpm}(147 \mathrm{lbs} / \mathrm{hr})$ to zero, then up to $0.5 \mathrm{gpm}(163 \mathrm{lbs} / \mathrm{hr})$, and finally to $0.7 \mathrm{gpm}(228 \mathrm{lbs} / \mathrm{hr})$. At each flow rate, the flow was maintained constant for several days and then a step change to a different flow rate was made, along with corresponding step changes in electrode heater and dome heater powers. The second set covers the period 2/8/012/19/01, when Macrobatch 2 feed was varied from $0.55 \mathrm{gpm}(180 \mathrm{lbs} / \mathrm{hr})$ to zero, and then back to $0.55 \mathrm{gpm}$. The third set covers the period, 7/1/99-7/4/99. In this case, Macrobatch 2 feed, starting at a constant value of $0.275 \mathrm{gpm}(90 \mathrm{lbs} / \mathrm{hr}$ ) was reduced to zero and maintained at zero for at least 30 hrs. Thus, we have cases in which two different Macrobatches were used and step changes in flow rates were made between zero, intermediate, and maximum flows.

For the calculation, the actual electrode power, dome heater power, and feed rate of the production run were specified as inputs and the resulting average glass melt, vapor space and dome heater temperatures were calculated. The following assumptions were made:

- First, the step changes in feed and power were simulated as exponentials with a time constant of $2 \mathrm{hrs}$ for numerical solution convenience.

- Second, since the transient model is a lumped parameter method, the effect of flow circulation on the glass temperature time constant is unknown at this time. (This necessitates a transient 2-D or 3-D Computational Fluid Dynamics (CFD) solution, which is unavailable at present.) The expected decrease in the glass temperature time constant, however, was taken into account by arbitrarily halving the glass melt thermal mass.

- Third for convenience, the feed and power transients were not faithfully followed but constant values were maintained for $24 \mathrm{hrs}$ before a step change and at least $36 \mathrm{hrs}$ after a step change, or when the data or the solution did not appear to change much. Fourth, for Macrobatch 1, the convective heat transfer coefficient for heat transfer between the glass melt and the cold cap, hcon, was given the value $0.0648 \mathrm{~kW} / \mathrm{m}^{2}-{ }^{\circ} \mathrm{C}$ while for Macrobatch 2, hcon $=0.0525 \mathrm{~kW} / \mathrm{m}^{2}{ }^{\circ} \mathrm{C}$ (Appendix A). 
Before presenting the results, the limitations of the model must be explained. First, a lumped parameter model is inherently limited in that it does not account for space-related variations in heat transfer coefficients and temperatures. The heat transfer coefficients used are average values obtained from the steady state data. During the transients, cold cap areas and foam thickness do not follow the steady state values due to pile up (non-constant cold cap height) and due to the time lag of melting. Second, the glass surface temperature is different from the bulk glass temperature, and for accurate determination, a conduction/convection model must be used, which was not available. For the lumped model, the glass surface temperature is only loosely connected to the bulk glass temperature by a one-for-one temperature increase with respect to the glass temperature increase. Third, the thermal mass of the upper plenum insulation was not taken into account, which may affect the vapor-space temperature. Therefore, the lump parameter model provides close but not necessarily highly accurate solutions and should be taken only as a guide in determining expected but relative results from given inputs.

Also, some characteristics of the solutions are herewith discussed.

- First, at the start of the solutions, some transients may be observed, which however quickly settled to a steady state. These are due to initial guesses of the glass and vapor space temperatures, as well as the cold cap area.

- Second, the model is based on average conditions of electrode and dome heater powers for a given flow rate, as established by the regression analyses of Figures 4 and 5 .

The subject runs departed from these averages, which can explain some of the deviations between the data and analyses. For example, the actual electrode power may be higher than the average but this may be compensated by a lower dome heater power. The higher electrode power would result in a higher glass surface temperature, which increases heat transfer to the vapor space and higher upper plenum heat loss. As explained above, only a small effect of the bulk glass temperature is included in the model. For this reason, a second calculation was made using the average values of electrode and dome heater power, which appear to provide closer agreement with the data.

\section{Macrobatch 1 Run for Period 12/1-23/97}

The Macrobatch 1 data of 12/1-23/97 are given in Figure 21. Here, the feed was held constant at $147 \mathrm{lbs} / \mathrm{hr}$ for $72 \mathrm{hrs}$ after 12/1/97 but only $24 \mathrm{hrs}$ are shown. Then a step change was made to zero feed for $36 \mathrm{hrs}$; then a step change to $163 \mathrm{lbs} / \mathrm{hr}$ was maintained for $36 \mathrm{hrs}$. This was followed by a step change to $228 \mathrm{lbs} / \mathrm{hr}$, which was maintained constant for $24 \mathrm{hrs}$. The corresponding electrode power for $147 \mathrm{lbs} / \mathrm{hr}$ feed was $149 \mathrm{~kW}$, while the average value is 163 $\mathrm{kW}$. The corresponding dome heater power was $230 \mathrm{~kW}$, while the average value is $208 \mathrm{~kW}$. For the second feed plateau of zero feed, the electrode power was $174 \mathrm{~kW}$ (173 kW for average conditions) and the dome heater power was $100 \mathrm{~kW}(104.3 \mathrm{~kW}$ for average conditions). For the third feed plateau of $163 \mathrm{lbs} / \mathrm{hr}$, the electrode power was maintained constant at $173 \mathrm{~kW}$ (166 $\mathrm{kW}$ average value) and the dome heater value was $215 \mathrm{~kW}(219 \mathrm{~kW}$ average conditions). For the fourth power plateau of $228 \mathrm{lbs} / \mathrm{hr}$, the electrode power was still $173 \mathrm{~kW}(163 \mathrm{~kW}$ average conditions) and the dome heater power was $260 \mathrm{~kW}(266 \mathrm{~kW}$, average conditions). The electrode and dome heater powers for average conditions, which are obtained from the power trend-lines of Figure 4, are plotted in Figure 22. 
The calculated glass temperatures for run and average conditions are shown in Figure 23 together with the data. The initial transients in the calculated temperatures are due to the solutions settling from an initial guess to a stable steady state values. The solution using the average conditions are closer to the actual data than when actual electrode and dome heater powers are used as inputs, suggesting that it is the total power that is important. Initially, the actual (upper) glass temperature was higher than calculated values for average conditions because the total power was higher than for average conditions. Then as the feed rate was decreased to zero, the glass temperature tended to decrease due to increased radiation loss to the vapor space. For this reason, the electrode power was increased. For the actual run, the electrode power was increased $25 \mathrm{~kW}$, while for average conditions, the increase was only $10 \mathrm{~kW}$, which explains the sharper glass temperature decrease for the average conditions.

The measured and calculated vapor space temperatures are shown in Figure 24. A corrected vapor space temperature was also obtained by applying Equation 12 to the indicated or measured vapor temperature. This figure shows good agreement between calculated and corrected measured temperatures.

The measured and calculated dome heater temperatures are given in Figure 25. The actual data shows only small variations for the large dome heater power changes. This may be due to the fact that the thermocouples are located near the ends (which are cooler than the center) and probably do not measure the average heater temperature.

DWPF Run, 12/1-23/97

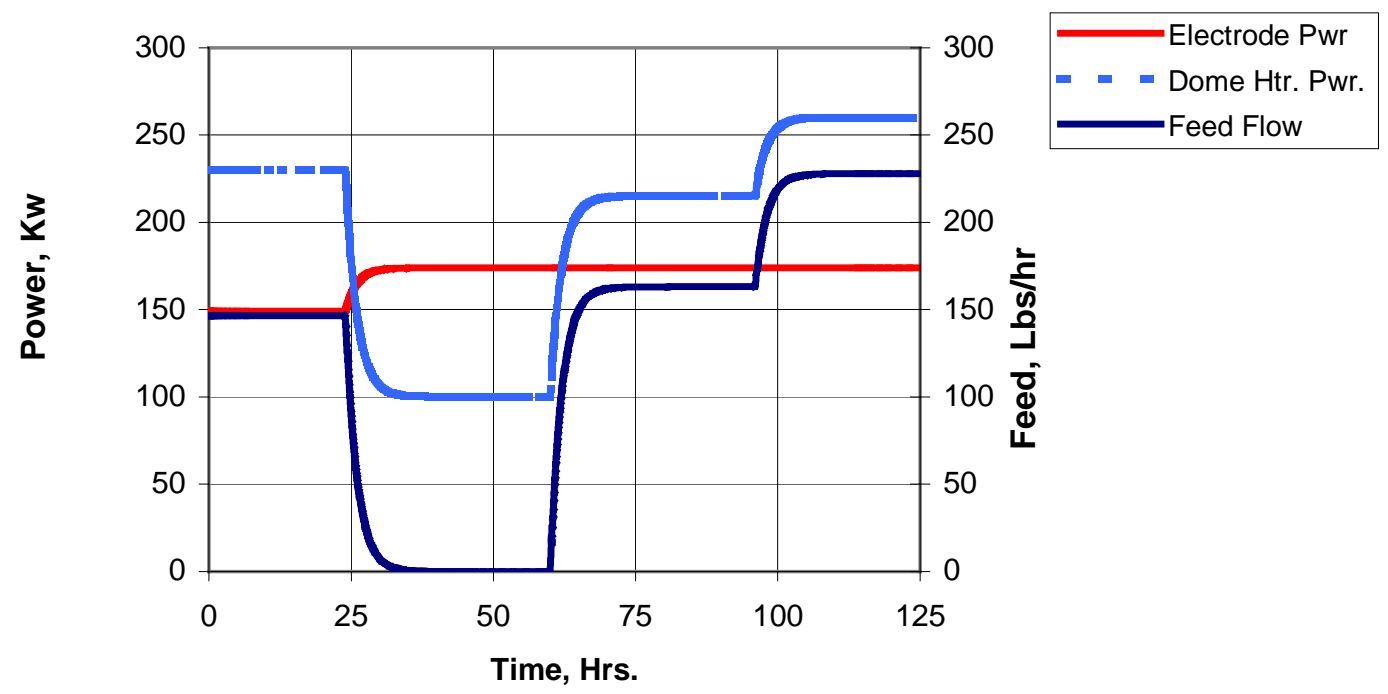

Figure 21 DWPF Melter Macrobatch 1 Feed Rate, Electrode Power, and Dome Heater Power Data for the Period, 12/01-23/97 
Macrobatch 1 Average Conditions for 12/1-23/97

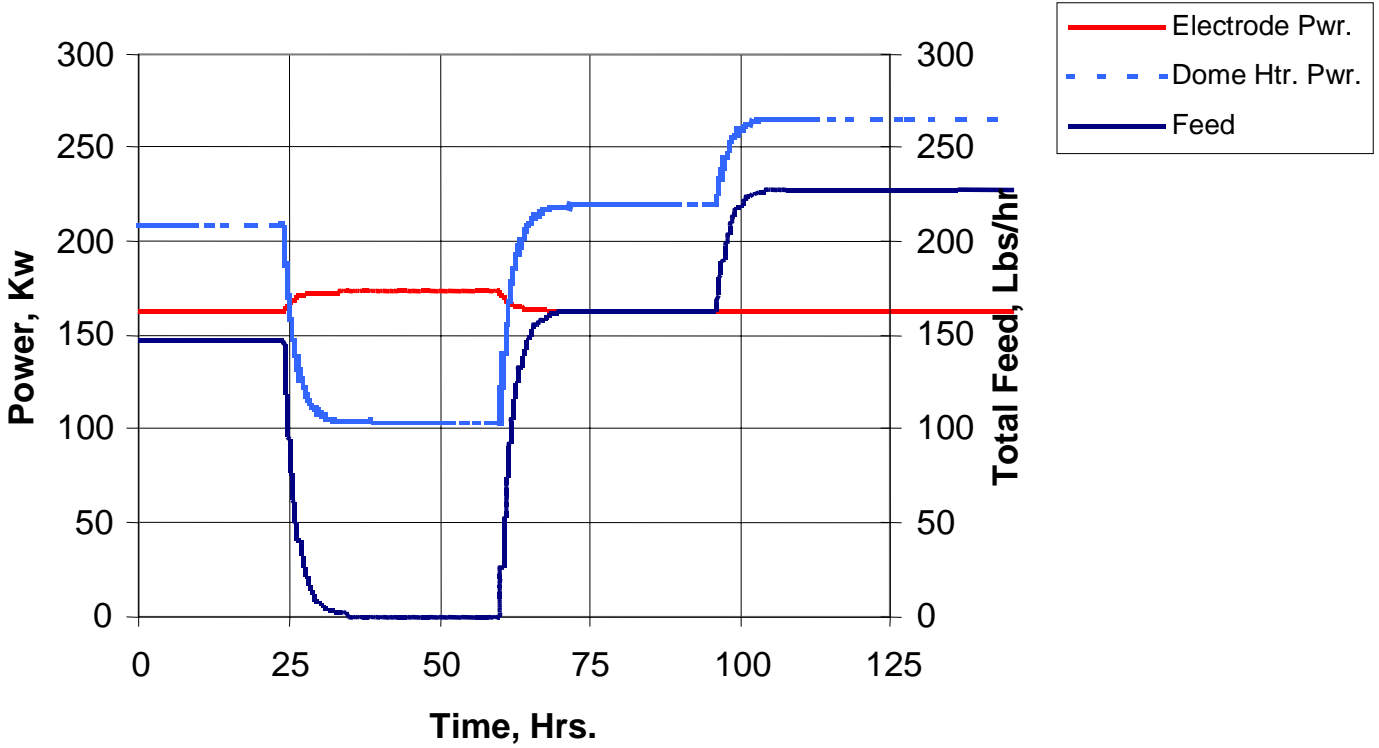

Figure 22

Average Power Conditions for DWPF Melter Run 12/1-23/97

Glass Temperatures for DWPF Run 12/1-23/97

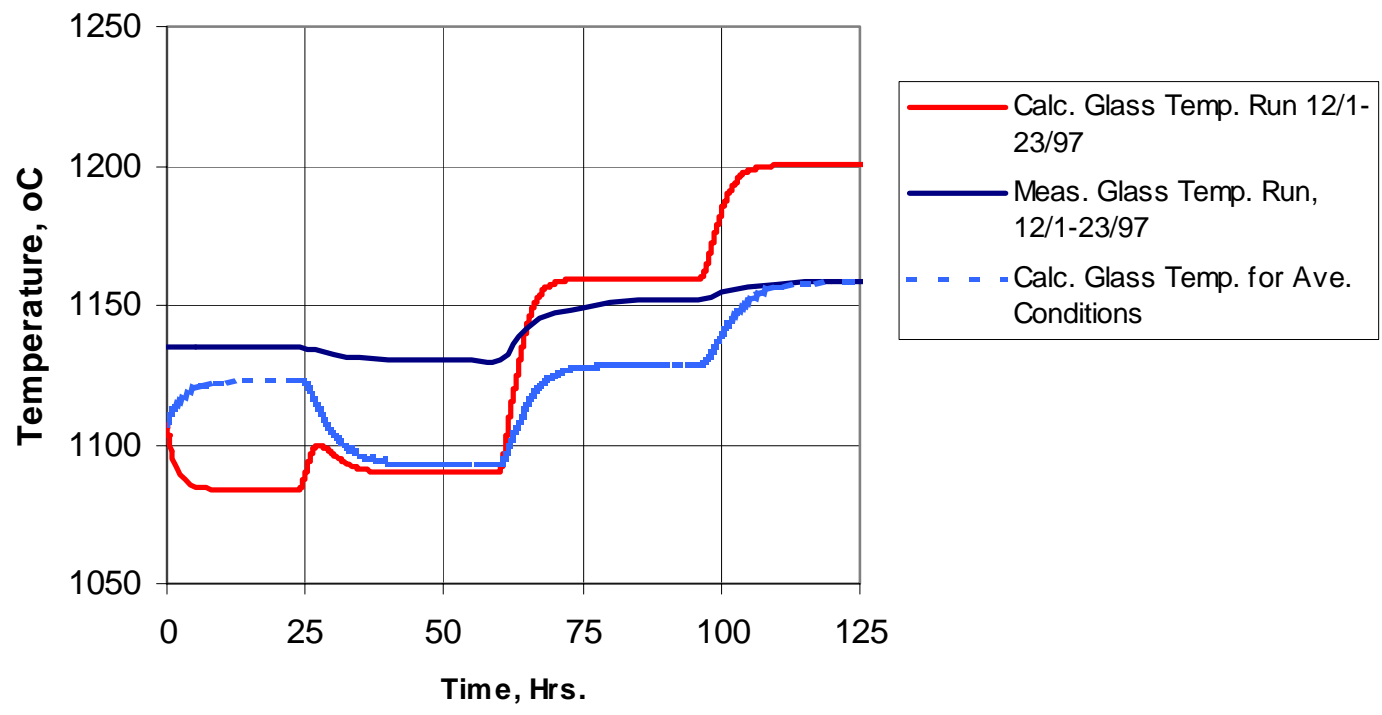

Figure 23

Measured and Calculated Glass Melt Temperatures for DWPF Run 12/1-23/97 
Vapor Temperatures, DWPF Run 12/1-23/97

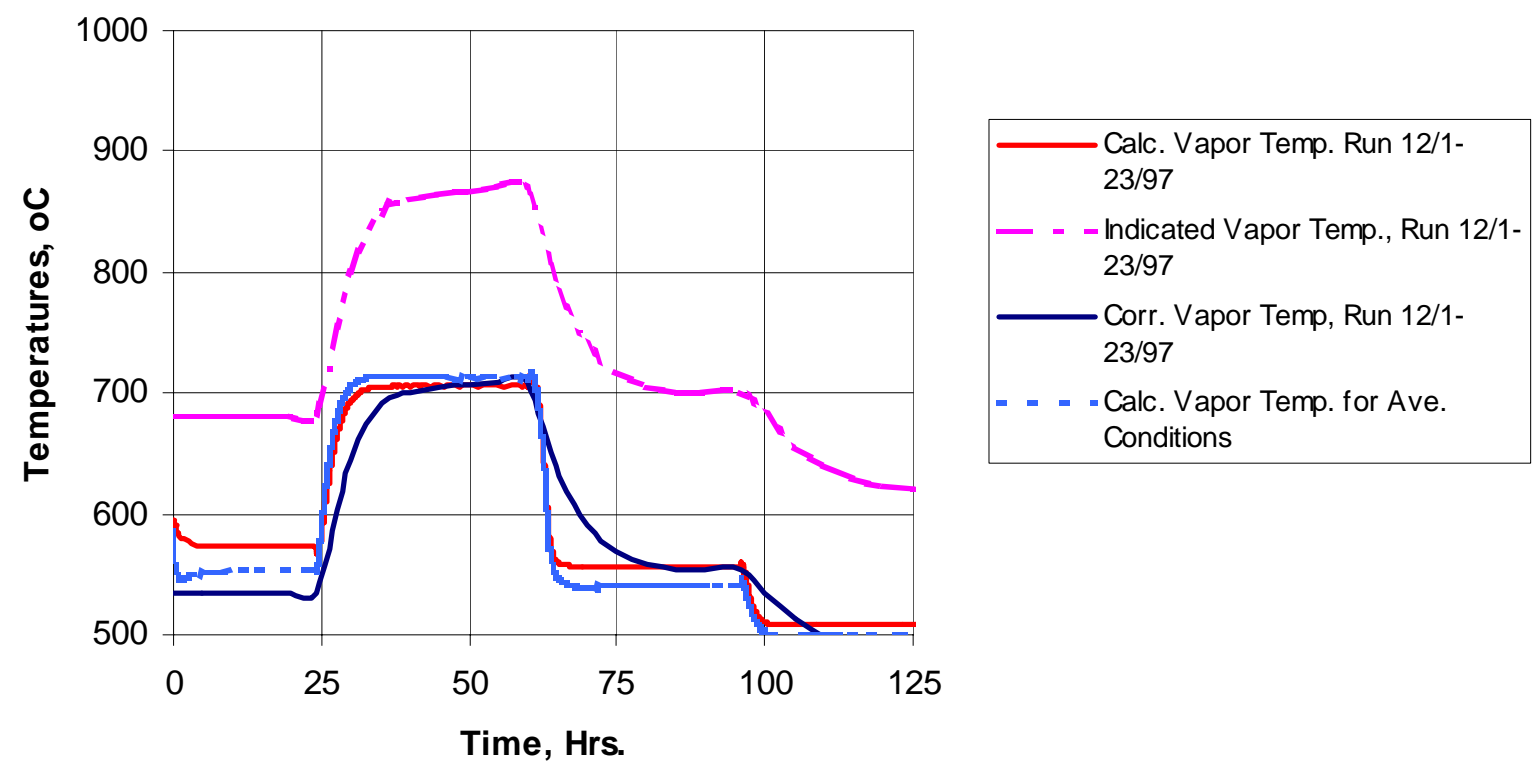

Figure 24

Measured and Calculated Vapor Space Temperatures for DWPF Run 12/1-23/97

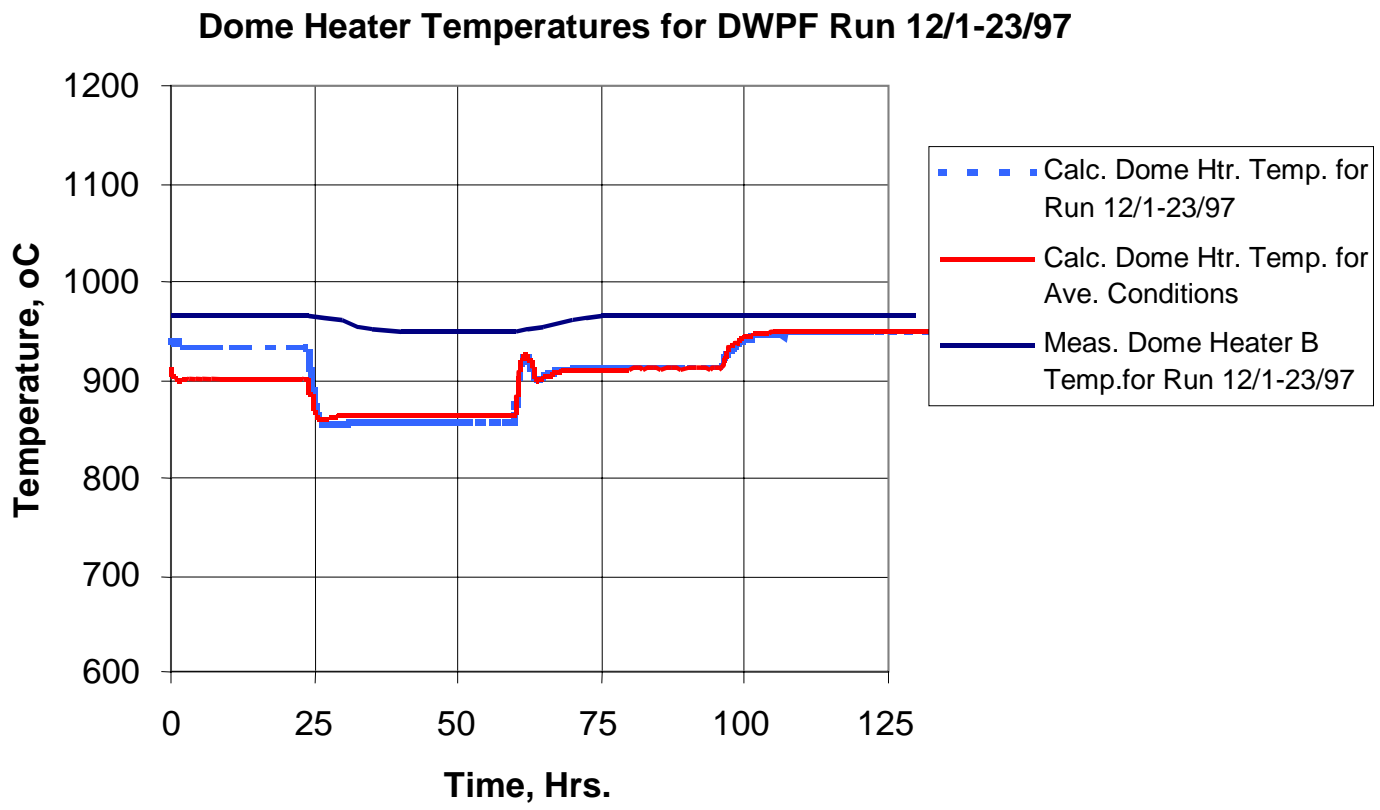

Figure 25

Measured and Calculated Dome Heater Temperatures for DWPF Run 12/1-23/97 


\section{Macrobatch 2 High Flow Run for Period 2/9-19/01}

The Macrobatch 2 data for the period 2/09-19/01 are given in Figure 26. In this case, the feed flow had been constant since 2/01/01 at $0.55 \mathrm{gpm}(180 \mathrm{lbs} / \mathrm{hr})$, the electrode power at $146 \mathrm{~kW}$ and the dome heater power at $233 \mathrm{~kW}$. Then the flow was shut off, while the electrode power was increased to $162 \mathrm{~kW}$ and the dome heater power was decreased to $89 \mathrm{~kW}$. After 5 days, the feed, electrode power, and dome heater power were restored to the original settings. The actual time periods were reduced in the simulation to $24 \mathrm{hrs}$. at $180 \mathrm{lbs} / \mathrm{hr}$ feed, $36 \mathrm{hrs}$ at zero feed, and another $24 \mathrm{hrs}$. after the feed was restored.

The corresponding average conditions are given in Figure 27. The electrode power at a feed flow of $180 \mathrm{lbs} / \mathrm{hr}$ is $147 \mathrm{~kW}$ and the dome heater power is $239 \mathrm{~kW}$. At zero feed, the electrode power is $160 \mathrm{~kW}$ and the dome heater power is $105 \mathrm{~kW}$.

The measured (upper) and calculated glass temperatures for actual and average conditions are shown in Figure 28. There is good agreement between the calculated values and the data, considering that the measured temperatures are for the upper glass thermocouples. The measured lower glass temperatures are in the range $1100^{\circ} \mathrm{C}$. Thus, the calculated average temperature of the glass is at least between the measured upper and lower glass temperatures.

The measured and calculated vapor space temperatures for actual and average conditions are given in Figure 29. There is also good agreement between the calculated values and the meansured dome heater temperatures, Figure 30 . One must also consider that the measured dome heater temperatures also vary among the thermocouples and heaters.

DWPF Run, 2/09-19/01

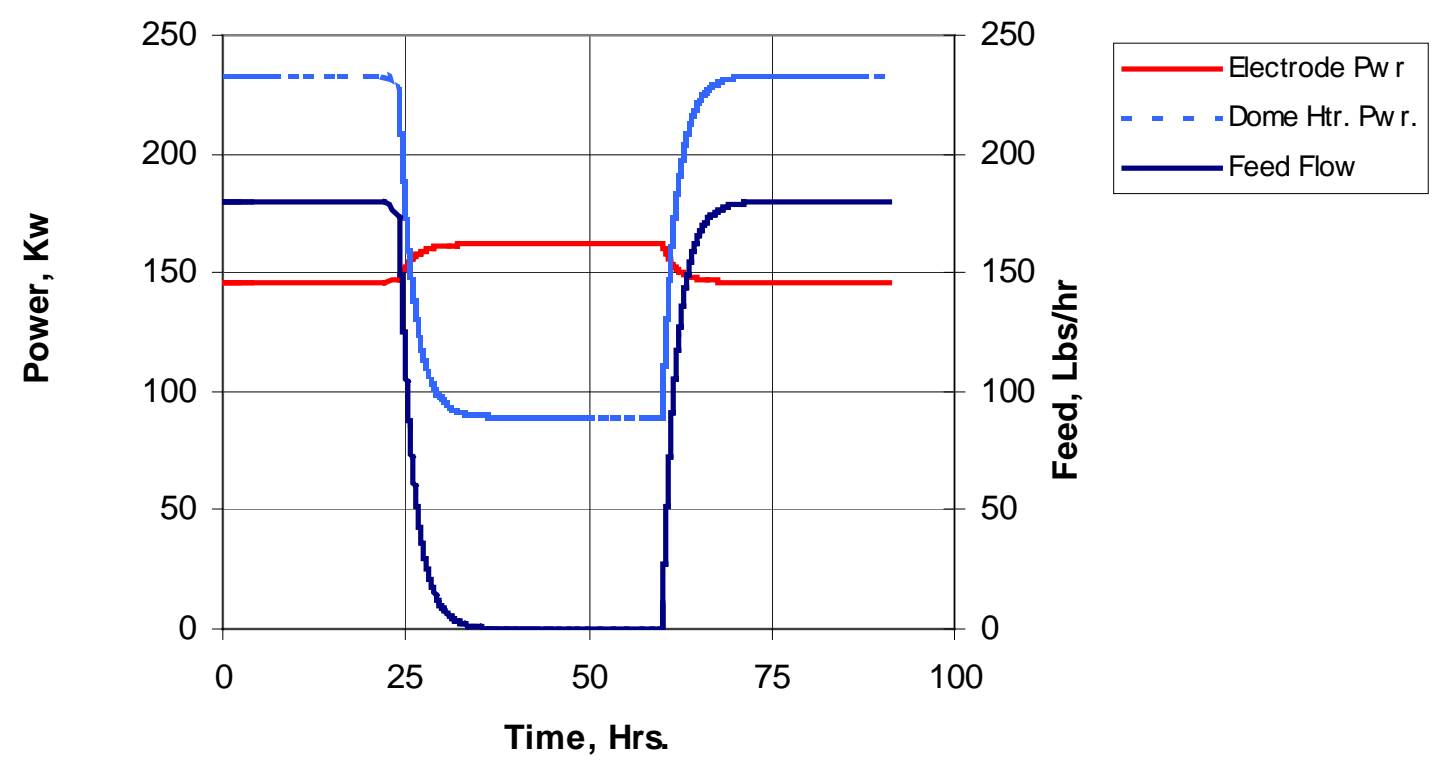

Figure 26

DWPF Melter Macrobatch 2 Feed Rate, Electrode Power, and Dome Heater Power Data for the Period, 2/09-19/01 


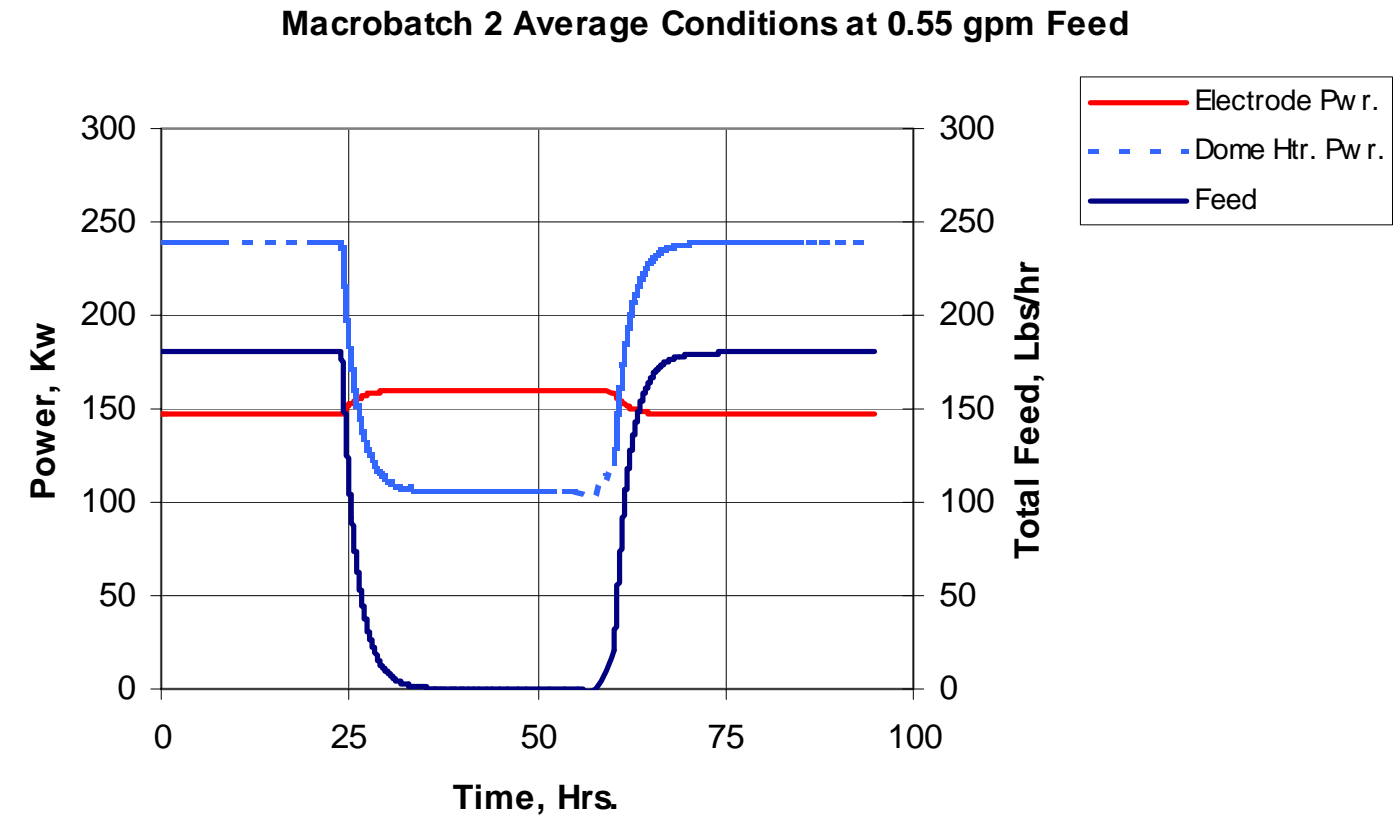

Figure 27

Average Power Conditions for Flow Transient of Run 2/09-19/01

Glass Temperatures for DWPF Run 2/09-19/97

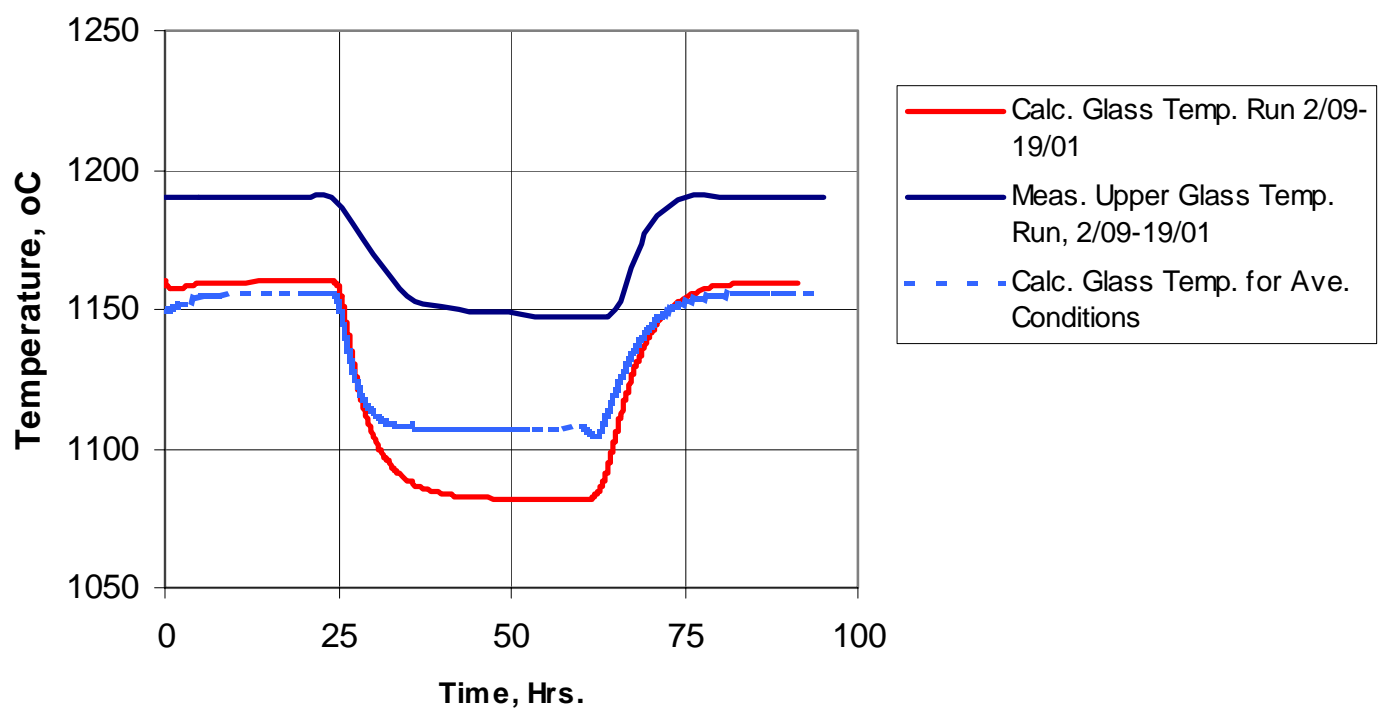

Figure 28

Measured and Calculated Glass Melt Temperatures for DWPF Run 2/09-19/01 


\section{Vapor Temperatures, DWPF Run 2/09-19/01}

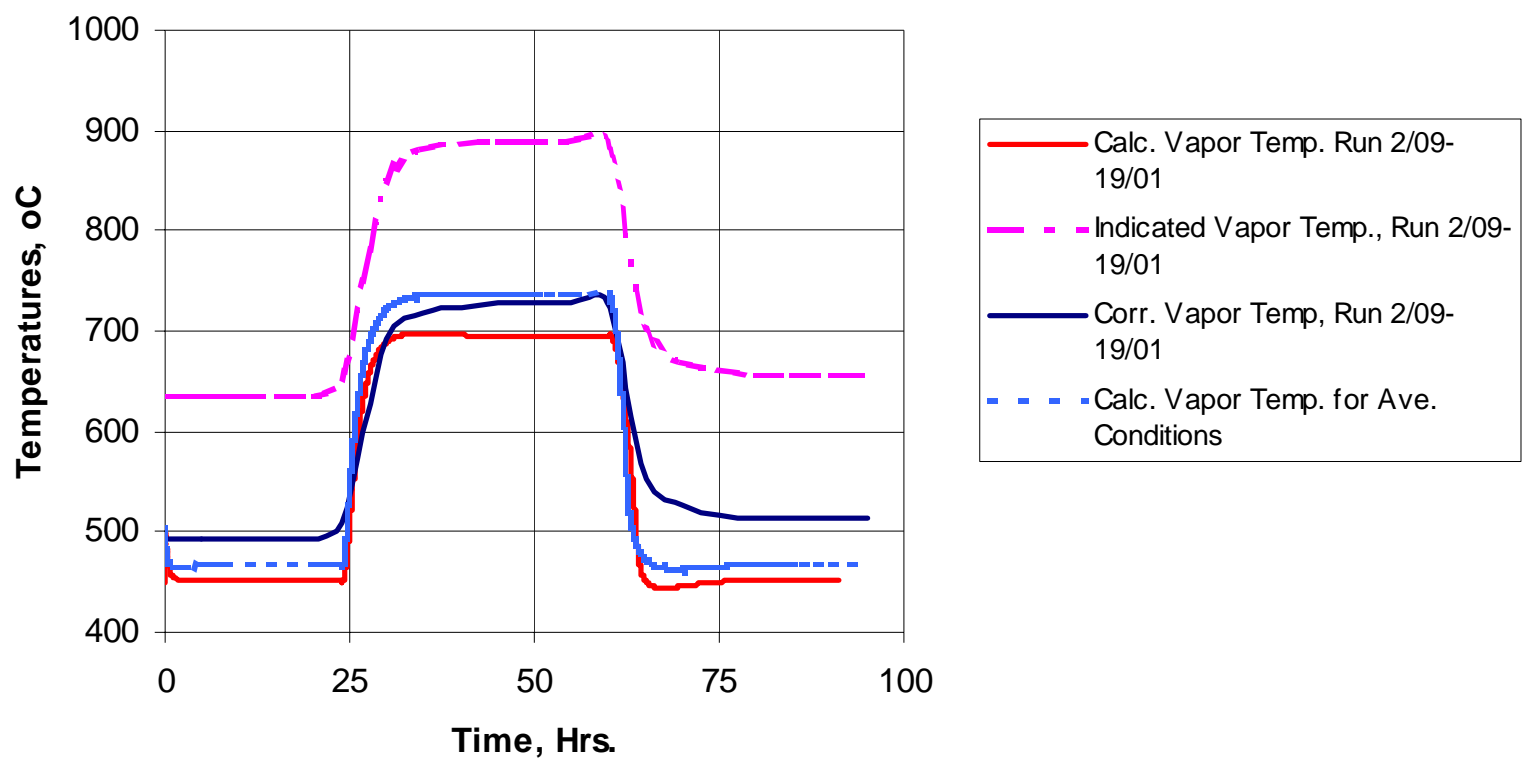

Figure 29

Measured and Calculated Vapor Space Temperatures for DWPF Run 2/09-19/01

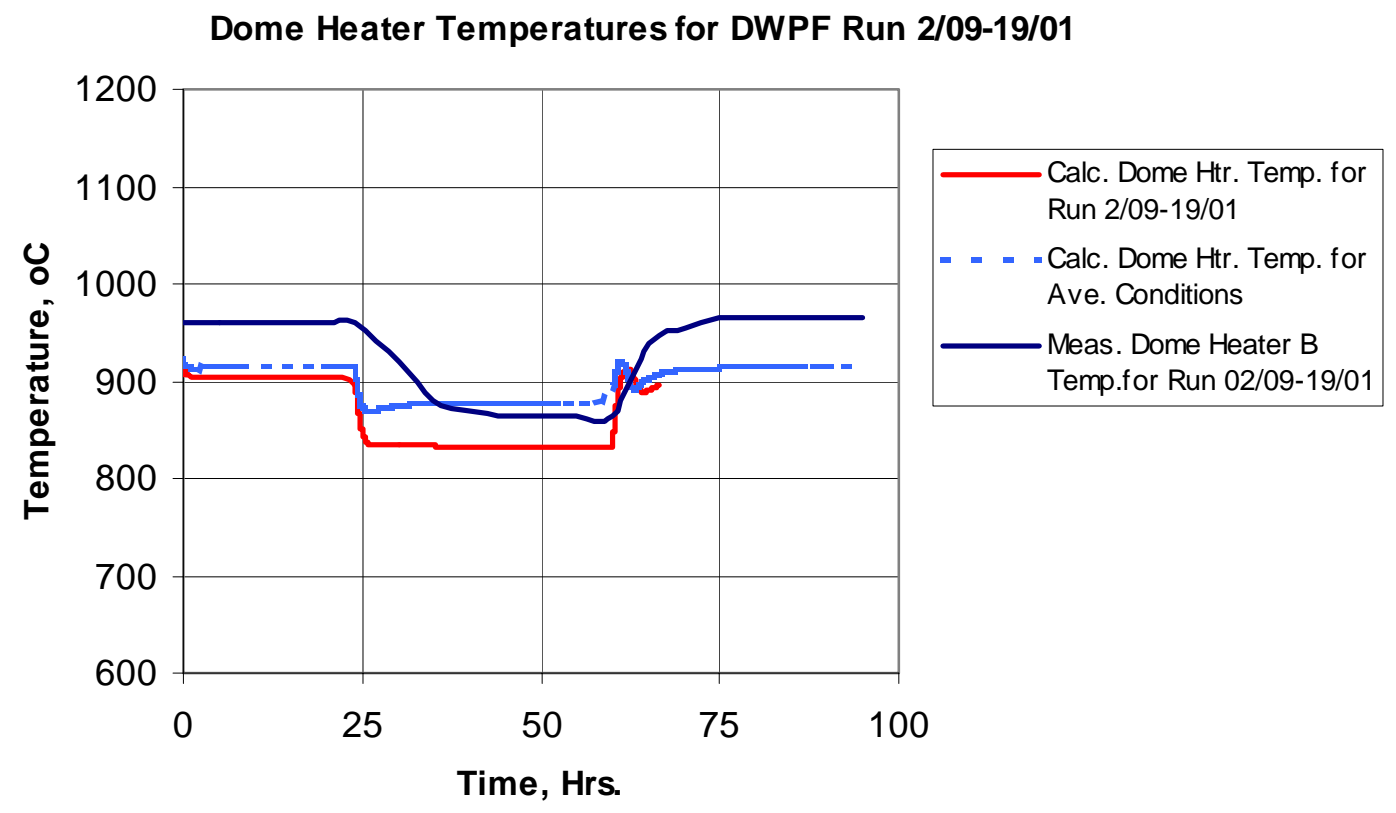

Figure 30

Measured and Calculated Vapor Space Temperatures for DWPF Run 2/09-19/01 


\section{Macrobatch 2 Low Flow Run for Period 7/1-4/99}

The Macrobatch 2 data for the period 7/2-4/99 are given in Figure 31. Here, the flow was initially constant at $0.275 \mathrm{gpm}(90 \mathrm{lbs} / \mathrm{hr})$ for about $36 \mathrm{hrs}$, after which the feed was stopped for another $36 \mathrm{hrs}$. The electrode power was $144 \mathrm{~kW}$ at $90 \mathrm{lbs} / \mathrm{hr}$ feed flow, which was reduced to $127 \mathrm{~kW}$ at zero feed. The dome heater power was initially $189 \mathrm{~kW}$, which was reduced to 98 $\mathrm{kW}$ at zero feed.

The average power conditions for the same flow conditions are given in Figure 32. The electrode power is $153 \mathrm{~kW}$ and at $90 \mathrm{lbs} / \mathrm{hr}$ feed and $173 \mathrm{~kW}$ at zero feed. The dome heater power is 172 $\mathrm{kW}$ at $90 \mathrm{lbs} / \mathrm{hr}$ and $105 \mathrm{~kW}$ at zero feed.

The measured and calculated glass temperatures are shown in Figure 33. The measured values are those of the upper glass thermocouple, which may explain the higher values than the calculated ones. When the flow drops down to zero, the measured values and the calculated ones using the actual power data decreases because of a reduction in the electrode power (144 to 127 $\mathrm{kW}$ ). For average power conditions, the electrode power increases slightly (153 to $156 \mathrm{~kW}$ ) so that the glass temperature also increases slightly.

The measured vapor space temperatures (Figure 34) at $0.275 \mathrm{gpm}$ flow are higher than the calculated average values because the dome heater power was higher than for average power conditions (189 kW vs. $172 \mathrm{~kW}$ ). At zero feed flow, the measured temperatures are lower than for average power conditions even though the dome heater powers are

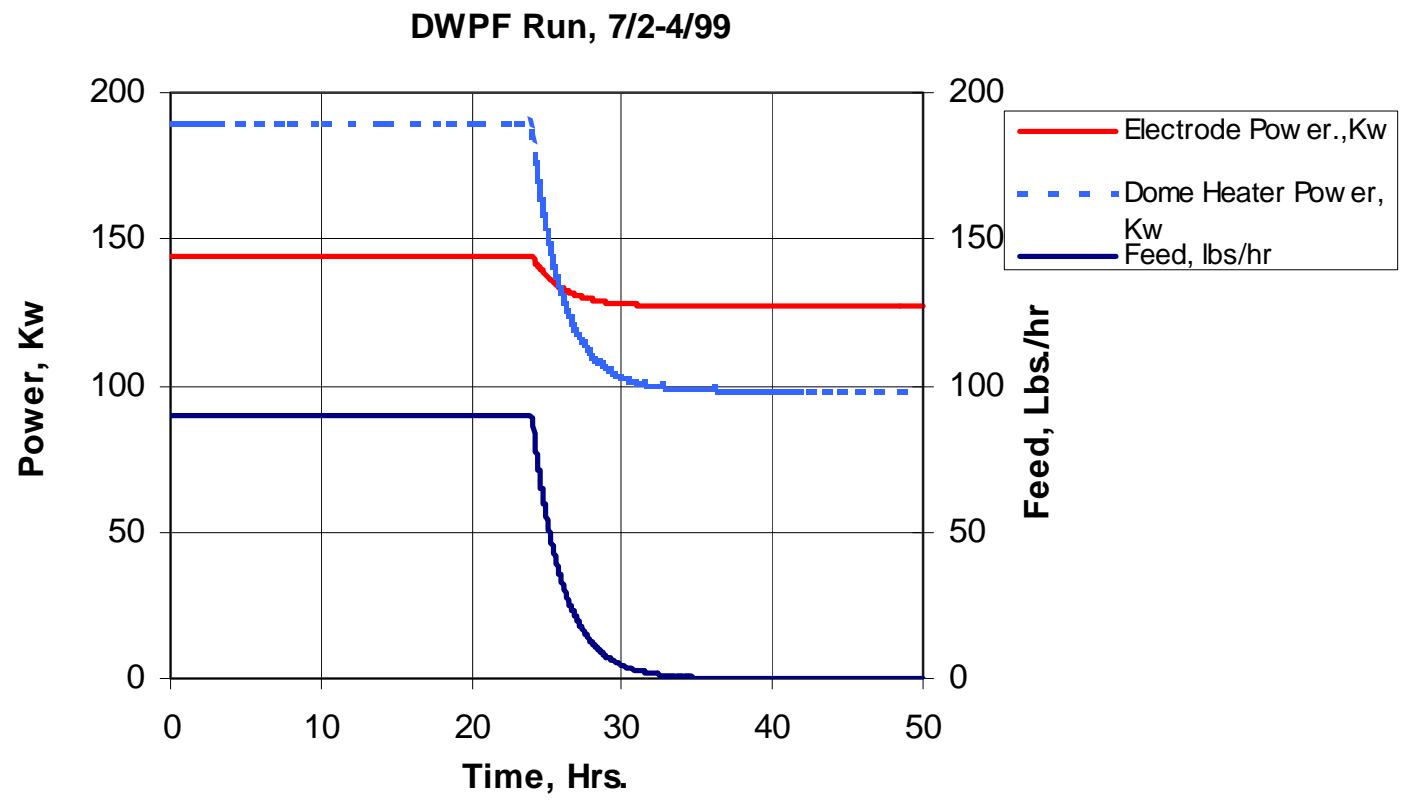

Figure 31

DWPF Melter Macrobatch 2 Feed Flow, Electrode Power and Dome Heater Power for Period 7/2-4/99 
MacroBatch 2 Average Conditions at $0.275 \mathrm{gpm}$ Feed

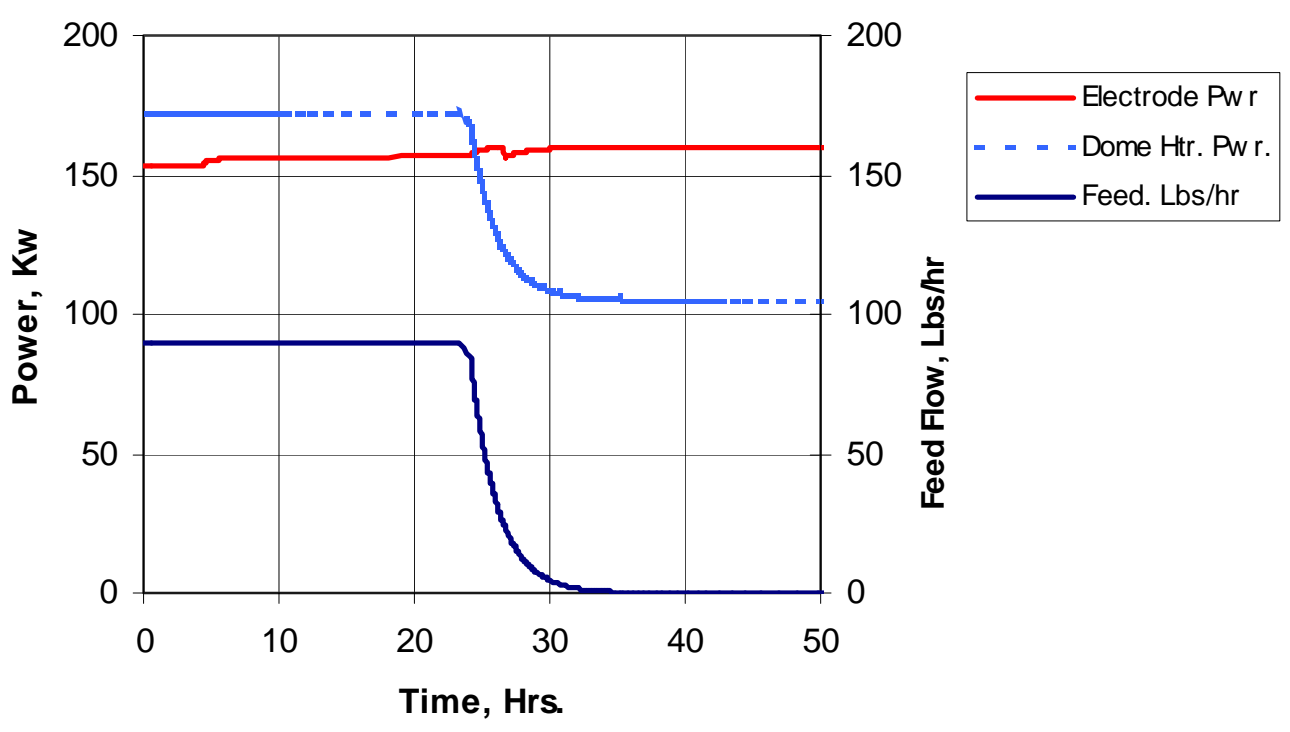

Figure 32

Average Power Conditions for Flow Transient of Run 7/2-4/99

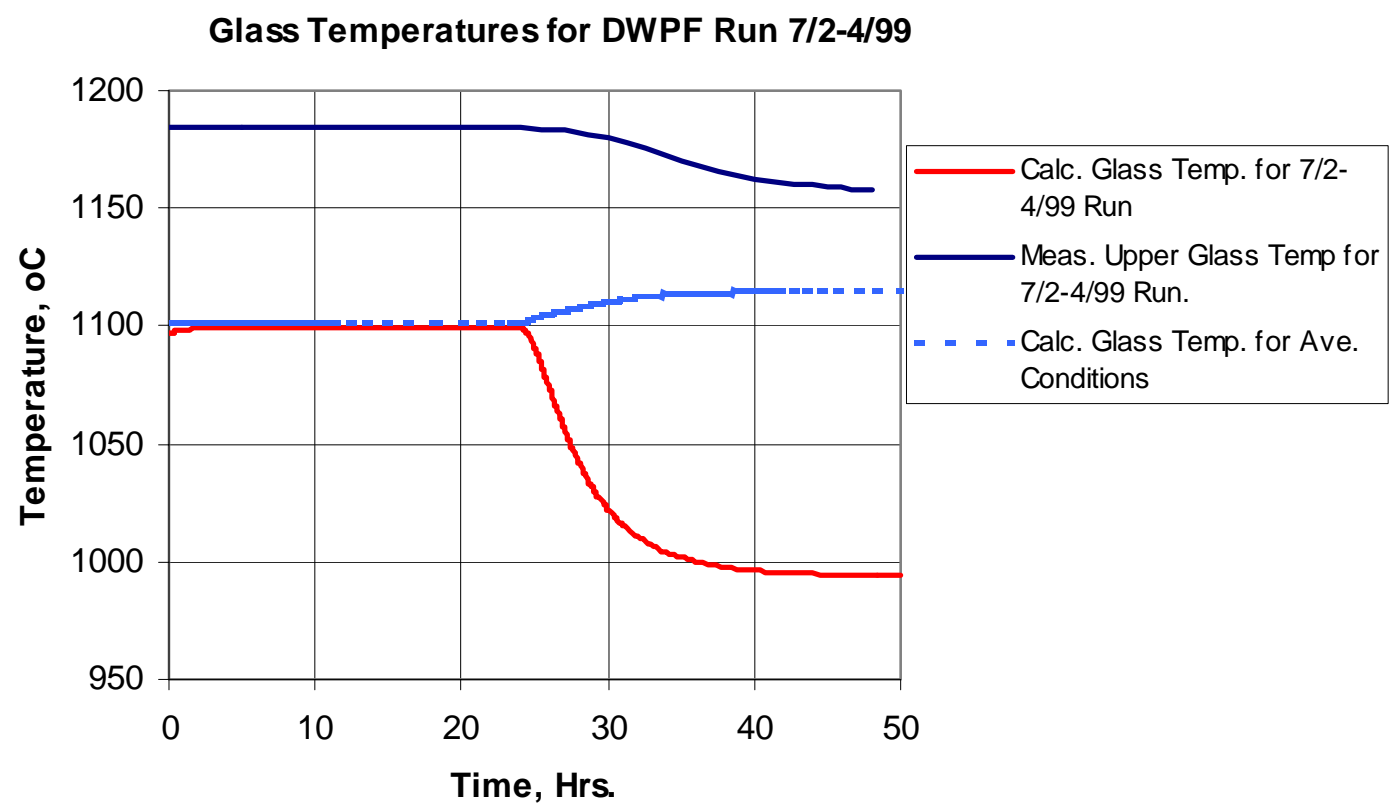

Figure 33

Measured and Calculated Glass Temperatures for Run 7/2-4/99 
Vapor Space Temperatures, DWPF Run 7_2-4/99

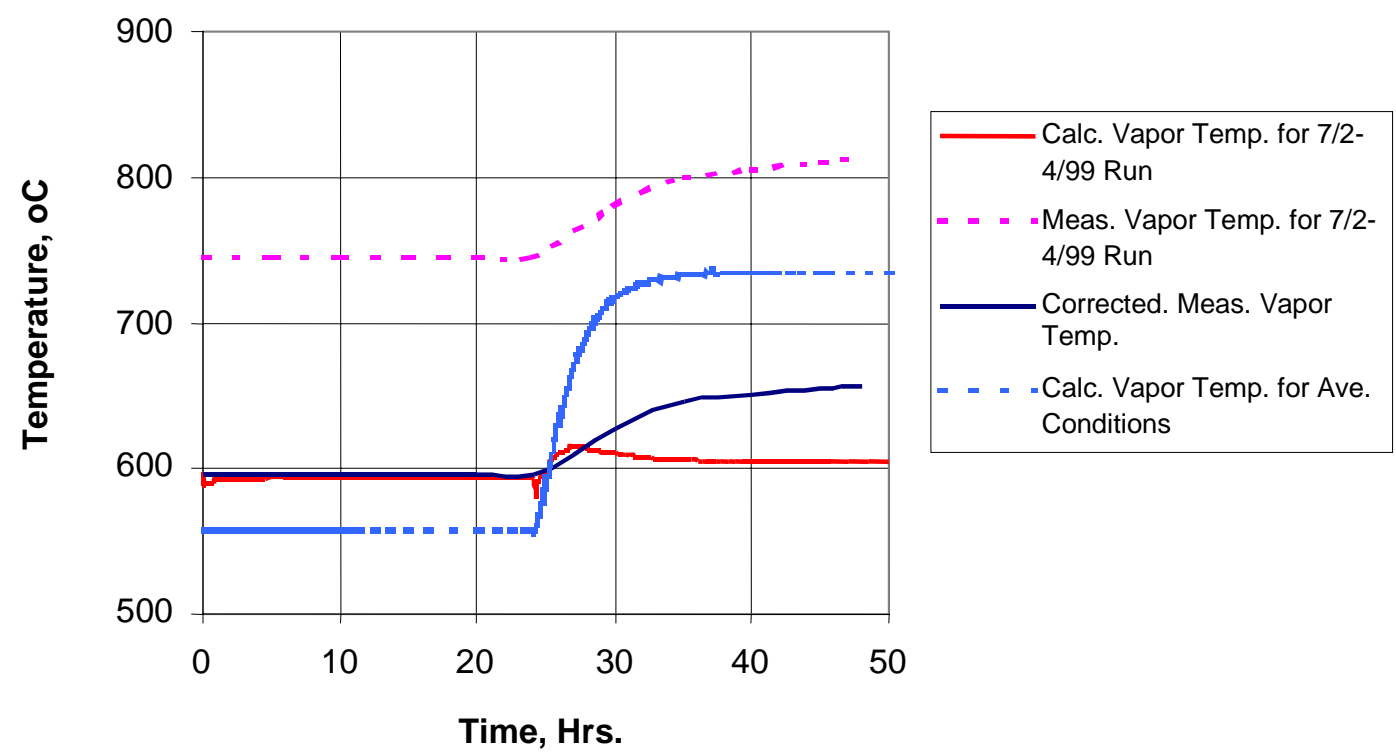

Figure 34

Measured and Calculated Vapor Space Temperatures for Run 7/2-4/99

Dome Heater Temperatures for DWPF Run, 7/2-4/99

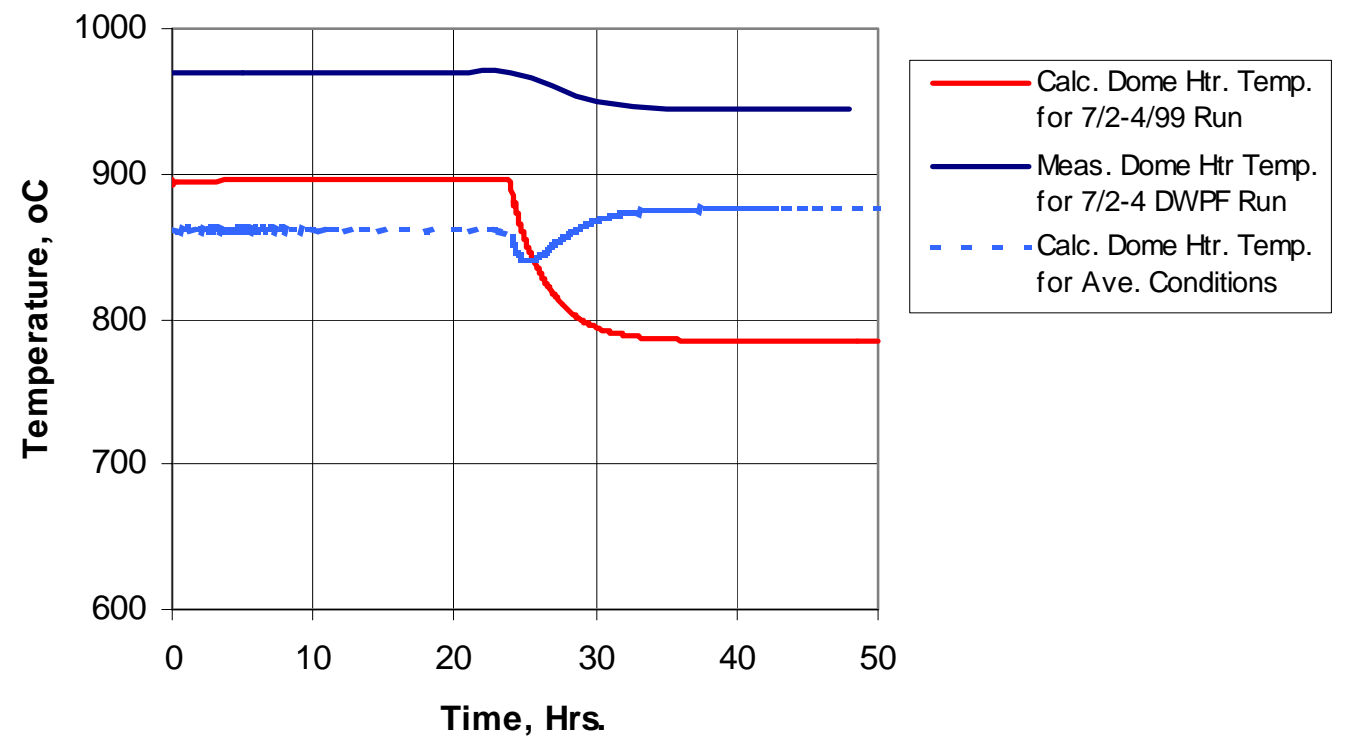

Figure 35

Measured and Calculated Dome Heater Temperatures for Run 7/2-4/99 
almost equal (98 kW vs. $105 \mathrm{~kW}$ ) because the total power (including electrode power) was lower for the actual run than for average conditions ( $225 \mathrm{~kW}$ vs. $265 \mathrm{~kW})$. There is a small discontinuity in the calculated vapor temperature at the start of the transient because of the competing effects of drop in dome heater power and increased glass radiant heat as feed decreases. The time constants of these effects may not be accurately modeled, so that there is not a smooth variation with time. Over a longer time frame, these squiggles would not be important.

The measured dome heater temperatures and the corresponding calculated values are given in Figure 35. The measured temperatures and the calculated ones using the actual power data show a drop in temperature after the feed reduction to zero, while the calculated ones using average power conditions show a slight increase even though the dome heater powers are equivalent in both cases. This is due to the higher calculated vapor space temperature for the average power conditions as a result of higher total power. In this particular case, actual power conditions were significantly differ from average power conditions. This may be due to higher solids ratio in the feed or other operational conditions.

\subsubsection{Separation of Effects}

In the previous section, actual melter operations were discussed where feed rate, electrode power and dome heater power were simultaneously varied to keep the glass temperature, the dome heater temperature, or the vapor space temperature within technical limits. This section provides some effects of varying one of the inputs and holding the other two constant. The purpose of this is to investigate the trends in the controlled temperatures due to the change in only one of the inputs as an aid in operation. This also provides some insight into the physical processes going on in the melter. Three cases will be run based on the Macrobatch 2 run during the period, 2/919/01 (Sec. 6.4.1).

\section{Case 1. Separation of Effects - Electrode Power Increase}

For the first case, the effect of changing the electrode power, while maintaining the feed and the dome heater power values, is investigated. For this purpose, we will consider the Macrobatch 2 run (Fig. 27). The feed rate and the dome heater power are held constant at $180 \mathrm{lbs} / \mathrm{hr}$ and 233 $\mathrm{kW}$, respectively. Then the electrode power is increased $16 \mathrm{~kW}$ (from 146 to $162 \mathrm{~kW}$ ) and the feed is reduced to zero. What would happen if the feed rate were maintained constant, while only the electrode power is increased? Figure 36 shows the electrode and dome heater power transients to be analyzed. The calculated changes in the glass, vapor space, and dome heater temperatures are shown in Figure 37. The vapor space and dome heater temperatures are only slightly changed, but the glass temperature increases $57^{\circ} \mathrm{C}$ to $1207^{\circ} \mathrm{C}$, which exceeds the technical limit. The higher glass temperature melts more of the cold cap and increases the exposed glass surface area (Figure 38). This in turn allows more radiant heat to the upper plenum, Q3, (Figure 39 ) by $13 \mathrm{~kW}$. There is a small momentary increase in melt rate by $2.5 \%$, as the cold cap area is reduced. The melt rate goes back to its original value because at steady state, there is a fixed amount of glass melted for a given total feed rate. There would however be a step change in melt rate if the feed rate were also correspondingly increased in step wise fashion in conjunction with a step increase in electrode power. 


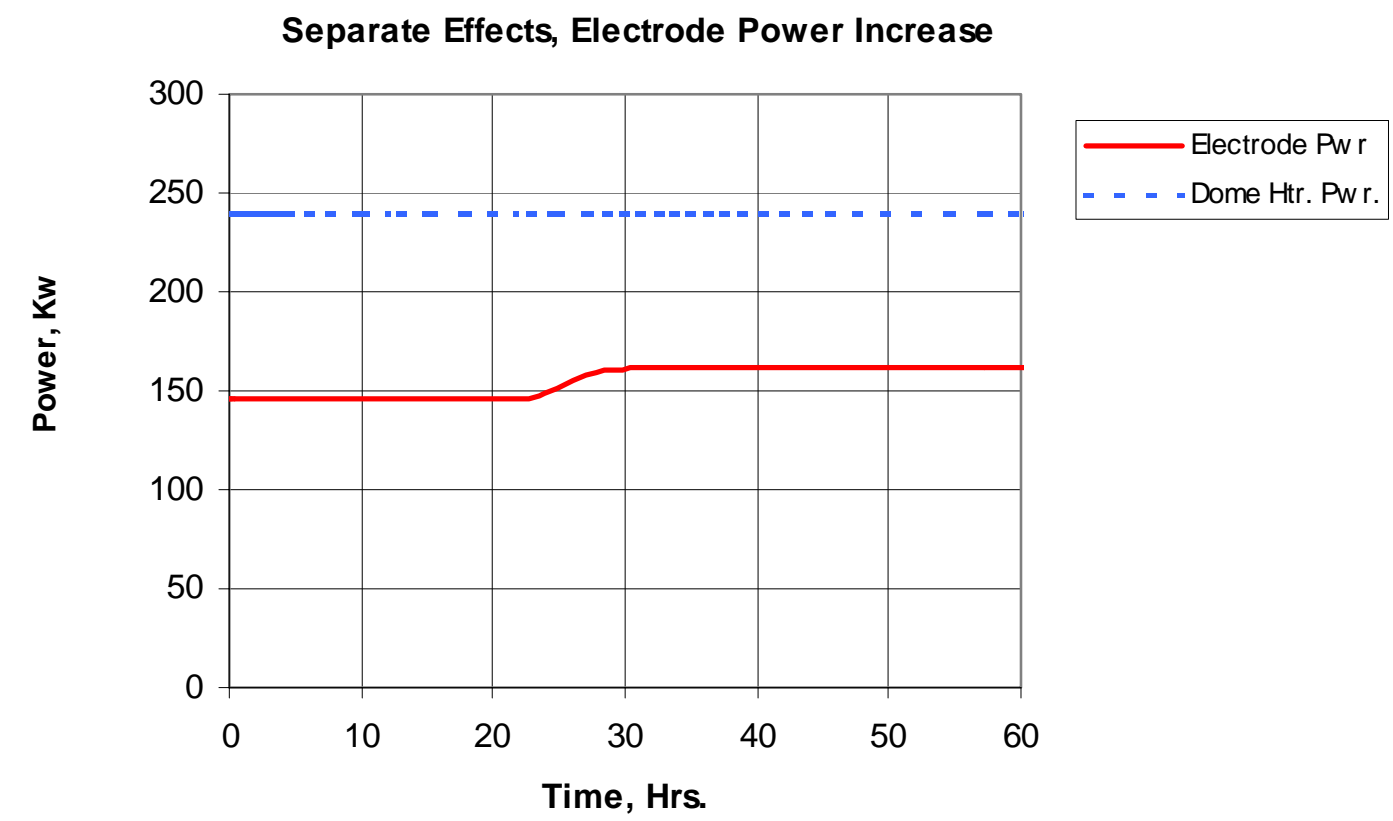

Figure 36

Electrode Power Increase Transient - Case 1

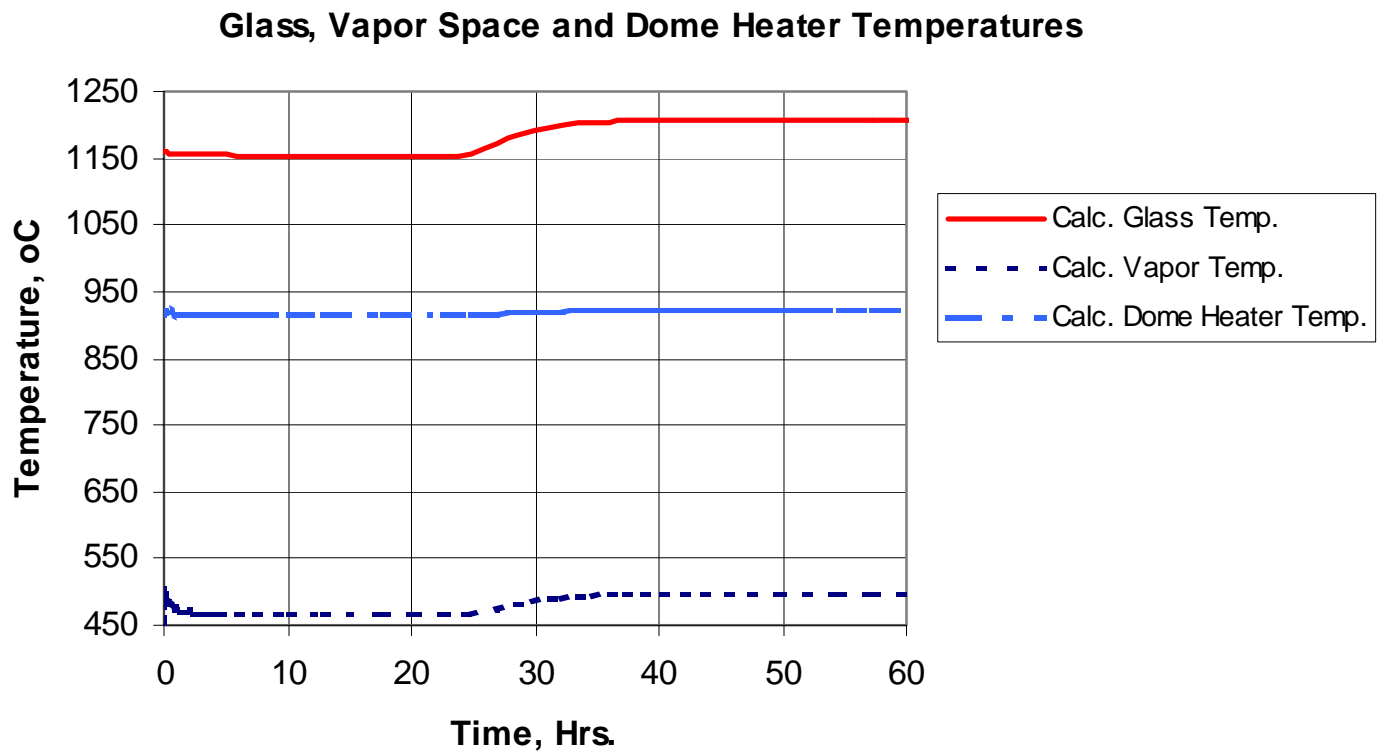

Figure 37

Glass, Vapor Space and Dome Heater Temperature Increase

Due to Electrode Power Increase - Case 1 
Exposed Glass Surface Area

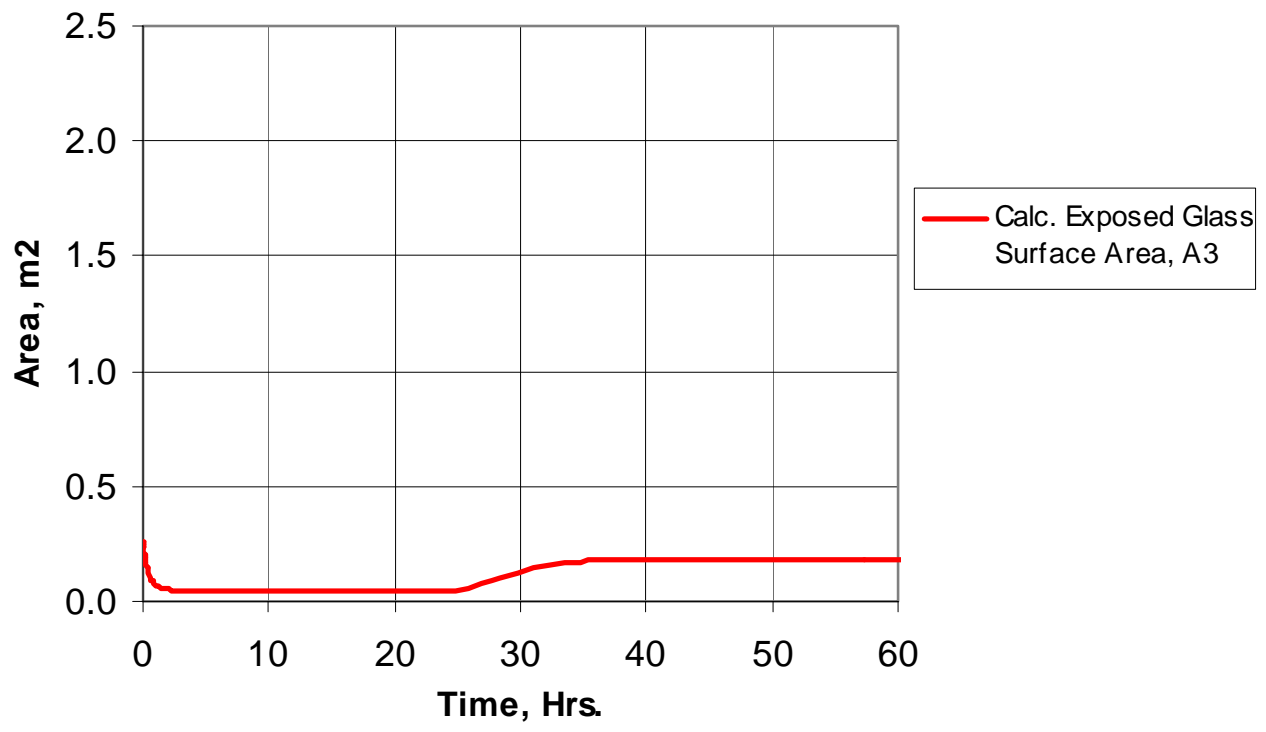

Figure 38

Increase in Glass Surface Area due to Electrode Power Increase - Case 1

Separate Effects, Electrode Power Increase Glass, Vapor Space and Dome Heater Temperatures

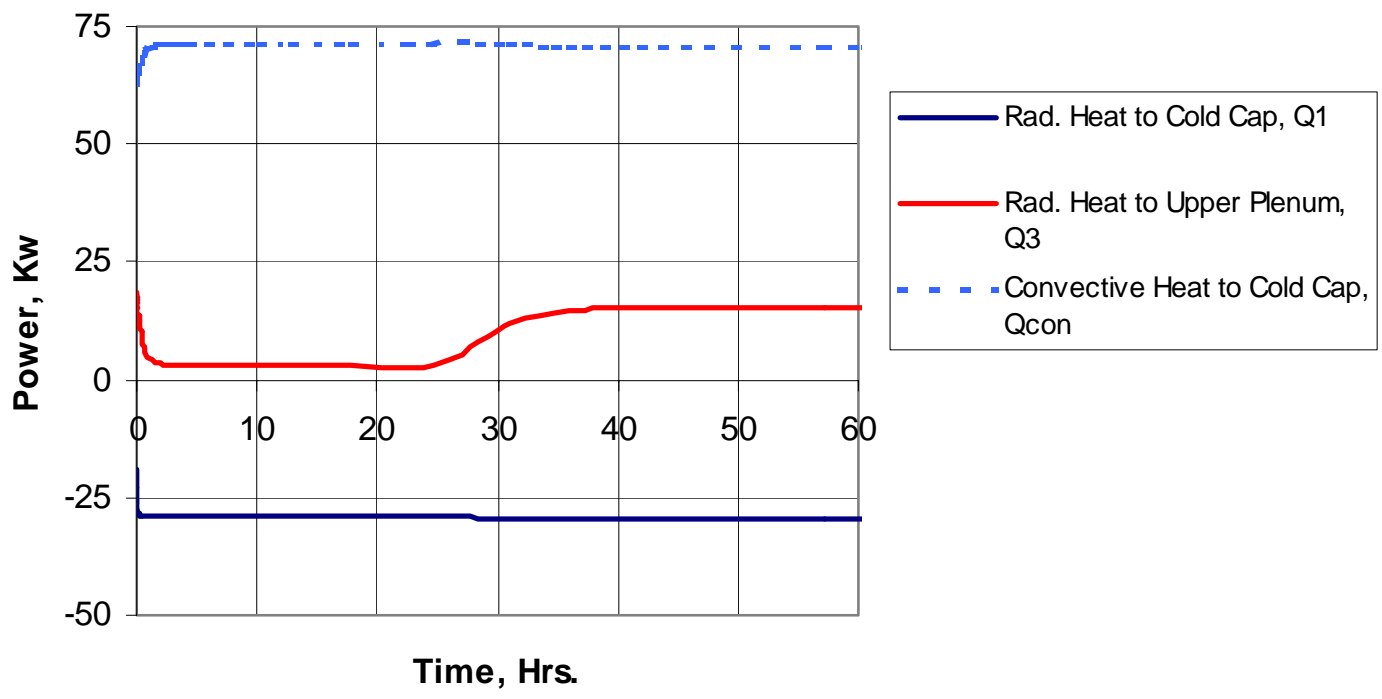

Figure 39

Radiant and Convective Heat Transfer during Electrode Power Increase - Case 1 
Total Feed Rate and Calculated Melt Rate

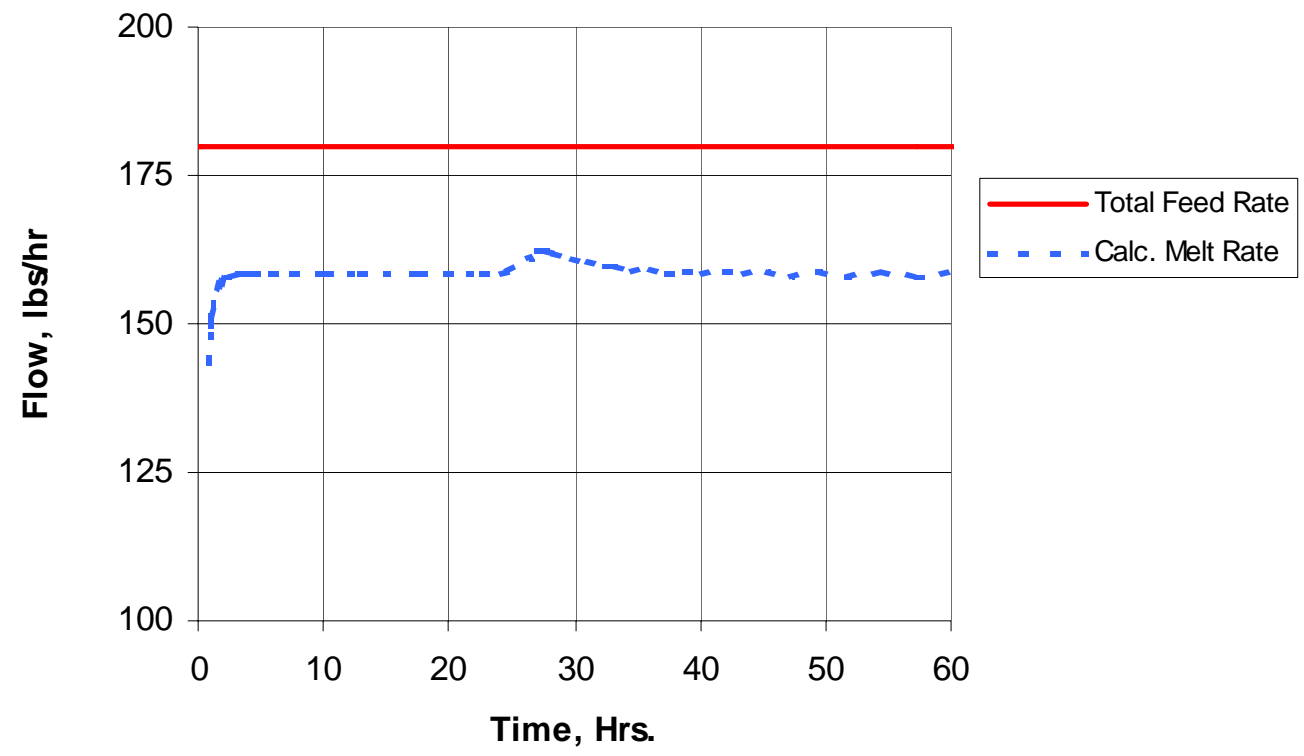

Figure 40

Change in Melt Rate Due to Electrode Power Increase - Case 1

Case 2 - Separation of Effects, Total Feed Rate Increase

In Case 2, we look at the second part of the transient in Figure 27. The scenario is that the feed is initially zero; the electrode power and dome heater power are $160 \mathrm{~kW}$ and $104 \mathrm{~kW}$, respectively. Then feed is added stepwise fashion. While in Figure 27 both electrode and dome heater powers are changed, we will consider the case where the electrode power and dome heater powers are not changed. The increase in feed rate to be studied is only $50 \%$ of the normal feed or $90 \mathrm{lbs} / \mathrm{hr}$., as shown in Figure 41. The resulting melt rate is also shown in Figure 41, which is less than the total feed due to the calcination ratio. The glass, vapor space, and dome heater temperatures (Figure 42) all decrease to new stable values that maintain a heat balance. The exposed glass surface area (Figure 43) decreases from the full tank area of $2.295 \mathrm{~m}^{2}\left(24.7 \mathrm{ft}^{2}\right)$ to $0.9 \mathrm{~m}^{2}$ or a $39 \%$ exposed glass area (61\% cold cap area coverage). The radiant heat from the glass surface (Q3) overall decreases because of the decreasing glass area (Figure 44). There is a slight increase in radiant heat Q3 before decreasing because the cold cap area is calculated on a steady state, heat balance basis and since the vapor temperature decreases rapidly, there is a momentary increase in Q3 before dropping. In reality, the cold cap may increase much faster in a transient due to film boiling (the rate of which is unknown at this time), which would reduce Q3 at the early part of the transient. The radiant heat to the cold cap (-Q1) increases due to the increase in cold cap area. The convective heat to the cold cap (Qcon) increases for the same reason. 


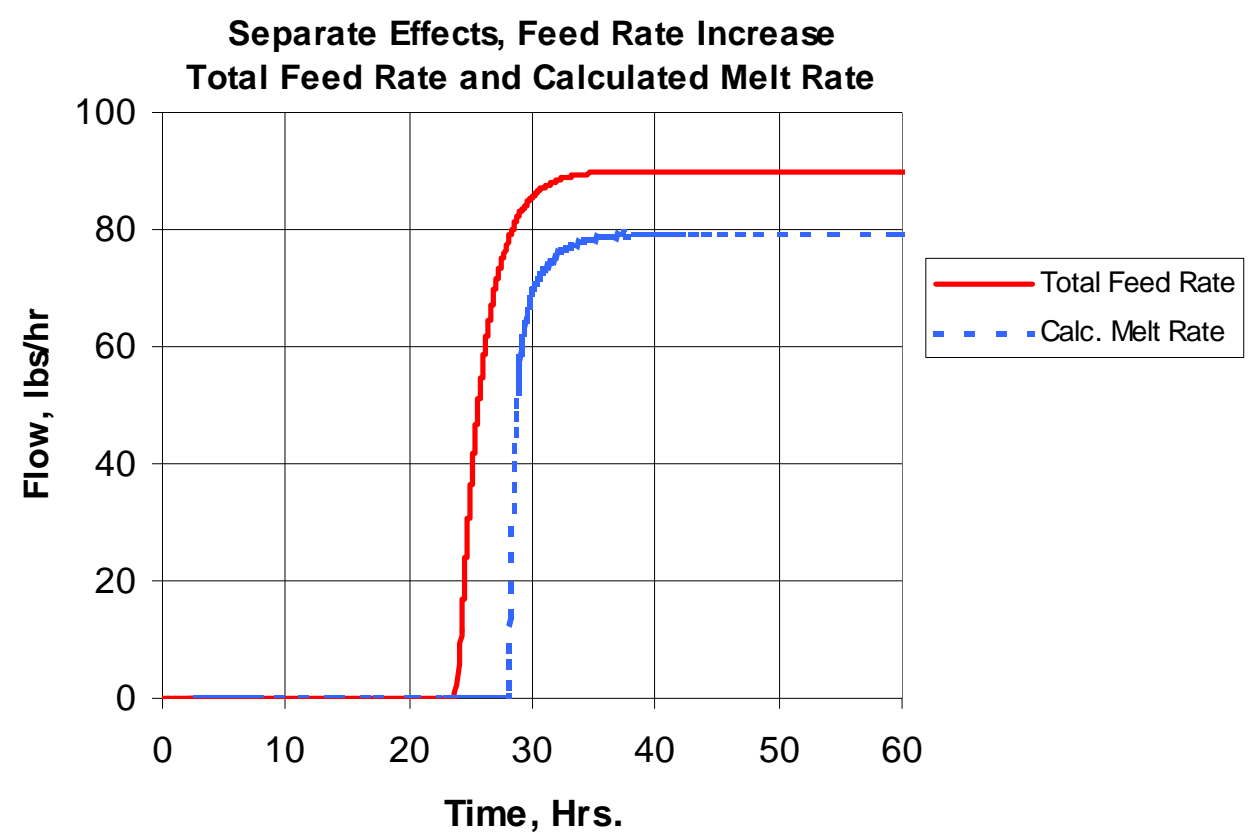

Figure 41

Step Increase in Feed Rate to $90 \mathrm{lbs} / \mathrm{hr}$ from Zero Feed and Corresponding Calculated Melt Rate - Case 2

Separate Effects, Feed Rate Increase Glass, Vapor Space and Dome Heater Temperatures

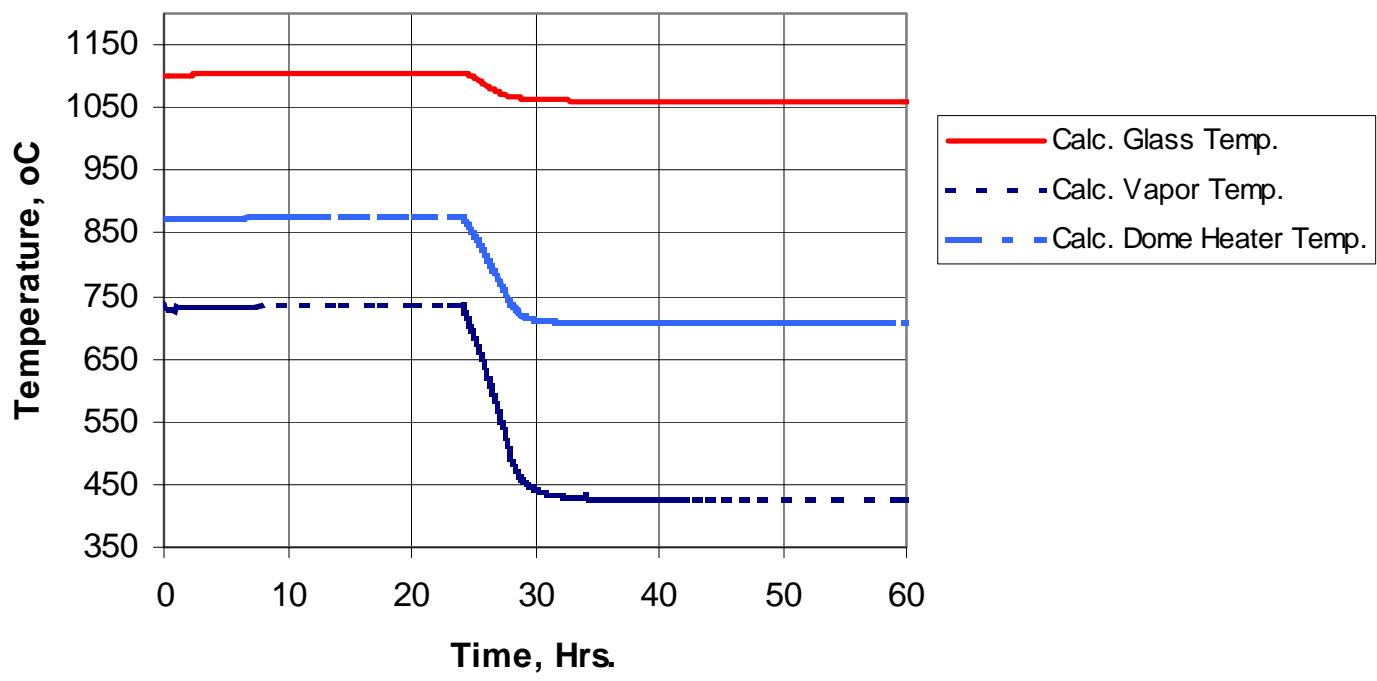

Figure 42

Changes in Glass, Vapor Space and Dome Heater Temperatures Due to a Step Increase in Feed Rate - Case 2 


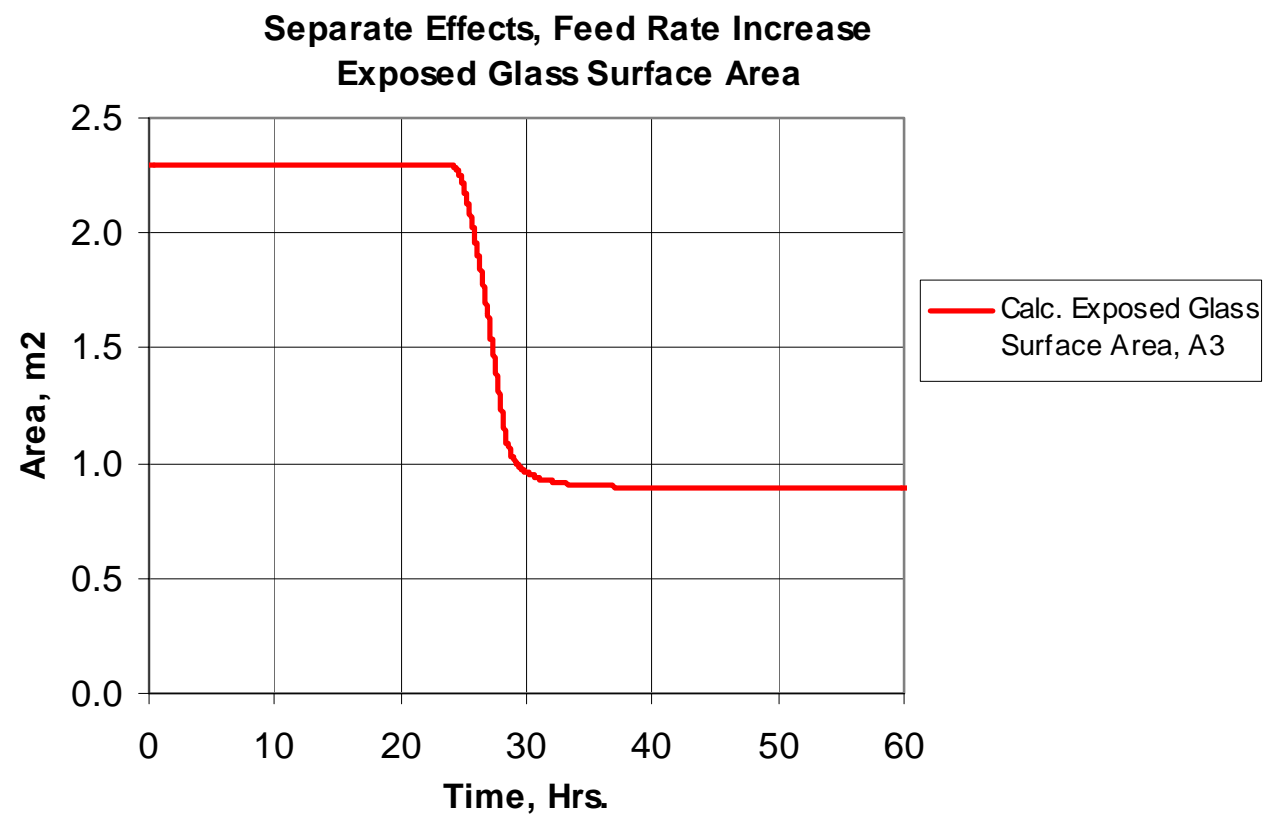

Figure 43

Decrease in Glass Surface Area as a Result of a Step Increase in Feed Rate - Case 2

Separate Effects, Feed Rate Increase Radiant Heats to Upper Plenum, Cold Cap and Convective Heat

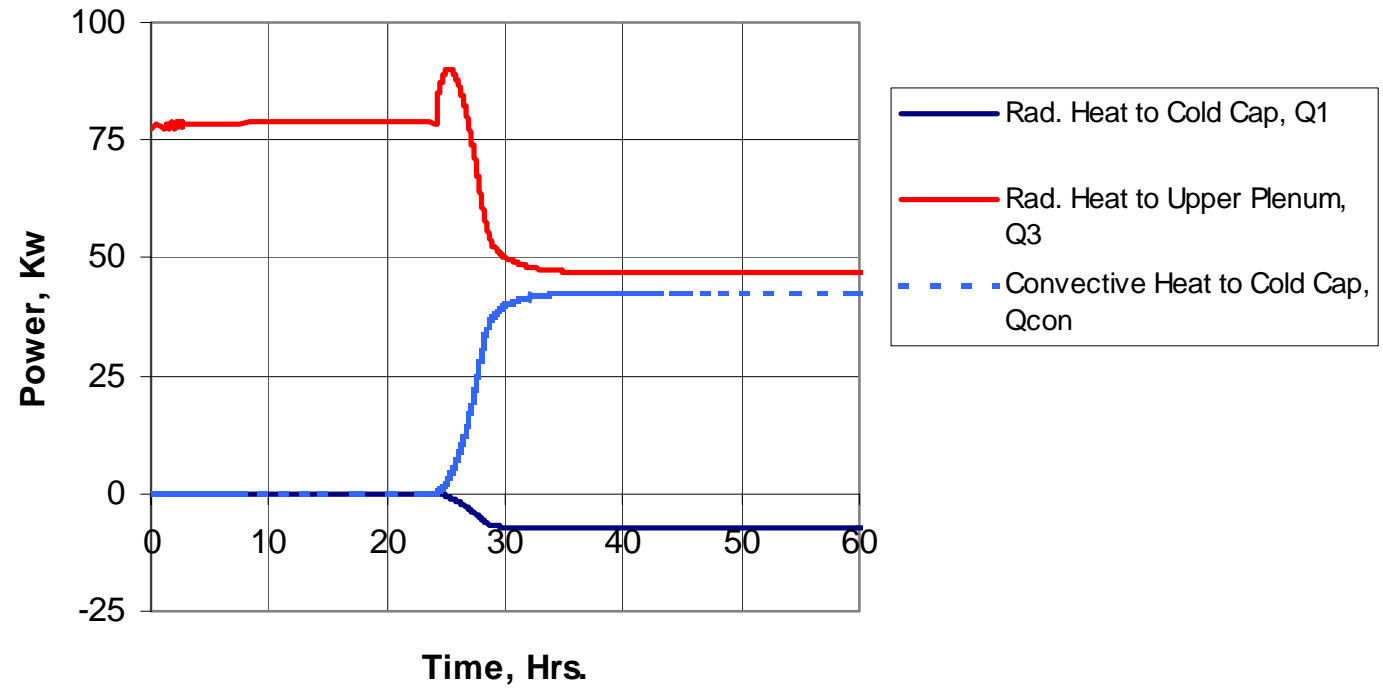

Figure 44

Changes in Radiant Heat to Upper Plenum and to Cold Cap, Convective Heat to Cold Cap as a Result of a Step Change in Feed Rate - Case 2 
Case 3 - Separation of Effects, Dome Heater Power Increase

This case investigates what would happen if the dome heater power were increased while maintaining feed and electrode power. This assumes that we can exceed the present temperature limit of $950^{\circ} \mathrm{C}$ of the dome heater. This also provides some understanding for the case of supplying additional power to the upper plenum through increased radiation from the glass. This may be achieved via the use of bubblers that introduce hot glass into the cold cap region melting the cold cap and increasing the exposed glass surface area.

The scenario is as follows: The feed rate is held at $180 \mathrm{lbs} / \mathrm{hr}$, the electrode power is $146 \mathrm{~kW}$ and the dome heater power is $266 \mathrm{~kW}$. Then the dome heater power is increased by $65 \mathrm{~kW}$ to $331 \mathrm{~kW}$ (Figure 45). The result is that both the dome heater temperature and the vapor space temperature increase (Figure 46), as can be expected. The glass temperature decreases slightly (Figure 46) due to an increase in exposed glass surface area (Figure 47). This in turn is due to increased radiant heat from the upper plenum (higher vapor space temperature) as shown in Figure 48, which requires less cold cap area for the same total feed. This increases the radiant heat from the glass surface. Since the cold cap area is reduced, the convective heat is also reduced. The increased radiant heat to the cold cap momentarily increases the melt rate (Figure 49) until a heat balance is achieved at a reduced cold cap area. If the feed were increased, the melt rate can be maintained at a higher value with reduced vapor space and dome heater temperatures back to their original values.

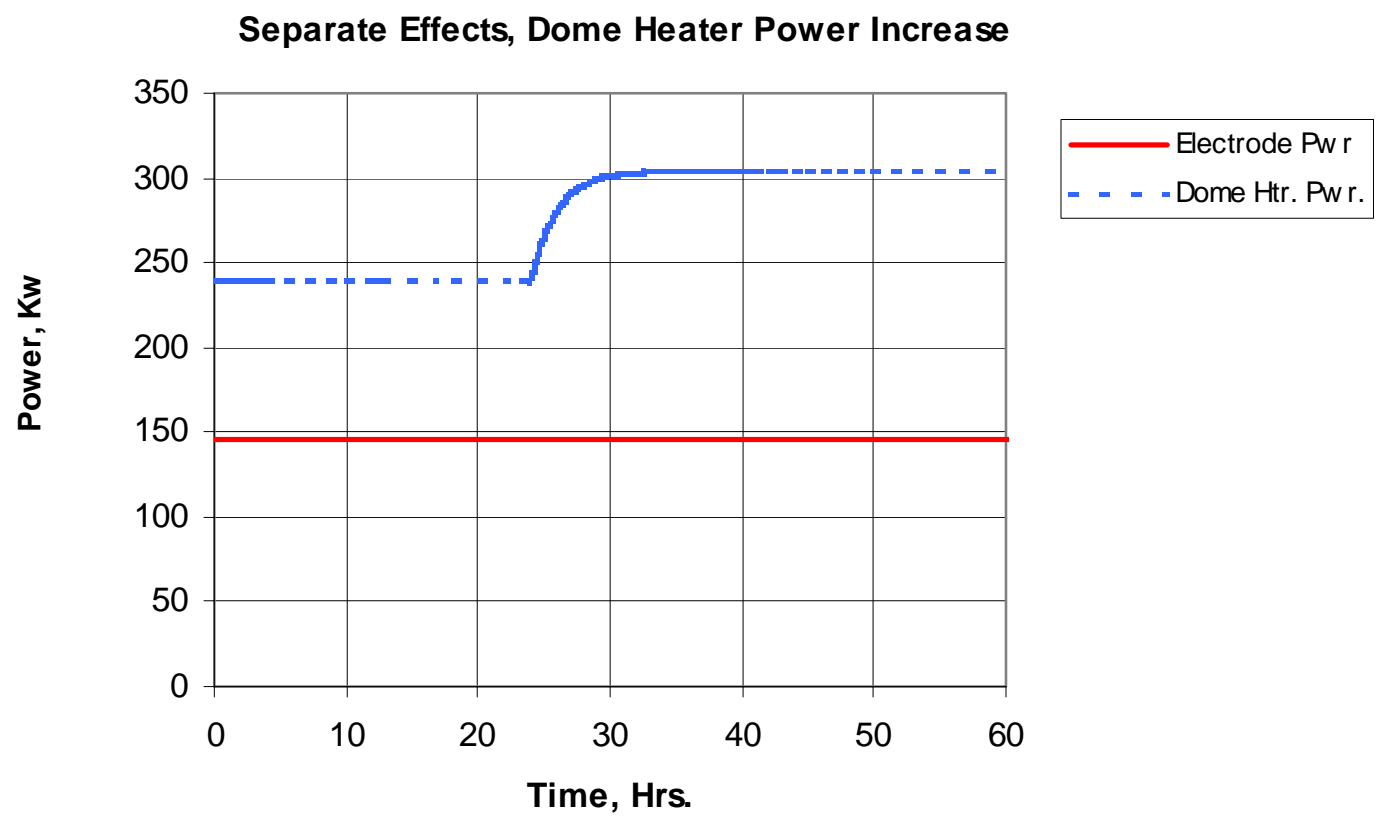

Figure 45

Dome Heater Power Increase Transient - Case 3 
Separate Effects, Dome Heater Power Increase Glass, Vapor Space and Dome Heater Temperatures

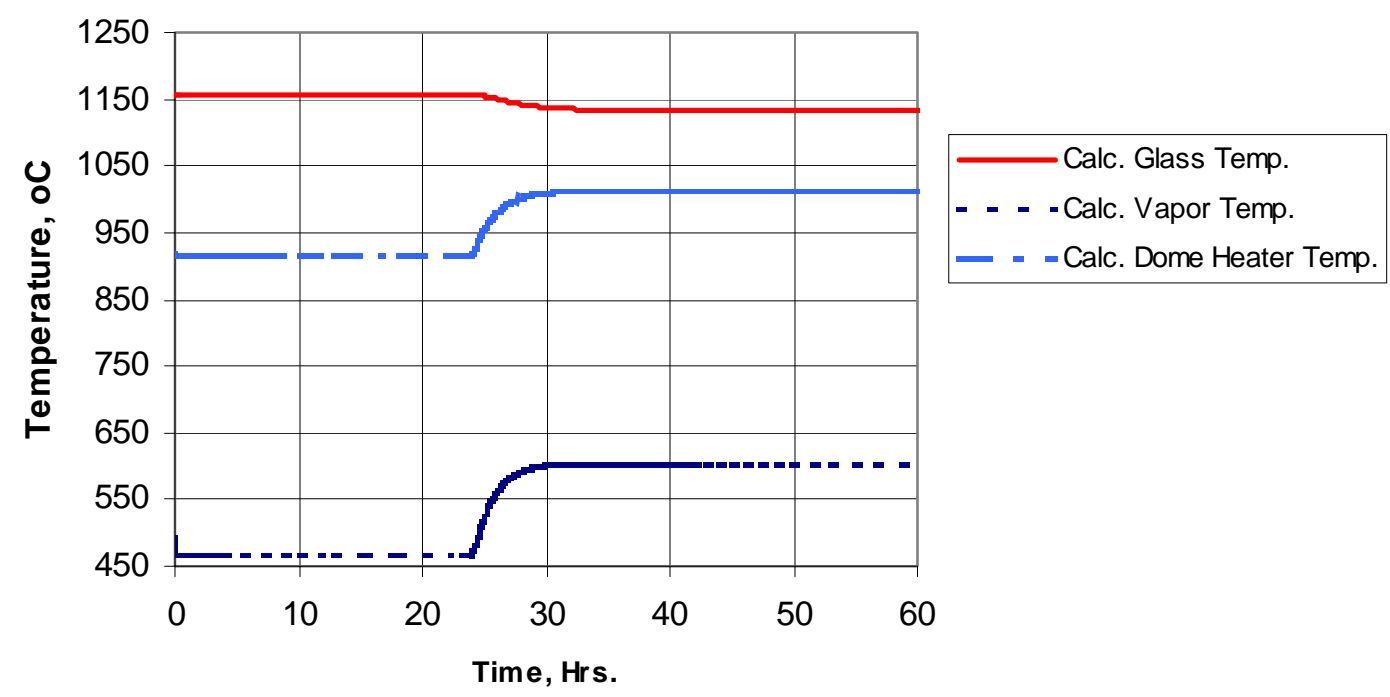

Figure 46

Glass, Vapor Space and Dome Heater Temperatures

Due to a Dome Heater Power Increase - Case 3

\section{Exposed Glass Surface Area}

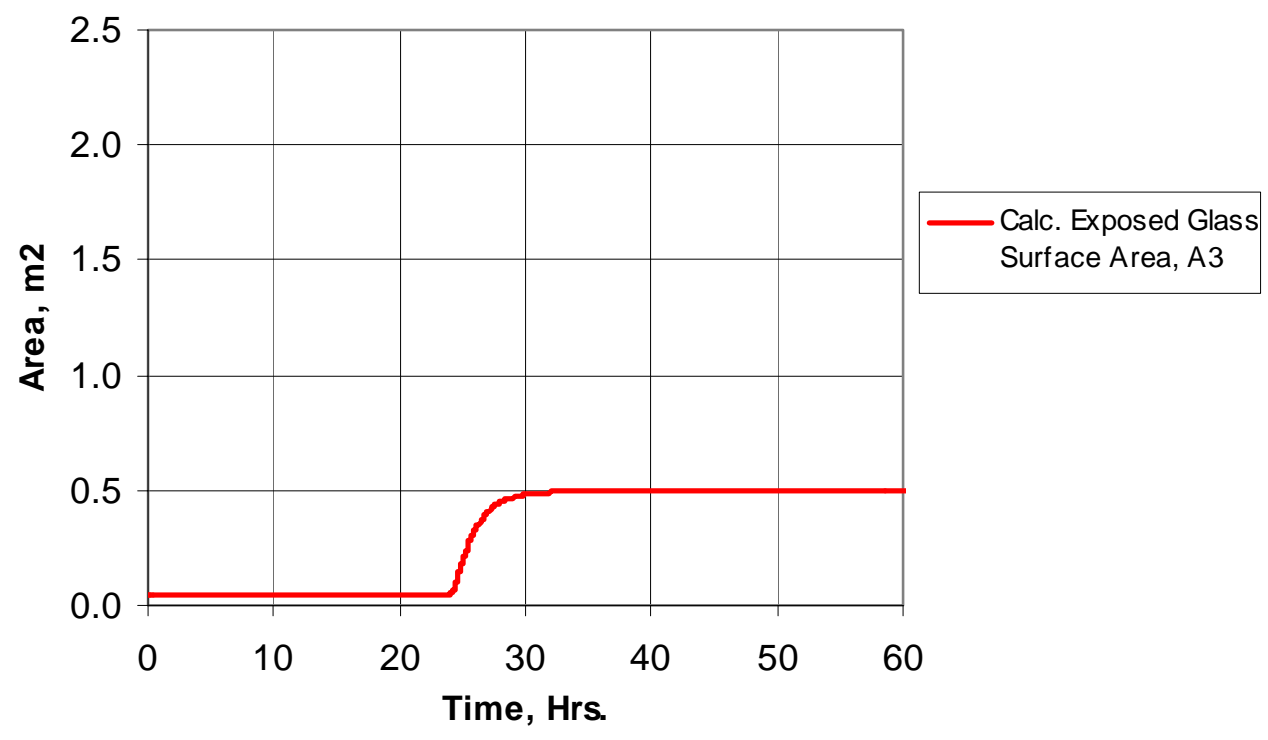

Figure 47

Glass Surface Area Increase Due to a Dome Heater Power Increase - Case 3 


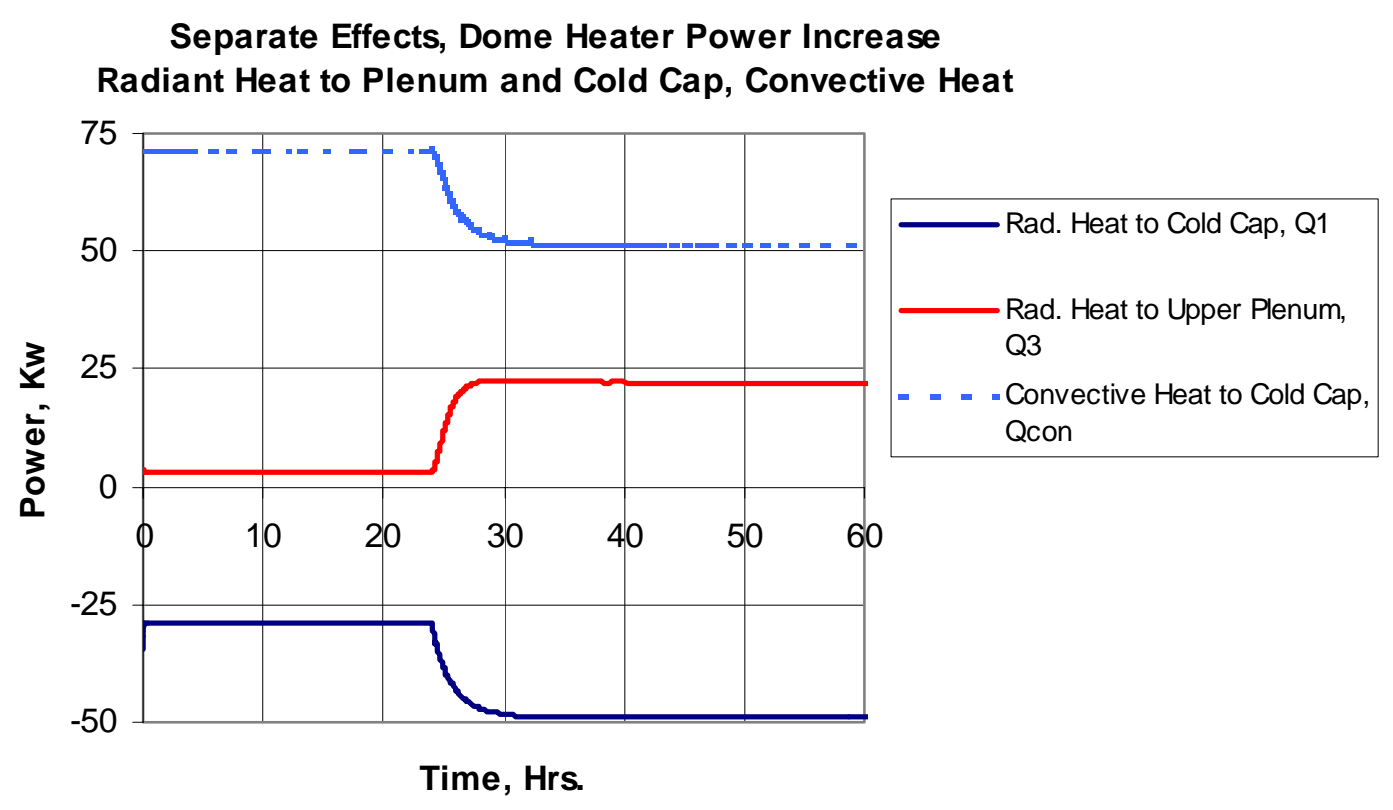

Figure 48

Radiant Heats to Upper Plenum and Cold Cap

Due to a Dome Heater Power Increase - Case 3

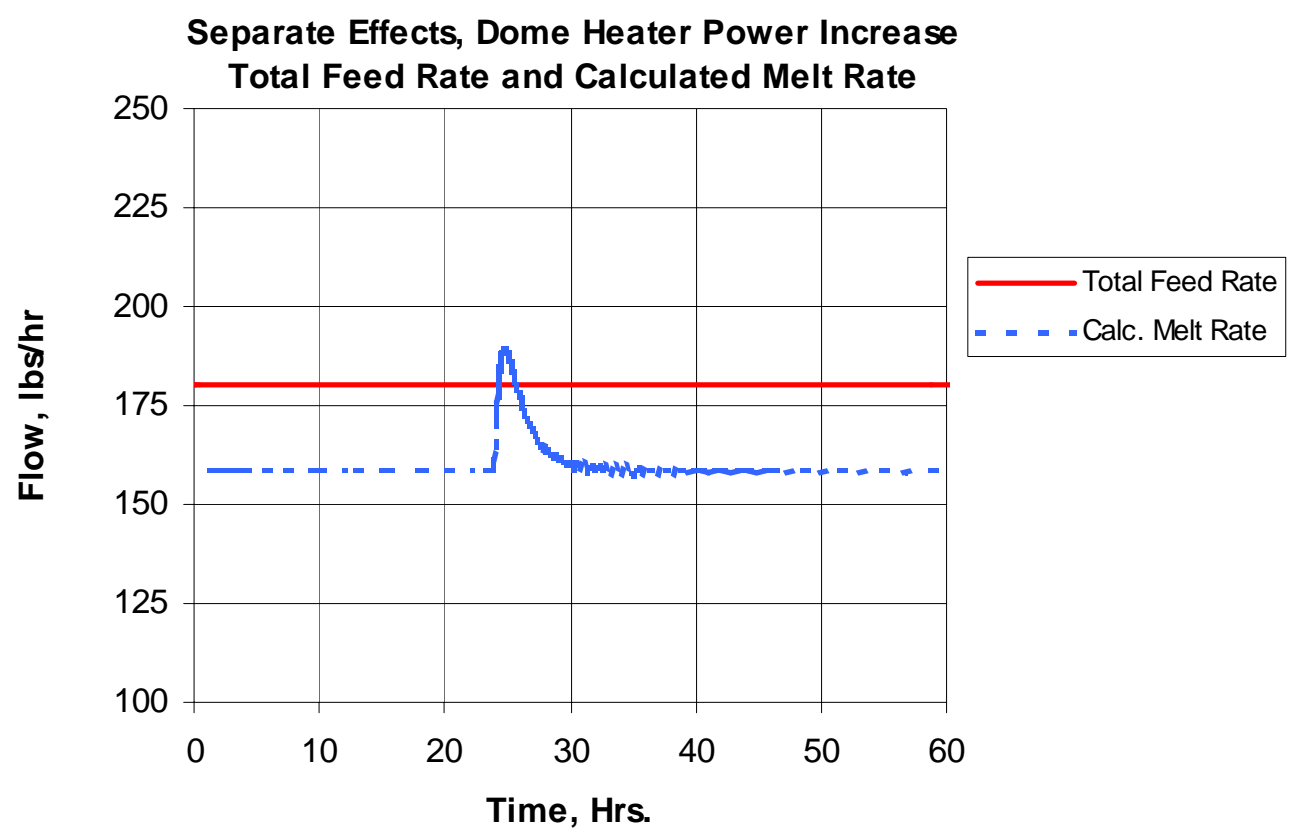

Figure 49

Increase in Melt Rate Due to a Dome Heater Power Increase - Case 3 


\section{Conclusions and Recommendations}

A lumped parameter steady and transient thermal analysis model of the DWPF melter has been completed. The steady state analysis has been benchmarked against actual DWPF Melter data. The difference between the design basis predictions and the actual data can be attributed to:

(1) larger heat losses through the melter shell than can be accounted for in the analysis;

(2) scale up effects; and

(3) a larger thermal resistance between the cold cap and the glass melt pool, probably due to a foam layer present with the actual waste, or current nitric acid based feed.

This thermal resistance results in a larger cold cap area for the same feed rate (with less venting) than experienced in the SGM and IDMS runs. Therefore, the design feed rate of 0.939 gpm can not be achieved due to almost complete cold cap coverage at $0.7 \mathrm{gpm}$ for Macrobatch 1 feed and $0.55 \mathrm{gpm}$ for Macrobatch 2 feed.

By incorporating the shell heat losses (estimated from DWPF data), good agreement between temperature predictions and the data at different feed rates is achieved with the present analysis. By assuming the cold cap area is linearly proportional to feed rate, the breakdown of radiant heat from the glass surface to the upper plenum, radiant heat incident on the cold cap and convective heat to the cold cap is calculated. This linear assumption follows from the linear relationship of total power with feed rate and which results in good heat balances at these feed rates. From these results, it is concluded that the radiant heat incident on the cold cap is insufficient to evaporate the slurry water. Additional heat is required from the glass pool. This heat which passes through the glass/foam layer significantly affects the melt rate.

Some conclusions from the steady state analysis are the following:

- $\quad$ The decrease in electrode power from Macrobatch 1 to Macrobatch 2 and then Macrobatch 3 is consistent with an interface layer buildup on top of the glass of foam or crystalline deposits which reduce heat transfer from the melt pool to the cold cap and hence melt rate.

- A decrease in electrode power for Macrobatch 3 feed under idling conditions is also consistent with an interface layer buildup which reduce heat transfer to the plenum. The lumped model predicts a decreased glass surface temperature and reduced radiant heat to the plenum, as a result of the reduced measured vapor space temperature.

- The design basis melt rate can be achieved by increasing the effective convective coefficient between the glass and cold cap by $50 \%$ of its current value. This may be achieved by reduced foaming of the melt batch and by increasing the convection film coefficient between liquid and cold cap by chemistry changes or air sparging.

- An increased melt rate may be achieved by maintaining the uncovered glass surface temperature high by increased natural convection flow, bringing hot glass from lower glass depths. This increases heat radiation to the upper plenum to aid evaporation of the slurry water. 
- If in addition to reducing the thermal resistance, the glass chemistry is adjusted so that the glass melting results in an exothermic reaction of $+100 \mathrm{cal} / \mathrm{gm}$ rather than an endothermic one, it is possible that the melt rate may be increased up to $30 \%$. This must be confirmed by bench top melter tests where a steady state feed rate is maintained.

The transient analysis model is benchmarked against DWPF Melter data that are representative of typical feed rate increase and decrease transients. The transient model is also used to investigate the separate effect of varying one parameter (feed rate, electrode power or dome heater power) while holding the others constant. The objective is to understand the interplay of the various heat transfer mechanisms in the melter, as these affect the controlled temperatures and melt rates.

- Reasonable agreement between the analysis and the data is achieved for 3 melter runs where the feed rate was initially constant for several days then decreased to zero, maintained at zero for several days and then restored to its original or other value and held constant again at that value. The electrode and dome heater powers were simultaneously varied during the transient to maintain glass and dome heater temperatures below limits. Two runs show the effect of different Macrobatch 1 and Macrobatch 2 feeds. Also, two different initial feed rates were simulated. The results show that reasonably close agreement between predictions and data can be achieved if the actual runs have the same electrode and dome heater powers as the average values over several runs. This is because the analysis is based on the correlations of the electrode/ dome heater powers to the feed rate. When there is a large deviation of the actual run powers to the average values, better agreement can be achieved if the average values for the corresponding feed rates were used. This is due to possible inaccurate prediction of the glass surface temperature (as affected by the glass bulk temperature and flow circulation) which controls radiant heat to the plenum.

- Three separate effect cases are investigated based on a Macrobatch 2 run (2/09-19/02). In the first case, the electrode and dome heater powers are held constant corresponding to an initial flow of $0.55 \mathrm{gpm}$ and then the electrode power is increased an amount equal to what would be added if the feed rate were reduced to zero. The result is to increase the glass temperature, the exposed glass surface area and the radiant heat to the upper plenum

- In the second case, conditions for zero feed rate are initially held constant. Then a step increase in feed rate is initiated while maintaining electrode and dome heater powers. The result is that the glass, vapor space and dome heater temperatures all decrease as the cold cap area increases. The convective and radiant heats to the cold cap increase with the increase in cold cap area, with a corresponding decrease in radiant heat to the upper plenum.

- In the third case, conditions for full feed of $0.55 \mathrm{gpm}$ is maintained and then a step increase in dome heater power is initiated. The dome heater and vapor space temperatures increase while the glass temperature decreases as the cold cap area decreases. The radiant heat to the upper plenum and cold cap also increases resulting in a momentary increase in melt rate. 


\section{$\underline{\text { Recommendations }}$}

This lumped parameter model is another step forward after Yosioka's analysis. Understandably, there are still many areas that can be improved upon since large gaps in understanding of many physical processes in the melter still exist. However, the model provides a framework where experimental values or good averages from 3-dimensional CFD analysis of the following parameters can be inserted in place of current assumptions. Improvements in the model should include:

- convective heat transfer coefficient between cold cap and melt pool for new macrobatches, possibly from bench top slurry melt rate furnace tests,

- re-evaluation of linearity of cold cap area vs. feed rate, especially at low feed rates, and during transients,

- values of Hbatch for different macrobatches from bench top experiments,

- more accurate calculation of shell heat losses,

- relation between measured and true average dome heater temperatures,

- average cold cap surface temperature from 3D analysis,

- more accurate determination of the dome heater view factors,

- experimental determination of actual glass surface temperature and a more accurate method to tie it to the bulk glass temperature.

- more accurate determination of glass thermal time constant that includes mixing.

- inclusion of the effect of upper plenum insulation in the thermal analysis.

Thus, with input from bench top experiments and iteration with 3-dimensional CFD analysis, a good simple lumped parameter model can be developed for use in evaluating melter performance with new waste macrobatches and also for transient analysis of melter operation.

\section{Nomenclature}

Acc - cold cap area

A3 - uncovered glass area

Abs- lower melter shell surface area

AFR - air in-leakage into the melter

Aus - upper melter shell surface area

beta - glass coefficient for thermal expansion

CC- fraction of the glass surface covered by the cold cap

cpa - air specific heat

cpg - glass specific heat

cps - steam specific heat

cpw - water specific heat

$\mathrm{fc}$ - calcination ratio

fs - slurry solids fraction

FR- feed rate, gpm

Fij - view factor from surface $\mathrm{i}$ to surface $\mathrm{j}$.

hbs - effective heat transfer coefficient from glass pool to bottom shell insulation

hc - cold cap height

hcon - heat transfer coefficient for convection from glass to cold cap

hus - effective heat transfer coefficient from upper plenum to upper shell insulation 
Hbatch- heat of melting defined by Eq. 1 .

HLAR - heat loss due to superheating of leakage air and calcine gas

Hlgs - heat required to melt glass equal to melt rate times Hbatch

hbs - effective transfer coefficient through lower plenum

hus - effective transfer coefficient through upper plenum

$\Delta \mathrm{Hr}$ - heat of reaction of batch components as a function of temperature

$\Delta$ Hevap - heat of evaporation of water

$\Delta$ Hmelting - heat of reaction of glass plus heat of melting of silica frit

$\mathrm{kg}$ - glass thermal conductivity

$\mathrm{Ma}$ - mass of leakage air and calcine gas

$\mathrm{Mp}$ - mass of glass melt pool

Ms- mass of steam in upper plenum

MR - glass melt rate

$\mathrm{Qi}$ - net radiant heat from surface i (emissive power less radiant heat from other surfaces

incident on surface $\mathrm{i}$,

where $\mathrm{i}=1$, cold cap

$\mathrm{i}=2$, lid heater (less heater box heat loss 0

$\mathrm{i}=3$, uncovered glass surface

$\mathrm{i}=4$, upper plenum side

$\mathrm{i}=5$, upper plenum top lid

Qcc - total heat absorbed in evaporating slurry water and melting glass

Qcon - total heat flow from glass to underside of cold cap

Qcover box - heat loss from lid heater cover box

Qdhtr - dome heater power

Qel - electrode power

Qevap - heat loss due to evaporation of slurry water

Qfeed tube - heat loss from feed tubes

Qgas - heat loss due to superheating of calcine gas

Qlbs - heat loss from melter bottom shell

Qlus - heat loss from melter upper shell

Qstem - heat loss from instrumen stems

Qsub - heat loss due to removal of slurry water subcooling

QLSL- sum of lower shell heat loss, stem loss, convected heat Qcon and radiated heat Q3

QUSL- total of all heat lost through upper shell by conduction and mass flow of steam, gas and vapor.

Qvs - heat loss due to mass flow of steam

Qhtrloss- heat loss at dome heater ends due to connector resistances and transformer bus bars

SFR - steam feed rate

$\mathrm{Tg}$ - glass pool temperature, $\mathrm{K}$

$\mathrm{tg}$ - glass pool temperature, ${ }^{\circ} \mathrm{C}$

Tgs - glass surface temperature, $\mathrm{K}$

$\mathrm{Ti}$ - temperature of surface $\mathrm{I}, \mathrm{K}$

tind - indicated vapor space temperature, ${ }^{\circ} \mathrm{C}$

TFR - total solids feed rate (includes calcine gas)

Tsoft - softening temperature of the glass

$\mathrm{Tv}$ - temperature of upper plenum vapor, $\mathrm{K}$ 
Revision

tv - temperature of upper plenum vapor, ${ }^{\circ} \mathrm{C}$

vis - glass viscosity

$\varepsilon_{\mathrm{s}}-$ effective emissivity of vapor

$\rho$ - glass density

pcc- cold cap density

$\sigma$ - Stefan-Boltzman constant

tauij - transnmission factor from surface I to surface $\mathrm{j}$.

9. References

9.1 DPST-88-660, "Prediction of Joule-Heated Glass Melter Operation” Memo from M. Yoshioka to M.D. Boersma, June 24, 1988.

9.2 PDEase2DTM Reference Manual, $3^{\text {rd }}$ Ed., November, 1996, Macsyma, Inc. SRS Work group computer file: Wg09/Melterg/Perf(MLT-Daily Data)

9.3 Siegel, Robert and John R. Howell, Thermal Radiation Heat Transfer, $3^{\text {rd }}$ ed. Hemisphere Publishing Corporation, 1992.

9.4 WSRC-TR-2000-00100, "Validation of DWPF Melter Offgas Combustion Model”, by A. S. Choi, June 23, 2000. 
WSRC-TR-2002-00159

Page 63 of 78

Revision

\section{Appendix A}

\section{Calculation for Steady State and Transient Thermal Response} of DWPF Melter 


\section{A-1.0 Scope}

This appendix provides the detailed calculational methods used in obtaining the results presented in the text. The specific scope of the calculations are to provide: a steady state heat balance of the DWPF melter will be calculated for:

1. Macrobatch 1 feed at feed rates of 0 to $0.7 \mathrm{gpm}$,

2. Macrobatch 2 feed at a typical feed rate of $0.55 \mathrm{gpm}$,

3. Macrobatch 2 feed with high air in-leakage,

4. Macrobatch 2 with reduced foaming,

5. Macrobatch 2 with reduced foaming and exothermic reaction.

The transient heat balance calculations provide the melter performance under the following scenarios:

1. simulation of an actual DWPF run,

2. exponential increase in electrode power, while maintaining slurry feed rate and dome heater power - Case 1;

3. exponential decrease in feed rate, while maintaining electrode and dome heater power - Case 2,

4. linear decrease in slurry feed rate, while maintaining electrode and dome heater powers - Case 3,

5. linear decrease in dome heater power, while maintaining feed rate and electrode power.

The objective of these calculations is to determine the glass melt rate under the above conditions and to provide an understanding of the heat transfer processes and other physical mechanisms that enhance or limit the glass melting. Further, the calculation will provide a measure of the response times of the glass temperature, the cold cap area expansion, and melt rate variation under the above operational changes. Other objectives are to calculate the steady state and transient heat contributions to the melting of the glass, and how these affect the vapor space temperature.

\section{A-2.0 References}

A-1 DPST-88-660, "Prediction of Joule-Heated Glass Melter Operation," Memorandum from M. Yoshioka to M. D. Boersma, June 24, 1988.

A-2 WSRC-RD-91-11 Rev. 0, "Summary of DWPF Waste Glass Physical Properties - (U), Memorandum from R. F. Schumacher to M. J. Plodinec, January 30, 1991.

A-3 Siegel, Robert, and John R. Howell, Thermal Radiation Heat Transfer, $3^{\text {rd }}$. Ed. Hemisphere Publishing Corporation, 1992.

A-4 Howell, J. R., A Catalog of Radiation Configuration Factors, McGraw-Hill Book Company, 1982.

\section{A-3.0 Inputs}

For the steady state calculation, the following conditions are given and listed in Table 1 in the text and in the Excel program, Melt_Htbal for the different cases:

1. electrode power, Qel

2. dome heater power, Qdhtr

3. slurry feed rate

4. solids weight fraction, $\mathrm{fc}$ is 0.46 for the design case (Ref. A-1)and 0.49 for all DWPF runs (Ref. 7.2)

5. slurry specific gravity is 1.33 at the inlet of the feed tubes 
6. calcination ratio, fc, is 0.8 for the design case and 0.89 for all DWPF runs.

7. The air in-leakage rates are:

- $460 \mathrm{lbs} / \mathrm{hr}$ for the design case

- $560 \mathrm{lbs} / \mathrm{hr}$ for all DWPF runs,

- $785 \mathrm{lbs} / \mathrm{hr}$ for the high air leakage run.

8. vapor space temperature is given by $\mathrm{tv}=0.9168 *$ tind -60 (due to $\mathrm{TC}$ radiation error), where tv and tind are in ${ }^{\circ} \mathrm{C}$.

9. average melter shell cooling water temperature is $40^{\circ} \mathrm{C}$.

10. The glass heat of fusion is $-120 \mathrm{cal} / \mathrm{gm}$ for endothermic reaction, $+80 \mathrm{cal} / \mathrm{gm}$ for endothermic reaction. This includes $-20 \mathrm{cal} / \mathrm{gm}$ for melting glass frit and $-100 \mathrm{cal} / \mathrm{gm}$ for endothermic reaction, and $+100 \mathrm{cal} / \mathrm{gm}$ for exothermic reaction.

11. The glass bulk temperature in the upper region is $1150 \mathrm{C}$ and $1100 \mathrm{C}$ in the lower region.

12. The glass property variations with temperature are given by Ref. A-2. The equations used to compute these properties are obtained from Ref. 1, and listed below. Here, $t$ is temperature in ${ }^{0} \mathrm{C}$.

Glass (liquid) specific heat $\left(\mathrm{KJ} / \mathrm{Kg} /{ }^{0} \mathrm{~K}\right)$ :

$$
\operatorname{cpg}=((0.188446+0.001305 * \operatorname{tg}) /(1+0.003172 * \operatorname{tg})) * 4.1868
$$

[A-1]

Glass density $\left(\mathrm{Kg} / \mathrm{m}^{3}\right)$ :

$$
\rho=(2.86169-0.00049 * \operatorname{tg}) /(1-0.000049 * \mathrm{t}) * 1000
$$

Glass diffusivity (m2-sec): $\operatorname{diff}=(0.003461-0.000003437 * \operatorname{tg}+0.00000000987 * \operatorname{tg} \wedge 2) * 0.0001 \quad[\mathrm{~A}-3]$

Glass coefficient for thermal expansion: beta $=(0.000355 * \operatorname{tg}-0.09969) /(2.86169-0.00049 * \operatorname{tg}) / \operatorname{tg}$

Glass viscosity $(\mathrm{N}-\mathrm{s} / \mathrm{m} 2)$ : vis $=(0.0005 * \operatorname{tg} \wedge 2-1.42 * \operatorname{tg}+1040.5) * 0.1$

Glass thermal conductivity $(\mathrm{kW} / \mathrm{m}-\mathrm{K})$

$$
\mathrm{kg}=\rho^{*} \mathrm{cpl} \mathbf{d}^{*} \text { diff }
$$

(The above relations are programmed in the Excel spreadsheet HTBAL.)

13. The glass softening temperature, Tsoft, is $554^{\circ} \mathrm{C}$.

14. The cold cap surface temperature, T1, varies from $100^{\circ} \mathrm{C}-600^{\circ} \mathrm{C}$. The original temperature used in the design case was $100^{\circ} \mathrm{C}$ based on the assumption that the top surface of the cold cap is at the boiling point of water. However, since the two feed tubes are at local positions, the pool of water may be localized, while the rest of the cold cap is at much higher temperatures. In the calculation, trial values were used until a heat balance was achieved, leading to cold cap temperatures, $400^{\circ}-600^{\circ} \mathrm{C}$.

15. The cold cap coverage is linear with feed rate, 0 at zero feed and $100 \%$ at $0.7 \mathrm{gpm}$ for Macrobatch 1, 0 at zero feed and 100\% at $0.6 \mathrm{gpm}$ for Macrobatch 2, 89\% for the design case. Because of the lump parameter approach, this linear assumption is the only assumption we can make. However, this is justified by the results of the heat balance, Figure 4.

The outputs of the Excel program, HTBAL, are the following: Qsub, Qevap, Hlgs, Qvs, Qgas, HLAR, Q1, Q3, T2(check).

The inputs to the Excel program, Melt_Htbal are the above plus the lower shell heat loss, Qlbs. The inputs are also given in Table 1 as the items in bold face. The outputs are the following:

Qcon, QLSL, Qcc, Qlus, QUSL, Q2. 
Calculations of Qcon and Qcc are illustrated later in this section. QLSL is the sum of all glass pool losses as given in Table 1 and should equal the electrode power (Equation A-7)

Qcc is the total heat absorbed by the slurry while converting to molten glass, as given by Equation A-8. QUSL is the sum of all heat losses in the upper plenum,

$$
\text { QUSL=Qvs+Qgas+HLAR+Qlus. }
$$

Q2 is the net heat radiated by the dome heaters. It is the total dome heater power less heat lost through heater end cover boxes and heater end connections, as given in Table 1. It is also equal to the heat absorbed in the plenum, QUSL, less heat radiated by the glass, Q3, plus heat radiated to the cold cap (-Q1).

$$
\mathrm{Q} 2=\mathrm{QUSL}-\mathrm{Q} 3-\mathrm{Q} 1 \text {. }
$$

For the transient cases, the parameters for an earlier estimate of the upper and lower shell heat losses were used, as discussed later. The input transients for the feed rate, electrode power, and dome heater power are shown in the text.

\section{A-4.0 Methods and Computations}

\section{A-4.1 Steady State Computation}

The steady state heat balance equations solved in the Excel spreadsheet Melt_Htbal are given below:

\section{Glass Pool}

The electrode power generated by the electrodes is equal to the sum, QLSL which is made of:

1. the heat convected from the glass to the bottom of the cold cap, Qcon,

2. the heat losses to the side and bottom of the melter in contact with the glass, Qlbs

3. heat lost by radiation from the uncovered glass surface, Q3

4. In addition there is a small heat lost by conduction from instrument stems, approximately 4 kW (Ref. A-1).

$$
\mathrm{Qel}=\mathrm{QLSL}=\mathrm{Q} 3+\mathrm{Qcon}+\mathrm{Qlbs}+\mathrm{Qstem}
$$

The heat losses to the side and bottom of the melter in contact with the glass, Qlbs, and Q3, are obtained by considering the cases of zero feed and $100 \%$ cold cap coverage. Thus, for Macrobatch 1 at zero feed, Qel=173 kW, and

$$
\text { Q3+Qcon=173-4-Qlbs }
$$

But Qcon=0, Q3=169-Qlbs. Q3 is obtained from radiation exchange relations in the Excel program, Htbal, as $90 \mathrm{~kW}$.

Thus, Qlbs=79 kW.

The upper shell heat loss is obtained from the heat balance in the upper plenum:

At $0.7 \mathrm{gpm}$ feed, Q3=0,

$$
\text { Qcon=169-79=90 kW. }
$$

All of the heat from the glass pool must pass through the bottom surface of the cold cap to reach its surface (while melting the glass and raising the glass frit temperature to its softening temperature). Then the remaining convected heat, in conjunction with the heat radiated from the upper plenum, evaporates the slurry water. Thus for any feed rate, Q3+Qcon=90 kW and the partition of the heat loss from the glass pool to the cold cap and to the upper plenum is obtained in linear proportion to the cold cap coverage. 


\section{Cold Cap}

The heat absorbed by the cold cap, Qcc, is equal to:

1. the heat to remove the sub-cooling of the slurry water, Qsub,

2. the heat to evaporate the water, Qevap,

3. the heat to raise the glass frit temperature to its softening point, $554^{\circ} \mathrm{C}$

4. the heat to melt the glass and the heat to raise the molten glass temperature to the bulk glass temperature, Hlgs,

$$
\text { Qcc }=\text { Qsub + Qevap + Hlgs }
$$

This is also equal to the sum of the heat convected from the glass pool and the heat radiated from the upper plenum.

$$
\mathrm{Qcc}=\mathrm{Qcon}-\mathrm{Q} 1 .
$$

Here, due to the convention used in the radiation analysis of the upper plenum, Q1 is positive going away from the cold cap to the plenum.

(The following parameters are calculated in the Excel program, HTBAL:)

Total solids feed rate $\mathrm{TFR}=\mathrm{FR} * \mathrm{fs} * 60 * 62.4 * 1.33 / 7.48 \mathrm{Lbs} / \mathrm{hr}$

@ $\mathrm{FR}=0.55 \mathrm{gpm}$

solids fraction $\quad$ fs $=0.49$

(includes calcine gas)

Glass melt rate is $\begin{aligned} & \mathrm{MR}=\mathrm{TFR} * \mathrm{fc} \\ & \mathrm{fc}=0.89 \text { (calcination ratio) }\end{aligned}$

$\mathrm{TFR}=179.4 \mathrm{lbs} / \mathrm{hr}$

Steam feed rate is $\quad \mathrm{SFR}=\mathrm{TFR} *(1-\mathrm{fs}) / \mathrm{fs}$

Heat of subcooling $\quad$ Qsub $=\mathrm{SFR}^{*} \mathrm{cpw}^{*}(100-25) * 1.8 / 3412$

where specific heat of water, cpw, is taken as $1 \mathrm{Btu} / \mathrm{hr}-\mathrm{lb}-{ }^{\circ} \mathrm{F}$.

Qevap $=$ SFR $* 0.3077$

Qevap $=57.5 \mathrm{~kW}$

Hlgs $=\left(\mathrm{TFR}^{*} \Delta\right.$ Hmelting $/ 3412+\mathrm{TFR} *\left(\left(\mathrm{cpl}_{25 \mathrm{C}}+\mathrm{cpl}_{554 \mathrm{C}}\right) / 2\right) *($ Tsoft-

$\left.25) /(2.205 * 3600)+\mathrm{MR} *\left(\mathrm{cpl}_{1150 \mathrm{C}}\right) *(\mathrm{Tg}-\mathrm{Tsoft}) /(2.205 * 3600)\right)$

where $\Delta \mathrm{Hmelting}=100 \mathrm{cal} / \mathrm{gm}$ (reaction) $+20 \mathrm{cal} / \mathrm{gm}(\mathrm{glass}$ heat of fusion $)$

$=120 \mathrm{cal} / \mathrm{gm} * 4.186 \mathrm{~J} / \mathrm{cal} * 454 \mathrm{gms} / \mathrm{lb} / 1055 \mathrm{Btu} / \mathrm{J}$

$=216 \mathrm{Btu} / \mathrm{lb} \quad$ (endothermic reaction)

$\Delta$ Hmelting $=-100 \mathrm{cal} / \mathrm{gm}($ reaction $)+20 \mathrm{cal} / \mathrm{gm}($ glass heat of fusion $)$

$=144 \mathrm{Btu} / \mathrm{lb} \quad$ (exothermic reaction)

Air heating loss

$\operatorname{HLAR}=\operatorname{AFR} *(-0.0136+0.000149 * \mathrm{tv})$

$\mathrm{Hlgs}=35.2 \mathrm{~kW}$

Vapor superheating Qvs $=\mathrm{SFR}^{*} \mathrm{CPS} *(\mathrm{tv}-100) * 1.8 / 3412$

$\mathrm{HLAR}=35.8 \mathrm{~kW}$

Calcine gas superheat. Qgas $=$ GFR $*(-0.0136+0.000149 * t v)$

Where GFR $=$ FR $* \mathrm{fs} *(1-\mathrm{fs}) * 60 * 62.4 * 1.33 / 7.48$

Qvs=20.5 kW 
Qgas $=1.4 \mathrm{~kW}$

(The following parameters are calculated in the Excel program Melt_Htbal.)

Dome Heater End Losses

The power measured for the dome heaters does not entirely go into the upper plenum. Yosioka

(Ref. 1) calculated a radiation heat loss from the dome heater cover boxes of $15.8 \mathrm{~kW}$ based on an assumed box temperature of $375^{\circ} \mathrm{C}$ with a surface area of $17 \mathrm{ft} 2$. To this must be added air natural convection cooling using a typical value of the natural convection coefficient of $1 \mathrm{Btu} / \mathrm{hr}$ -

$\mathrm{ft}^{2}$. This value is $1 \mathrm{Btu} / \mathrm{hr}-\mathrm{ft}^{2} * 17 \mathrm{ft} 2 *(350-25) * 1.8 / 3412=3 \mathrm{~kW}$. Therefore the total heat loss from the dome heater cover boxes is $15.8+2.9=18.7 \mathrm{~kW}$.

The heat loss above is not the only parasitic heat loss associated with the dome heaters. There are heat losses due to transformer bus bar cooling water and heater end connections. A calculation (Project 951789) by Abdul Haideri determined the dome heater resistance including the electrical end connectors. The dome heater resistance was calculated as 1.527 milli-ohms at operating temperature, the connector resistance as 0.682 milli-ohms. Therefore, $0.682 /(1.527+0.682)=0.309$ or $30.9 \%$ of the total heat is not generated inside the plenum, but some in the insulation and some outside the shell. The resistance of the heater end connections inside the cover box is 0.257 milliohms or $11.6 \%$ of the total heat. At an average feed rate of $0.35 \mathrm{gpm}$, the dome heater power is $160 \mathrm{~kW}$ and the heater box heat loss is $0.116^{*} 160=19 \mathrm{~kW}$, which agrees with the value of 18.7 $\mathrm{kW}$ above. We will assume a constant cover box heat loss of $18.7 \mathrm{~kW}$ based on an assumed constant box temperature.

The heat loss at the heater inlet connections may be estimated from the transformer bus bar cooling water temperature rise. The data for $8 / 25 / 95$ at $0 \mathrm{gpm}$ feed rate , dome heater power $=\mathrm{n}$ $97 \mathrm{~kW}$ will be used. The cooling water temperature rise is $1.5 \mathrm{oC}$ for a total cooling water flow of $6 \mathrm{gpm}$. The heat loss at zero feed is then $0.264 \mathrm{~kW} / \mathrm{gpm}-\mathrm{oC} * \Delta \mathrm{T}=0.264^{*} 6^{*} 1.5=11 \mathrm{~kW}$. The total heater end loss is $11+18.7=29.7$, which is $30.6 \%$ (29.7/97) of the total dome heater power, agreeing with the above ratio based on electrical resistances. At higher powers, say at $0.7 \mathrm{gpm}$, dome heater power $=267 \mathrm{~kW}$, the proportional busbar cooling water heat loss is $11 * 267 / 97=30$ $\mathrm{kW}$. The total end loss $(18.7+30=48.7)$ is only $18 \%$. Therefore, other parasitic resistances are involved at higher power. We will assume a larger heat loss of $39 \mathrm{~kW}$ at this feed rate for a total loss of $57.7 \mathrm{~kW}$ or $22 \%$.

For the zero feed case, Macrobatch 1, Qdhtr $=103.4 \mathrm{~kW}$.

$\mathrm{Q} 2=$ Qdhtr-Qcoverbox-Qhtrloss-Qfeedtubes

$\mathrm{Q} 2=103.4-18.7-11-4=69.7 \mathrm{~kW}$

For the maximum feed case, $0.7 \mathrm{gpm}$, Qdhtr $=266.8 \mathrm{~kW}$. Q2=266.8-18.7-4-39=205.1 kW.

\section{Upper Plenum}

The sum of the net radiant heats emitted from all surfaces of the upper plenum is equal to the following:

1. heat (Qvs) absorbed by the vapor in increasing its temperature from the evaporation temperature $\left(100^{\circ} \mathrm{C}\right)$, to its steady state value $(\mathrm{Tv})$,

2. the heat (HLAR) required to raise the in-leakage air temperature from $25^{\circ} \mathrm{C}$ to $\mathrm{Tv}$

$$
\mathrm{Qvs}+\mathrm{HLAR}+\mathrm{Qgas}=\mathrm{Q} 1+\mathrm{Q} 2+\mathrm{Q} 3+\mathrm{Q} 4+\mathrm{Q} 5
$$

The signs of the terms Q1, Q2, Q3, Q4, and Q5 are positive for heat flow into the interior of the enclosure. Thus, the heat absorbed by the cold cap is $-\mathrm{Q} 1$. The net radiation into the plenum from 
the upper plenum side wall (Q4) and from the upper lid (Q5) equals the negative of the heat loss from these walls, Qlus.

For the zero feed case, Qvs=Qgas=Q1=0, HLAR=53.3, Q2=69.7, Q3=90.

Thus, Qlus=69.7+90-53.3=106.4 kW

At maximum feed, Q3=0, Qvs=24.4, Qgas=1.6, HLAR=33.5, -Q1=36.5, Q2=205.1. Thus,

$$
\text { Qlus= 205.1-24.4-1.6-33.5-36.5=109.1 kW }
$$

\section{$\underline{\text { Radiation Terms }}$}

The general form of the net radiation heat terms in Eq. (A-12) is given by Siegel and Howell (Ref. A-3), which includes reflected heat terms and the gas radiation terms, as follows:

$$
\begin{aligned}
& \sum_{j=1}^{N}\left(\frac{\delta_{k j}}{e_{j}}-F_{k-j} \frac{1-\varepsilon_{j}}{\varepsilon_{j}} \tau_{k-j}\right) Q_{j}= \\
& \sum_{j=1}^{N}\left(\delta_{k j}-F_{k-j} \tau_{k-j}\right) e_{b, j}-F_{k-j} \alpha_{k-j} e_{b, g}
\end{aligned} .
$$

where $\delta_{\mathrm{kj}}=1$ when $\mathrm{k}=\mathrm{j}$ and $\delta_{\mathrm{kj}}=0$ when $k \neq j$. The view factors Fk-j are given below. The emissivities of the surfaces $\varepsilon j$ are assumed equal to 1 . The transmission factors tauij are obtained from Ref. 3, as given below. All surfaces and the gas are assumed grey so that the emissive power $e_{b, j}$ is not a function of wavelength. Thus, $e_{b j}=\sigma T j \wedge 4$, where $\sigma$ is the Stefan-Boltzman constant. The sum of the gas radiation terms is replaced by an effective gas emissivity, which is a function of the surface temperature. The component net radiation heat terms are thus written, as follows:

$$
\begin{aligned}
& \mathrm{Q} 1=\operatorname{Acc}{ }^{*} \sigma^{*}\left(\mathrm{~T} 1{ }^{\wedge} 4^{*}-\left(\mathrm{F} 12^{*} \operatorname{tau} 12^{*} \mathrm{~T} 2^{\wedge} 4+\mathrm{F} 14 * \operatorname{tau} 14^{*} \mathrm{~T} 4 \wedge 4+\mathrm{F} 15^{*} \operatorname{tau} 15^{*} \mathrm{~T} 5^{\wedge} 4+\varepsilon_{1} \mathrm{TV}^{\wedge} 4\right)\right) \\
& \mathrm{T} 2^{\wedge} 4=(1 / \sigma) *\left(\mathrm{Q} 2 / \mathrm{A} 2-\sigma^{*}\left(\mathrm{~F} 21^{*} \operatorname{tau} 21^{*} \mathrm{~T} 1^{\wedge} 4+\mathrm{F} 23 * \operatorname{tau} 23^{*} \mathrm{~T} 3^{\wedge} 4+\mathrm{F} 24 * \operatorname{tau} 24^{*} \mathrm{~T} 44^{\wedge} 4+\right.\right. \\
& \left.\left.\mathrm{F} 25^{*} \operatorname{tau} 25^{*} \mathrm{~T}^{\wedge} 4+\varepsilon_{2} * \mathrm{TV}^{\wedge} 4\right)\right) \\
& \mathrm{Q} 3=\mathrm{A} 3 * \sigma *\left(\mathrm{Tg}^{\wedge} 4-\left(\mathrm{F} 32^{*} \operatorname{tau} 32^{*} \mathrm{~T} 2 \wedge 4+\mathrm{F} 34 * \operatorname{tau} 34 * \mathrm{~T} 4 \wedge 4+\mathrm{F} 35^{*} \operatorname{tau} 35^{*} \mathrm{~T}^{\wedge} 4\right.\right. \\
& \left.\left.+\varepsilon_{3} * \mathrm{Tv}^{\wedge} 4\right)\right) \\
& \mathrm{Q} 4=\mathrm{A} 4 * \sigma^{*}\left(\mathrm{~T} 4 \wedge 4^{*}-\left(\mathrm{F} 42^{*} \operatorname{tau} 42^{*} \mathrm{~T} 2^{\wedge} 4+\mathrm{F} 43 * \operatorname{tau} 43 * \mathrm{~T} 3 \wedge 4+\mathrm{F} 45^{*} \operatorname{tau} 45^{*} \mathrm{~T}^{\wedge} 4+\varepsilon_{4} * \mathrm{Tv}^{\wedge} 4\right)\right. \\
& \mathrm{Q} 5=\mathrm{A} 5^{*} \sigma *\left(\mathrm{~T} 5^{\wedge} 4-\left(\mathrm{F} 52^{*} \operatorname{tau} 52^{*} 2^{\wedge} 4+\mathrm{F} 53^{*} \operatorname{tau} 53^{*} 3^{\wedge} 4+\mathrm{F} 54^{*} \operatorname{tau}^{*} 4^{*} \mathrm{~T}^{\wedge} 4+\varepsilon_{5} * \mathrm{Tv}^{\wedge} 4\right)\right)
\end{aligned}
$$

The equation for Q2 is written in terms of T2 as the unknown, since Q2 is assumed known.

The view factors were calculated from analytical expressions provided in Ref. A-4.

$$
\left.\mathrm{F} 14=0.5^{*}\left(1-1 / \mathrm{CC}-(1.7778 / \mathrm{CC})+(1+1 / \mathrm{CC}+1.7778 / \mathrm{CC})^{\wedge} 2-4 / \mathrm{CC}\right)^{\wedge} 0.5\right)
$$

(Ref. A-4, Fig. C-75) 


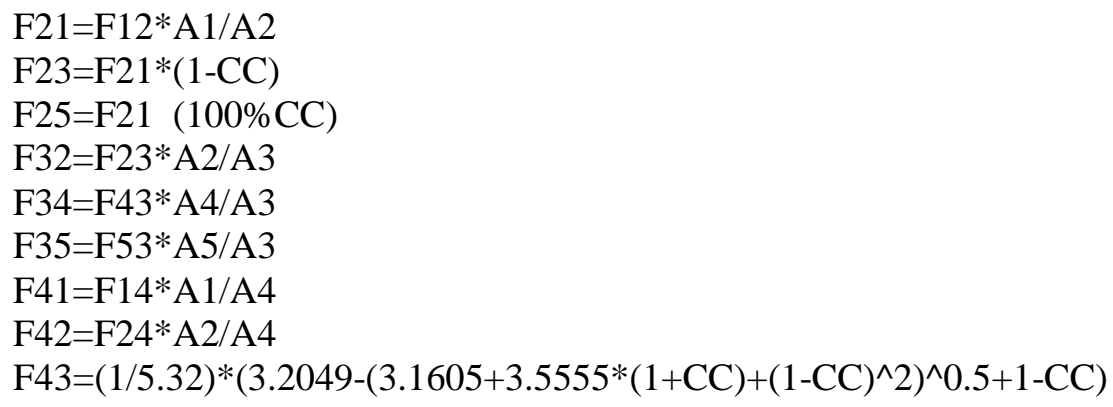

In the above, $\mathrm{CC}$ is the cold cap coverage fraction. The view factor from the lid heaters to the side wall of the upper plenum, F2-4, is obtained by considering the four heaters on one side of the plenum to radiate all their heat on one side of the plenum wall, and the other four heaters concentrating their heat on the opposite wall. This is logical because of symmetry. Each heater is considered a square heater with side length, w, equal to the diameter in order to use the view factor relations for a strip element to a parallel offset rectangle, Ref. A-4 Fig. B-68, and for a strip
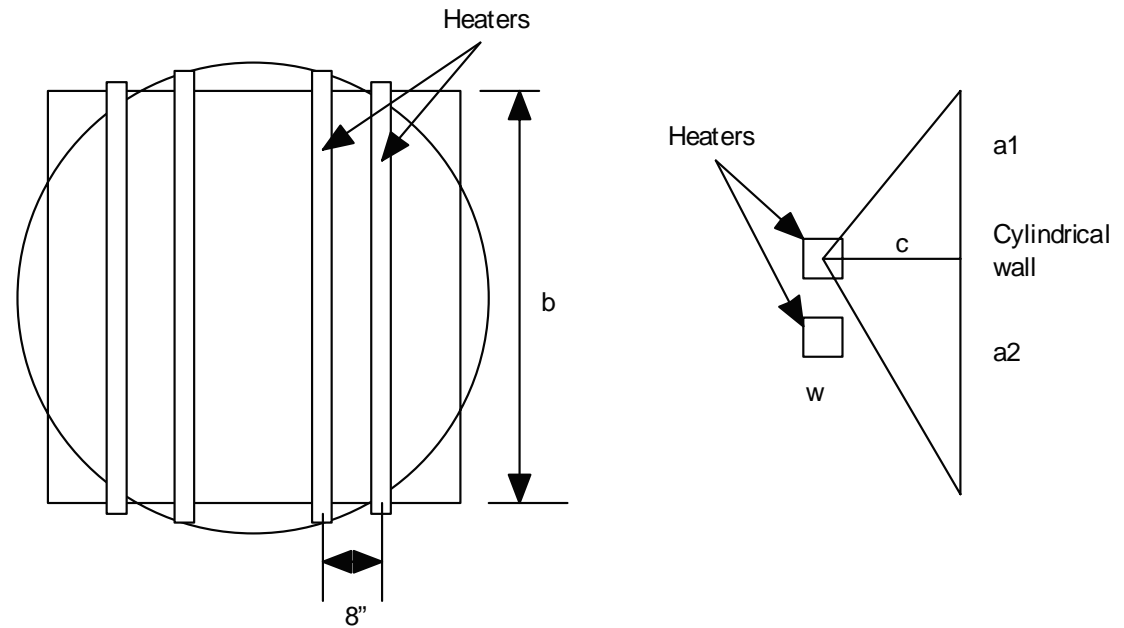

element perpendicular to the offset rectangle, Fig. B-69. The cylindrical wall next to the outermost heater is idealized as two rectangles on either side of the heater at an effective distance, c, of $0.66 \mathrm{ft}$. from the closest heater. The view factor from a strip to one parallel rectangle is given as,

$\mathrm{F} 2-4($ parallel $)=(1 /(3.14 * \mathrm{Y}))^{*}\left(\left(1+\mathrm{Y}^{\wedge} 2\right)^{\wedge} 0.5^{*} \mathrm{ATAN}\left(\mathrm{X} /\left(1+\mathrm{Y}^{\wedge} 2\right)^{\wedge} 0.5\right)-\right.$ $\left.\operatorname{ATAN}(\mathrm{X})+\left(\mathrm{X}^{*} \mathrm{Y}\right)^{*} \operatorname{ATAN}\left(\mathrm{Y} /\left(1+\mathrm{X}^{\wedge} 2\right)^{\wedge} 0.5 /\left(1+\mathrm{X}^{\wedge} 2\right)^{\wedge} 0.5\right)\right)$ 
Where $X=a / c, Y=b / c, a=$ vertical length of rectangle, $b=$ horizontal length of rectangle, $c=$ distance from rectangle to strip. For the front heater, $a 1=2.5^{\prime}, a 2=1.5^{\prime}, b=5^{\prime}, c=0.66^{\prime}$ For the back heater, $\mathrm{c}=1.33^{\prime}$. There is shadowing of the back heater by the front heater, so there will be adjustment of the view factor so that the sum of all view factors from the lid heater to all surfaces must equal 1.

The component view factors are:

$\begin{array}{lll} & 2.5^{\prime} \text { side } & 1.5^{\prime} \text { side } \\ \text { Front heater } & 0.392 & 0.319 \\ \text { Back heater } & 0.276 & 0.192\end{array}$

Assuming 50\% blockage of the back heater by the front heater, the average view factor for one heater is $\mathrm{dF} 2-4=\left[(0.392+0.319)+0.5^{*}(.278+.192)\right] / 2=0.5$. Based on the area of 4 heaters and the area of one half side wall, F2-4' $=0.5 / 2$ since one side of the heaters face the wall. For two half walls and 8 heaters, F2-4 would be twice this value since twice the amount of heat is transferred. Thus,

$$
\text { F2-4=0.5 based on all heaters and total wall area. }
$$

The view factor from the lid heaters to the cold cap is estimated using the same method and equations above. We simulate the circular cold cap as two rectangles on either side of a heater with the equivalent areas of the corresponding circular sectors. For this geometry, a1 1.5 , $\mathrm{a} 2=3.5, \mathrm{~b}=5, \mathrm{c} 1=1.5, \mathrm{c} 2=2.5$.

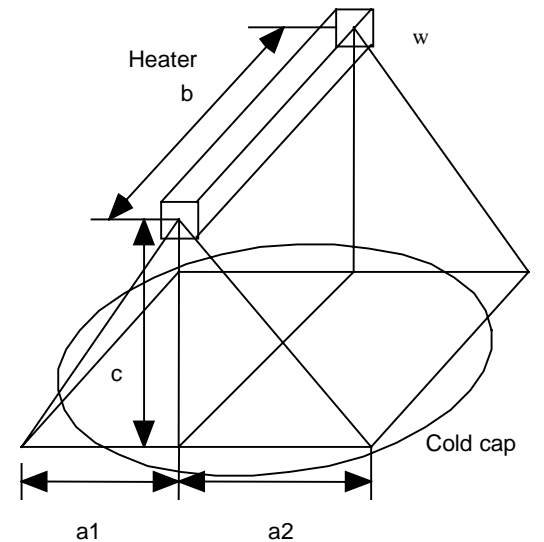

The component view factors are:

$\begin{array}{llll} & 2.5^{\prime} \text { side } & 1.5^{\prime} \text { ' side } & \text { Total } \\ \text { Front heater } & 0.353 & 0.208 & 0.561 \\ \text { Back heater } & 0.262 & 0.132 & 0.394\end{array}$

The average heater view factor, $\mathrm{F} 2-1=\left(0.561+0.8^{*} 0.394\right) / 2=0.438$, where a blockage factor 00.8 was used for the back heater. Since only one side of the heaters face the cold cap, the view factor based on the total heater area is $\mathrm{F} 1-2=0.438 / 2=0.219$. The sum of view factors,

$\mathrm{F} 2-1+\mathrm{F} 2-3+\mathrm{F} 2-4+\mathrm{F}-25=1$ 
When the cold cap coverage is $1, \mathrm{~F} 2-3=0, \mathrm{~F} 2-1=\mathrm{F} 2-5$. Thus, $\mathrm{F} 2-1=(1-0.5) / 2=0.25$. We will use the value, $\mathrm{F} 2-1=0.25$, which closely agrees with the previous calculated value 0.219 . The rest of the view factors are calculated in the Excel program, HTBAL. These are tabulated below as a function of cold cap coverage.

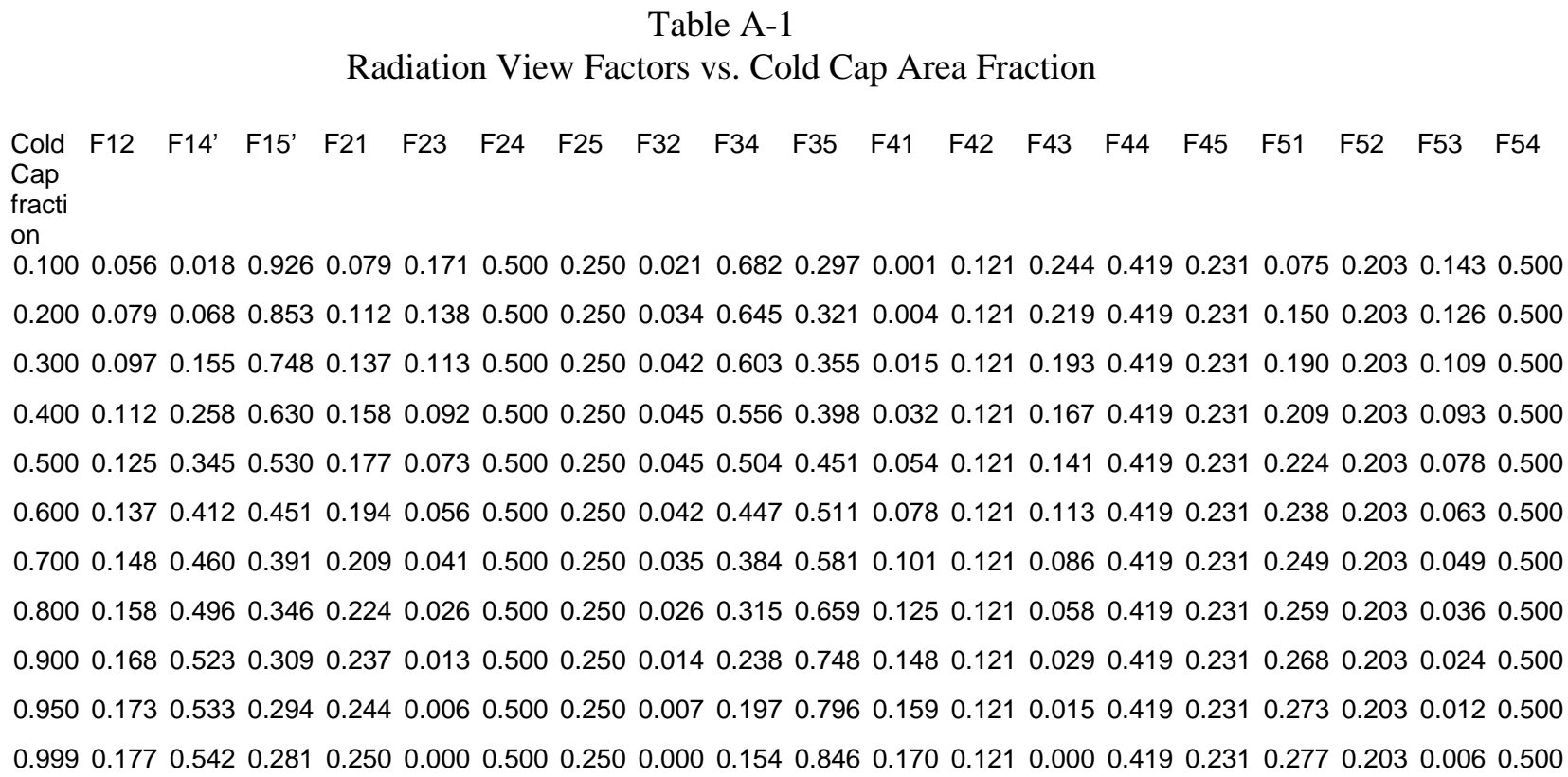

Doing a regression analysis on the relation between view factor and cold cap coverage, the following relations are obtained:

$\mathrm{F} 12=-0.0722 * \mathrm{CC}^{\wedge} 2+0.2092 * \mathrm{CC}+0.0385$

Transmission factors

The transmission factors, tauij, are obtained using the method in Ref. 4, Chapter 13. An equivalent beam length is first calculated, Le, from the geometry. Then this is corrected by the ratio of the wall to gas temperatures, $\mathrm{Le} '=\mathrm{Le} * \mathrm{Tw} / \mathrm{Tg}$. The parameter, $\mathrm{pH} 20 * \mathrm{Le}$ ', is calculated where $\mathrm{pH} 20$ is the partial pressure of the steam. Then going to the chart of Figure 13-15, Ref. 4, the gas emission $\varepsilon+$ at the gas/vapor temperature Tv is obtained. The emittance at the wall temperature is obtained as $\varepsilon=\varepsilon+*(\mathrm{Tv} / \mathrm{Tw})^{\wedge} 0.5$. The following transmittances are calculated assuming a partial pressure, $\mathrm{p}$, of $0.5 \mathrm{~atm}$. It is assumed that the emittance is proportional to the partial pressure. Thus, the transmittance for a different partial pressure is given by, tau2 $=\operatorname{tau} 1+(1-\operatorname{tau} 1) * \mathrm{p} 2 / \mathrm{p} 1$.

Tau12

For the transmission factor from cold cap to lid heater, tau12, Table 13-1 is used. Here, equal rectangles are assumed, where $\mathrm{a} / \mathrm{c}=\mathrm{b} / \mathrm{c}=5 / 2=2.5 . \mathrm{Skj} / \mathrm{c}=1.246 . \mathrm{Skj}=1.246 * 2=2.5 \mathrm{ft}$. Skj is the 
equivalent beam length. Calculate $\mathrm{pH} 20 * \mathrm{Le} * \mathrm{~T} 2 / \mathrm{Tv}=0.5 * 2.5 * 1070 / 953=1.4$. From Fig. 13-15, $\mathrm{e}+=0.26 . \quad \varepsilon=\varepsilon+*(953 / 1070)^{\wedge} 0.5=0.245$. Tau12 $=1-\varepsilon=1-0.245=0.755$.

\section{Tau14}

For the transmission factor from cold cap to plenum wall, we use Table13-2. We consider one half of the cold cap and plenum wall. Then $a=1.5^{\prime}, c=4^{\prime}, b=9.4^{\prime} . \mathrm{a} / \mathrm{b}=1.5 / 9.4=0.16 . \mathrm{c} / \mathrm{b}=4 / 9.4$ $=0.42 . \mathrm{AkSkj} / \mathrm{abc}=0.1463 . \mathrm{Skj}=1.5 * 9.4 * 4 * .1463 / 12.35=0.668^{\prime}$. Calculate $\mathrm{pH} 20 * \mathrm{Le} * \mathrm{~T} 2 / \mathrm{Tv}$ $=0.5 * 2.5 * 860 / 953=1.13$. From Fig. $13-15, e+=0.25 . \varepsilon=\varepsilon+*(953 / 860)^{\wedge} 0.5=0.263$. Tau $14=1-$ $\varepsilon=1-0.263=0.737$.

\section{Tau15}

For the transmission factor from cold cap to the plenum lid, tau15, Table 13-1 is used. Here, equal rectangles are assumed, where $\mathrm{a} / \mathrm{c}=\mathrm{b} / \mathrm{c}=5 / 4=1.25 . \mathrm{Skj} / \mathrm{c}=1.189 . \mathrm{Skj}=1.189 * 4=4.75 \mathrm{ft}$. Calculate $\mathrm{pH} 20 * \mathrm{Le} * \mathrm{~T} 5 / \mathrm{Tv}=0.5 * 4.75 * 953 / 953=2.378$. From Fig. 13-15, e+=0.32. $\varepsilon=\varepsilon+*(953 / 953)^{\wedge} 0.5=0.32$. Tau12=1- $\varepsilon=1-0.32=0.68$.

\section{Tau21}

For the transmission factor from lid heater to cold cap, tau21, Table 13-1 is used. Here, equal rectangles are assumed, where $\mathrm{a} / \mathrm{c}=\mathrm{b} / \mathrm{c}=5 / 2=2.5 . \mathrm{Skj} / \mathrm{c}=1.246 . \mathrm{Skj}=1.246^{*} 2=2.5 \mathrm{ft}$. Skj is the equivalent beam length. Calculate $\mathrm{pH} 20 * \mathrm{Le} * \mathrm{~T} 1 / \mathrm{Tv}=0.5 * 2.5 * 373 / 953=0.489$. From Fig. 13-15, $\mathrm{e}+=0.15$. $\varepsilon=\varepsilon+*(953 / 373)^{\wedge} 0.5=0.24$. Tau $21=1-\varepsilon=1-0.24=0.76$.

\section{Tau23}

The equivalent beam length is the same as for Tau $21, \mathrm{Le}=2.5 \mathrm{ft} . \mathrm{pH} 20^{*} \mathrm{Le} * \mathrm{~T} 3 / \mathrm{TV}$ $=0.5 * 2.5 * 1350 / 953=1.77$. From Fig. $13-15$, e $+=0.28 . \varepsilon=0.28+*(953 / 1350)^{\wedge} 0.5=0.235$. Tau23 $=1-\varepsilon=1-0.235=0.765$.

\section{$\underline{\text { Tau24 }}$}

Here, the average distance from the heaters to the plenum wall is $0.66{ }^{\prime} . \mathrm{a} / \mathrm{c}=5 / 0.66=7.6$. $\mathrm{b} / \mathrm{c}=4 / 0.66=6 . \mathrm{Skj} / \mathrm{c}=1.53 \mathrm{ft}$. Le $=1.53 * 0.66=1$ ' $\mathrm{pH} 20 * \mathrm{Le} * \mathrm{~T} 4 / \mathrm{Tv}=0.5 * 1 * 860 / 953=0.45$. From Fig. $13-15, \varepsilon+=0.16$. $\varepsilon=0.16^{*}(953 / 860)^{\wedge} 0.5=0.168$. Tau $24=1-\varepsilon=1-0.168=0.83$.

\section{Tau25}

As for Tau23, $\mathrm{Le}=2.5^{\prime} \cdot \mathrm{pH} 20 * \mathrm{Le} * \mathrm{~T} 5 / \mathrm{Tv}=0.5 * 2.5 * 953 / 953=1.25$. From Fig. 13-15, e+=0.25. $\varepsilon=0.25 *(953 / 953)^{\wedge} 0.5=0.25$. Tau $25=1-\varepsilon=1-0.25=0.75$.

\section{Tau32}

The equivalent beam length is the same as for Tau23, $\mathrm{Le}=2.5^{\prime} \cdot \mathrm{pH} 20 * \mathrm{Le} * \mathrm{~T} 2 / \mathrm{Tv}=$ $0.5^{*} 2.5^{*} 1070 / 953=1.4$. From Fig. $13-15, \varepsilon+=0.275$. $\varepsilon=0.275^{*}(953 / 1070)^{\wedge} 0.5=0.259$. Tau $34=1-$ $\varepsilon=1-0.259=0.74$.

\section{Tau34}

The uncovered glass surface is an annular ring at right angles to the cylindrical plenum wall. These two surfaces are idealized as two rectangles at right angles to each other. Then using Table 13-2, Ref. 4, $a=0.15^{\prime}, b=18.8^{\prime}, c=4, a / b=0.008, c / b=0.21$. AkFkjSkj/abc $=0.083$. Since $F k j=0.921$, $\mathrm{Ak}=2.76 \mathrm{ft} 2$, then $\mathrm{Skj}=0.15^{*} 4^{*} 18.8^{*} 0.083 /\left(2.76^{*} 0.921\right)=0.368{ }^{\prime} . \mathrm{pH} 20 * \mathrm{Le} * \mathrm{~T} 4 / \mathrm{Tv}$ $=0.5 * 0.368 * 860 / 953=0.166$. From Fig. $13-15, \varepsilon+=0.09$. $\varepsilon=0.09+*(953 / 860)^{\wedge} 0.5=0.095$. Tau34 $=1-\varepsilon=1-0.095=0.905$. 


\section{Tau35}

The glass surface and the upper lid are considered as equal rectangles. $a / c=b / c=6 / 4=1.5$. $\mathrm{Skj} / \mathrm{c}=(1.175+1.242) / 2 . \mathrm{Skj}=4.83 . \mathrm{pH} 20 * \mathrm{Le} * \mathrm{~T} 5 / \mathrm{Tg}=0.5 * 4.83 * 953 / 953=2.4$. From Fig. 13-15, $\varepsilon+=0.32$. $\varepsilon=0.32 *(953 / 953)^{\wedge} 0.5=0.32$. Tau35 $=1-\varepsilon=1-0.32=0.68$.

\section{Tau41}

For the transmission factor from plenum wall to cold cap, the equivalent beam length is the same as for Tau14, $\mathrm{Le}=0.668$ '. Calculate $\mathrm{pH} 20 * \mathrm{Le} * \mathrm{~T} 1 / \mathrm{Tv}=0.5^{*} 2.5^{*} 373 / 953=0.489$. From Fig. 13-15, $\mathrm{e}+=0.175$. $\varepsilon=\varepsilon+*(953 / 373)^{\wedge} 0.5=0.279$. Tau. $14=1-\varepsilon=1-0.279=0.72$.

$\underline{\text { Tau42 }}$

As for Tau24, Le $=1$ '. pH20*Le*T2/Tv=0.5*1*1070/953=0.56'. From Fig. 13-15, $\varepsilon+=0.19$. $\varepsilon=0.19 *(953 / 1070)^{\wedge} 0.5=0.179$. Tau24 $=1-\varepsilon=1-0.179=0.82$.

\section{$\underline{\text { Tau43 }}$}

As for Tau34, Le $=0.368 \cdot$ pH20*Le*T3/Tv $=0.5 * 0.368 * 1350 / 953=0.26$. From Fig. 13-15, $\varepsilon+=0.12 . \quad \varepsilon=0.12+*(953 / 1350)^{\wedge} 0.5=0.10$. Tau $34=1-\varepsilon=1-0.10=0.90$.

$\underline{\text { Tau45 }}$

As for Tau14, Le $=0.668$ '. Calculate $\mathrm{pH} 20 * \mathrm{Le} * \mathrm{~T} 5 / \mathrm{Tv}=0.5 * 0.668 * 953 / 953=0.334$. From Fig. 1315 , e+=0.14. $\varepsilon=\varepsilon+*(953 / 953)^{\wedge} 0.5=0.14$. Tau45=1- $\varepsilon=1-0.14=0.86$.

\section{Tau51}

For tau51, the equivalent beam length is the same as tau15, $\mathrm{Le}=4.75 \mathrm{ft}$. Calculate $\mathrm{pH} 20 * \mathrm{Le} * \mathrm{~T} 1 / \mathrm{Tv}=0.5 * 4.75 * 373 / 953=0.93$. From Fig. $13-15$, e+ $=0.24$.

$\varepsilon=\varepsilon+^{*}(953 / 373)^{\wedge} 0.5=0.384$. Tau $12=1-\varepsilon=1-0.263=0.616$.

\section{$\underline{\text { Tau52 }}$}

As for Tau25, $\mathrm{Le}=2.5$ '. pH20*Le*T2/Tv $=0.5 * 2.5 * 1070 / 953=1.4$. From Fig. 13-15, e $+=0.26$. $\varepsilon=0.26^{*}(953 / 1070)^{\wedge} 0.5=0.245$. Tau $25=1-\varepsilon=1-0.245=0.755$.

\section{Tau53}

As for tau35, Le $=4.83 . \mathrm{pH} 20 * \mathrm{Le} * \mathrm{~T} 3 / \mathrm{Tv}=0.5 * 4.83 * 1350 / 953=3.4$. From Fig. $13-15, \varepsilon+=0.4$. $\varepsilon=0.4+*(953 / 1350)^{\wedge} 0.5=0.334$. Tau53 $=1-\varepsilon=1-0.334=0.664$.

\section{Tau54}

As for Tau45, Le $=0.668$ '. Calculate $\mathrm{pH} 20 * \mathrm{Le} * \mathrm{~T} 4 / \mathrm{Tv}=0.5 * 0.668 * 860 / 953=0.301$. From Fig. 13-15, $\mathrm{e}+=0.13 . \varepsilon=\varepsilon+*(953 / 860)^{\wedge} 0.5=0.137$. Tau $45=1-\varepsilon=1-0.137=0.863$.

The above values are tabulated in Table 2 for a partial pressure of $0.5 \mathrm{~atm}$. A second column for a partial pressure of 0.3 atm is included. This 0.3 atm value is appropriate for the DWPF runs (e.g., $\mathrm{p}=237 \mathrm{lbs} / \mathrm{hr}($ steam $) /(237$ (steam) $+460 \mathrm{lbs} / \mathrm{hr}($ air $))=0.34)$. 
Table A-2

List of Transmission Factors at 0.3 atm Steam

\begin{tabular}{|c|c|c|}
\hline Surface I-J & $\begin{array}{c}\text { Tauij at 0.5 } \\
\text { atm }\end{array}$ & $\begin{array}{c}\text { Tauij corr. } \\
\text { At o.3 atm }\end{array}$ \\
\hline $1-2$ & 0.755 & 0.902 \\
\hline $1-4$ & 0.737 & 0.895 \\
\hline $1-5$ & 0.68 & 0.872 \\
\hline $2-1$ & 0.76 & 0.904 \\
\hline $2-3$ & 0.765 & 0.906 \\
\hline $2-4$ & 0.83 & 0.932 \\
\hline $2-5$ & 0.75 & 0.900 \\
\hline $3-2$ & 0.74 & 0.896 \\
\hline $3-4$ & 0.905 & 0.962 \\
\hline $3-5$ & 0.68 & 0.872 \\
\hline $4-1$ & 0.72 & 0.895 \\
\hline $4-2$ & 0.82 & 0.928 \\
\hline $4-3$ & 0.90 & 0.960 \\
\hline $4-5$ & 0.86 & 0.944 \\
\hline $5-1$ & 0.616 & 0.872 \\
\hline $5-2$ & 0.755 & 0.902 \\
\hline $5-3$ & 0.664 & 0.866 \\
\hline $5-4$ & 0.863 & 0.945 \\
\hline
\end{tabular}


The above parameters were entered into an Excel program, HTBAL, wherein Eqs.A-18 to A-21 were programmed, and using the following additional parameters:

$$
\begin{aligned}
& \mathrm{A}_{1}=2.295 \mathrm{~m}^{2}(100 \% \text { cold cap coverage }) \\
& \mathrm{A}_{2}=1.85 \mathrm{~m}^{2} \\
& \sigma=5.78 \mathrm{e}-11 \mathrm{~kW} / \mathrm{m}^{2}-\mathrm{K}^{4} \\
& \mathrm{~A}_{4}=7.29 \mathrm{~m}^{2} \\
& \mathrm{~A}_{5}=2.63 \mathrm{~m}^{2}
\end{aligned}
$$

\subsection{Transient Analysis}

Under transient conditions, the steady heat transfer and mass transfer equations surrounding the glass melt pool, the cold cap, and the upper plenum vapor are augmented by unsteady components. Thus, the transient heat equation /for the melt pool,

$$
\text { Qel - Q3- Qcon - Qlbs - Qstem = Mp*cpg*dTg/dt }
$$

For the results presented in the text the steady state analysis using averaged data in Figures 1 and 2 for Macrobatches 1 and 2, respectively were used. The power data were correlated as shown in those figures.

The steady state analysis resulted in the following heat losses:

For Macrobatch 1,

Qlbs=79 kW

Qlus=106.4 kW at zero feed, $100.4 \mathrm{~kW}$ at $0.7 \mathrm{gpm}$

A heat transfer coefficient (including area) for the bottom shell heat loss can be calculated, hlbsAbs $=$ Qlbs $/(\mathrm{Tg}-313)=79 /(1423-313)=0.07117$

A heat transfer coefficient (including area) for the upper shell can be calculated, husAus $=$ Qlus/(Tv-313) $=106.4 /(1003-313)=0.1542 \mathrm{~kW} /{ }^{\circ} \mathrm{K}$ at zero feed. $=109.1 /(766-313)=0.2216 \mathrm{~kW} /{ }^{\circ} \mathrm{K}$ at $0.7 \mathrm{gpm}$ feed.

The convective heat loss to the cold cap at $0.7 \mathrm{gpm}$ feed is Qcon=90 kW

A heat transfer coefficient for convective heat loss can be calculated, hcon=Qcon/[(Tg-T1)(2.3-A3)]

At $0.7 \mathrm{gpm}$, the cold cap temperature was calculated as $480^{\circ} \mathrm{C}$ to achieve heat balance in the upper plenum in the spreadsheet calculations. Thus,

$$
\begin{aligned}
\text { hcon } & =90 /\left[(1423-(480+273))\left(0.9^{*} 2.3\right)\right. \\
& =0.0648 \mathrm{~kW} / \mathrm{m}^{2}-{ }^{\circ} \mathrm{K}(\text { Macrobatch } 1)
\end{aligned}
$$

For Macrobatch 2,

$$
\text { Qlbs=79 kW }
$$

Qlus $=100.4$

Hlbs $=0.07117$ (same as Macrobatch 1)

hus $=100.4 /(520+273-313)=0.209 \mathrm{~kW} / \mathrm{oK}$ at $0.55 \mathrm{gpm}$.

Qcon $=68.5 \mathrm{~kW}$ at $0.55 \mathrm{gpm}$

hcon $=68.5 /[(1423-(520+273)) 2.3 * 0.9]$

$$
=0.0525 \mathrm{~kW} / \mathrm{m}^{2} /{ }^{\circ} \mathrm{K} \text {. }
$$

The transient equation for the glass melt is developed as follows:

$\mathrm{Mp}=2.295 * 3 * 0.3048 * 2435=5110 \mathrm{Kg}$

$\mathrm{cpg}=1.521 \mathrm{KJ} / \mathrm{Kg}-\mathrm{K}$. 


$$
\begin{aligned}
& \text { Qel - Q3 - Qcon - hlbs*Abs*(Tg-T1 }=5110 * 1.521 * \mathrm{dTg} / \mathrm{dt} / 3600 \\
& \text { Qel - Q3 - Qcon - hlbs*Abs*(Tg-T1) }=2.159 * \mathrm{dTg} / \mathrm{dt},
\end{aligned}
$$

where $\mathrm{dTg} / \mathrm{dt}$ is in ${ }^{0} \mathrm{~K} / \mathrm{hr}$.

$$
\text { Qcon }=\text { hcon*Acc* }(\mathrm{Tg}-\mathrm{T} 1)
$$

\section{Cold Cap}

For the cold cap, Eq. 6 may be written as,

Where

$$
\text { Qcon-Q1=Hlgs+Qsub+Qevap }
$$

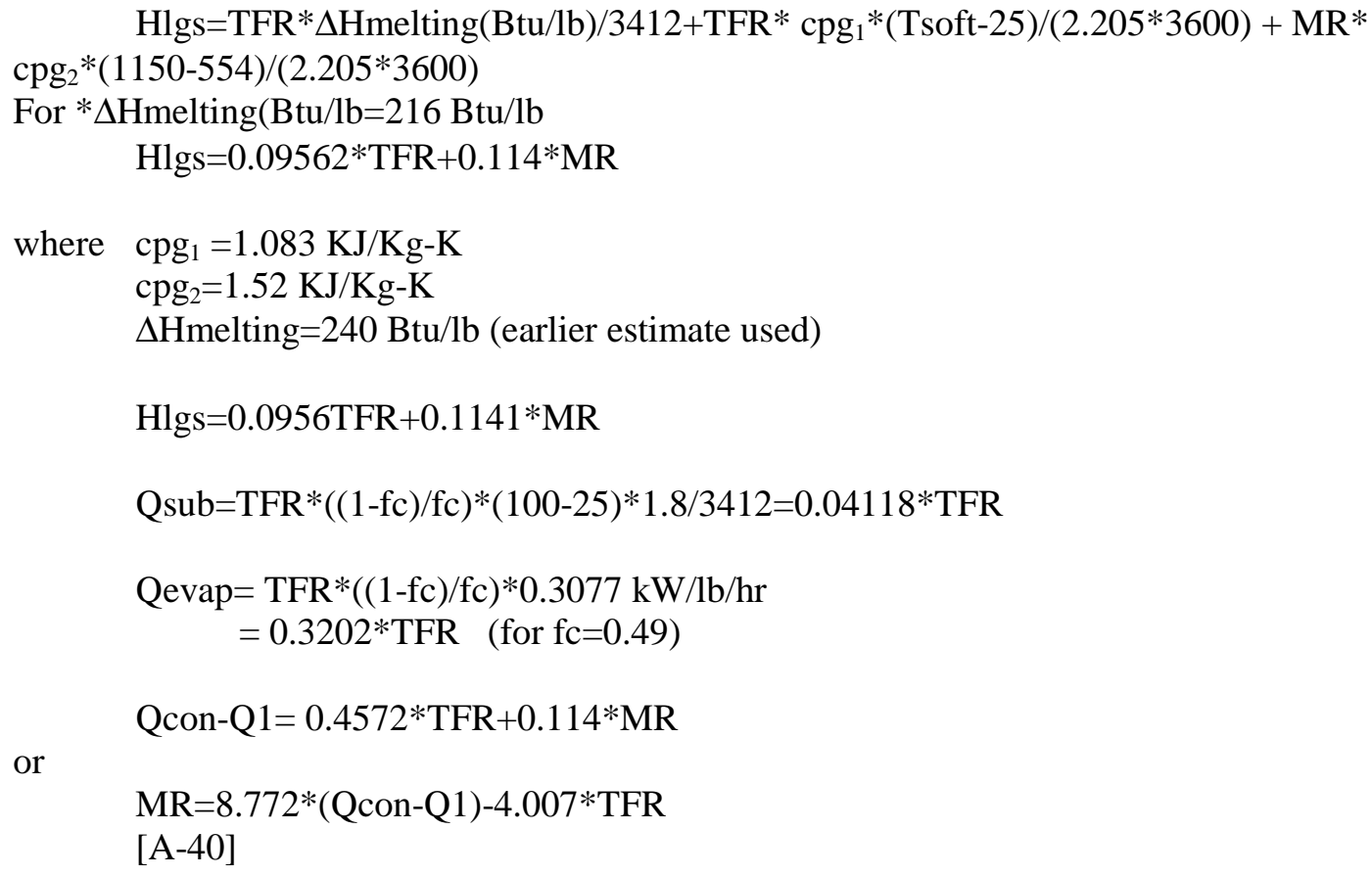

Upper Plenum

The transient heat equation for the upper plenum is

$$
\begin{aligned}
& \mathrm{Q} 1+\mathrm{Q} 2+\mathrm{Q} 3=\text { HLAR +Qvs +Qlus+ } \\
& \text { Ms*cps*dTv/dt + Ma*cpa*dTv/dt }
\end{aligned}
$$

Where steady state values, Qcoverbox, Qfeedtubes, are used, with only a small error expected.

Property values at $680 \mathrm{C}$ are:

Density of air $=0.032 \mathrm{lb} / \mathrm{ft} 3$

Density of steam $=0.008 \mathrm{lb} / \mathrm{ft} 3$

cpa $=0.2704 \mathrm{Btu} / \mathrm{lb}$

$\mathrm{cps}=0.522 \mathrm{Btu} / \mathrm{lb}$

Volume of upper plenum $=3.14^{*} 6.5^{\wedge} 2 / 4=132.6 \mathrm{ft} 3$

Mass of steam $=0.008 * 132.6=1.06 \mathrm{lbm}=0.48 \mathrm{Kg}$

Mass of air $=0.032 * 132.6=3.07 \mathrm{lbm}=0.68 \mathrm{Kg}$

$$
\text { Ms*cps*dTv/dt }+\mathrm{Ma}^{*}{ }^{*} \mathrm{pa}^{*} \mathrm{dTv} / \mathrm{dt}=0.0005 * \mathrm{dTv} / \mathrm{dt}
$$


Qlus=hus*Aus*(Tv-313)

Qvs $=(0.495 * 1.8 / 3412) *(\mathrm{Tv}-373) * \mathrm{SFR}=0.000261 *(\mathrm{Tv}-373) * \mathrm{SFR}$

HLAR $=$ AFR $*(-0.0136+0.000149 *(\mathrm{Tv}-313))$

For $\mathrm{AFR}=560 \mathrm{lbs} / \mathrm{hr}$,

HLAR $=0.0834 *(\mathrm{Tv}-293)-7.6$

$$
\begin{aligned}
& \mathrm{Ms} * \mathrm{cps}^{*} \mathrm{dTv} / \mathrm{dt}+\mathrm{Ma} * \mathrm{cpa} * \mathrm{dTv} / \mathrm{dt}=\mathrm{Q} 1+\mathrm{Q} 2+\mathrm{Q} 3-(\mathrm{HLAR}+\mathrm{Qvs}+\mathrm{Qgas}) \\
& 0.00025 * \mathrm{dTv} / \mathrm{dt}=\mathrm{Q} 1+\mathrm{Q} 2+\mathrm{Q} 3-\mathrm{Q} \text { lus-0.000261*(Tv-373)-0.0834*(Tv-293)+7.6 }
\end{aligned}
$$

[A-43]

Analysis of transient cold cap coverage

The rate of change of the cold cap mass is given by,

$\mathrm{DMcc} / \mathrm{dt}=$ solids feedrate-meltrate

$$
\begin{aligned}
& =\mathrm{TFR} * \mathrm{fc}-\mathrm{MR} \\
& =\text { pcc } * \text { porosity*dAcc } / \mathrm{dt} * \mathrm{hc}
\end{aligned}
$$

where $\rho c c$ is the density of the cold cap and foam, porosity is the porosity of the foam, Acc is the cold cap area, and hc is the height of the cold cap. Using $\rho c \mathrm{c}=2435 \mathrm{Kg} / \mathrm{m} 3$, porosity $=0.64$, $\mathrm{hc}=0.07 \mathrm{~m} ., \mathrm{fc}=0.9$,

$\mathrm{dAcc} / \mathrm{dt}=-\mathrm{dA} 3 / \mathrm{dt}=(0.88 * \mathrm{TFR}-\mathrm{MR}) / 109$

$\mathrm{Q} 1=5.78 \mathrm{e}-11 *(2.295-\mathrm{A} 3) *\left(\mathrm{~T} 1 \wedge 4-0.9 * \mathrm{~F} 12 * \mathrm{~T} 2 \wedge 4-0.895 * \mathrm{~F} 14 *(\mathrm{Tv}-30)^{\wedge} 4-(0.87 * \mathrm{~F} 15+.15) * \mathrm{Tv}^{\wedge} 4\right)$

$\mathrm{Q} 3=5.78 \mathrm{e}-11^{*} \mathrm{~A} 3 *\left((\mathrm{Tgs})^{\wedge} 4-0.9 * \mathrm{~F} 32 * \mathrm{~T} 2 \wedge 4-.962 * \mathrm{~F} 34 *(\mathrm{Tv}-30)^{\wedge} 4-(.96 * \mathrm{~F} 35+0.15)^{*} \mathrm{Tv}^{\wedge} 4\right)$

$\mathrm{T} 2=\left((\mathrm{Q} 2 / 10.69 \mathrm{e}-11)+.9 * \mathrm{~F} 21 * \mathrm{~T} 1 \wedge 4+0.95 * \mathrm{~F} 23 *(1150)^{\wedge} 4+(.15+.75 * .25)^{*} \mathrm{Tv}^{\wedge} 4+.444 *(\mathrm{Tv}-\right.$ $\left.30)^{\wedge} 4\right)^{\wedge} 0.25$

Where the transmission factors, tau $12=0.9$, tau $14=0.895$, tau $15=0.87$, tau32 $=0.9, \operatorname{tau} 34=0.962$, tau35 $=0.96$, tau2 $1=0.9$, tau23 $=0.95$ and es $=0.1$ (steam emissivity) were used.

The above transient equations were programmed using the mathematical software, PDEase 1.0 